San Jose State University

SJSU ScholarWorks

Master's Theses

Master's Theses and Graduate Research

Summer 2011

\title{
Nearshore Fish Assemblage Patterns with Respect to Landscape- Scale Habitats in Central California
}

Kristin Irene Hunter-Thomson

San Jose State University

Follow this and additional works at: https://scholarworks.sjsu.edu/etd_theses

\section{Recommended Citation}

Hunter-Thomson, Kristin Irene, "Nearshore Fish Assemblage Patterns with Respect to Landscape-Scale Habitats in Central California" (2011). Master's Theses. 4055.

DOI: https://doi.org/10.31979/etd.bspc-7zxa

https://scholarworks.sjsu.edu/etd_theses/4055

This Thesis is brought to you for free and open access by the Master's Theses and Graduate Research at SJSU ScholarWorks. It has been accepted for inclusion in Master's Theses by an authorized administrator of SJSU ScholarWorks. For more information, please contact scholarworks@sjsu.edu. 
NEARSHORE FISH ASSEMBLAGE PATTERNS WITH RESPECT TO LANDSCAPE-SCALE HABITATS IN CENTRAL CALIFONIA

\author{
A Thesis \\ Presented to \\ The Faculty of the Department of Marine Science \\ San José State University \\ In Partial Fulfillment \\ of the Requirements for the Degree \\ Master of Science
}

by

Kristin I. Hunter-Thomson

August 2011 
(C) 2011

Kristin I. Hunter-Thomson

ALL RIGHTS RESERVED 
The Designated Thesis Committee Approves the Thesis Titled

NEARSHORE FISH ASSEMBLAGE PATTERNS WITH RESPECT TO LANDSCAPE-SCALE HABITATS IN CENTRAL CALIFONIA

$$
\text { by }
$$

Kristin I. Hunter-Thomson

APPROVED FOR THE DEPARTMENT OF MARINE SCIENCE

SAN JOSÉ STATE UNIVERSITY

August 2011

Dr. Gregor Cailliet Department of Marine Science, Moss Landing Marine Laboratories

Dr. Michael Graham Department of Marine Science, Moss Landing Marine Laboratories

Dr. Richard Starr California Sea Grant Extension Program, Moss Landing Marine Laboratories 


\begin{abstract}
NEARSHORE FISH ASSEMBLAGE PATTERNS WITH RESPECT TO LANDSCAPE-SCALE HABITATS IN CENTRAL CALIFONIA

by Kristin I. Hunter-Thomson
\end{abstract}

In most ecosystems, the distribution of species across a landscape is greatly influenced by the type, amount, and spatial configuration of habitats. Studies in terrestrial environments have shown that species diversity, density, and length frequency often positively correlate with the size of a habitat patch, patch shape, and proximity to a patch edge. These patterns, however, have not been conclusively shown in temperate sub-tidal marine studies. Data from visual strip-transects collected from the Delta submersible were used to characterize fish assemblages with respect to rocky bank habitat patches. Specifically, the density, diversity, and length frequency of nearshore fishes were examined with respect to 1) proximity to the patch edge, 2) patch shape, and 3) patch size near Point Lobos and Point Sur, California. Diversity and length distributions of fishes were significantly greater at the edge than the interior of rocky bank patches. Therefore, landscape-scale patterns with respect to the distribution of nearshore fishes exist. However, this study also demonstrated that terrestrial paradigms are not directly applicable to temperate sub-tidal marine habitats. The relationship between species richness and patch shape was opposite of patterns observed in terrestrial systems. Additionally, patch size explained more of the variability in the nearshore fish assemblages than patch shape; however, neither were good predictive indicators of the density of fishes. 


\section{ACKNOWLEDGEMENTS}

I would like to thank my committee members: Dr. Greg Cailliet for his infectious passion for fish and amazing ability to remember every person and their projects which helped me pursue additional components of my research, Dr. Mike Graham for his support with statistics and an enthusiasm for spatial ecology, and Dr. Rick Starr for his support and encouragement. Rick, through the years of work, studies, and research you have provided a lot of advice and comic relief, thank you.

The data used for my thesis are the result of the hard work of: J. Bizzarro, J.

DeMarignac, J. Field, T. Laidig, A. Knight, R. Lea, M. Love, R. McCrea, M. Nishimoto, V. O'Connell, E. Sassone, D. Schroeder, L. Snook, B. Tissot, M. Yoklavich, and D. Watters. Also, thank you for to Delta crew (C. Ijames, J. Lilly, J. Pugh) and F/V Velero $I V$ crew (B. Collins, D. Duby, K. Henderson, I. Leask, R.L. Wilson).

The support from my many communities around Monterey Bay (Moss Landing Marine Laboratories, Monterey Bay National Marine Sanctuary, Monterey Bay Aquarium, and Stanford University Hopkins Marine Station) enabled me to stay sane along the way of completing my degree.

I would like to especially thank: Mariah Boyle for proving it could be done, Colleen Young for being the best carpool partner, distractor, and supportive friend, and Danielle Frechette for providing a great New England perspective on everything. Noëlle Yochum, without whom I would not have survived my first few years at MLML, 
sometimes you feel like a nut. Kristen Green, your positive attitude, determination, and fishy scientific passion are contagious, thank you for everything! Julie Stewart, from work parties to swimming to potlucks you always knew exactly what to say. And finally, Ashley Knight, the other fishy landscape ecologist on the bay. I cannot thank you enough for all of your assistance and support these past few years.

This thesis would not have been possible without the continual support and reserved questioning of my sanity from my many families: Hunter, Thomson, HunterThomson, Previte, Watson, and Pinsky. Thank you. Malin, without you I would not have been so successful. Thank you for talking through my research and reading endless drafts. Your never-ending encouragement and passion to get outside are greatly appreciated.

Funding for the data collection used for my thesis was provided by: the Ocean Protection Council, NOAA Fisheries, Monterey Bay National Marine Sanctuary, and California Sea Grant. Funding for this study was provided by: California Sea Grant, AmeriCorps National Education Trust, International Women's Fishing Association, San José State University, and Marine Technology Society. 


\section{TABLE OF CONTENTS}

Page

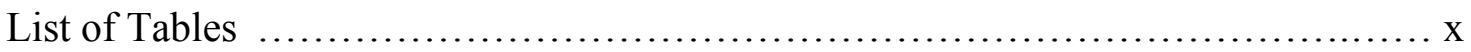

List of Figures ....................................................... xii

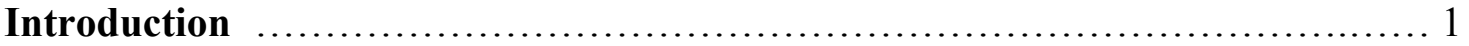

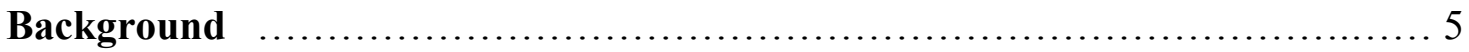

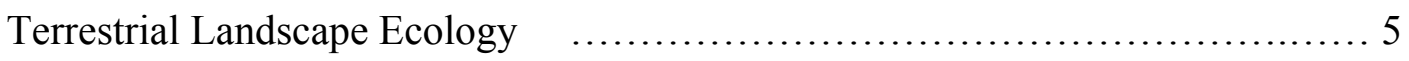

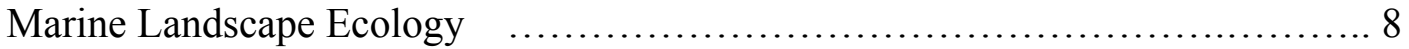

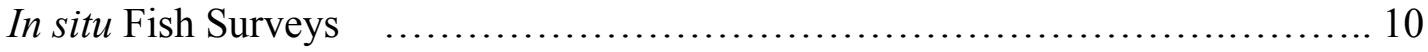

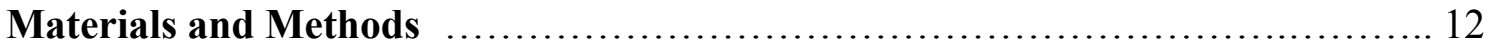

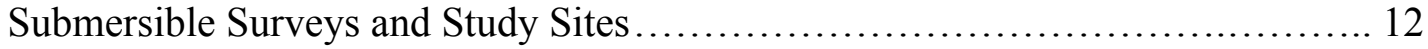

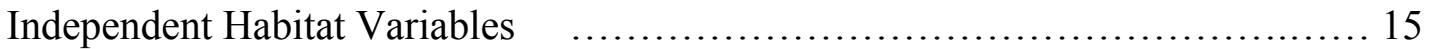

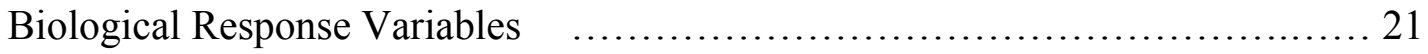

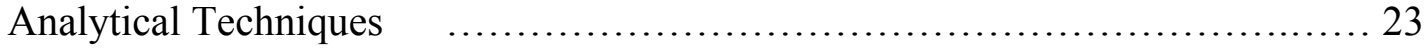

Density, Biomass, and Abundance Analyses .............................. 25

Assemblage Diversity Analyses (Richness, Evenness, and Heterogeneity)..... 26

Mean Length and Length Frequency Distribution Analyses ................. 27

Regional Comparison Analyses ........................................ 27

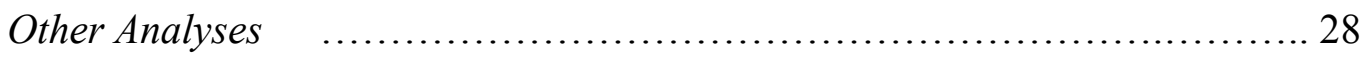

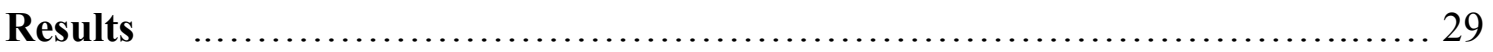

Species Abundance and Composition....................................... 29

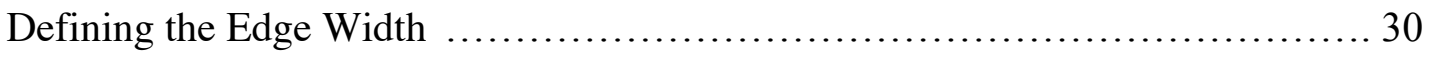

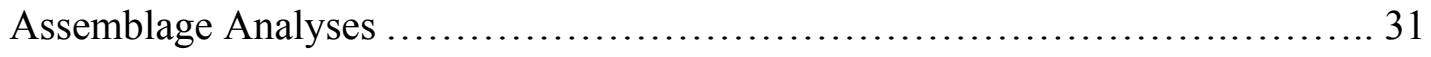

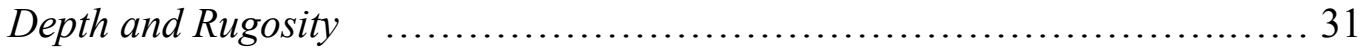

Proximity to Edge ................................................. 35

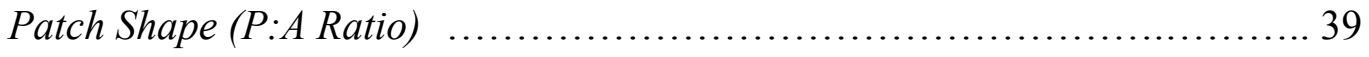

Patch Size (Area) .................................................. 40

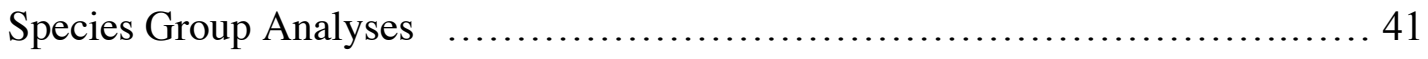

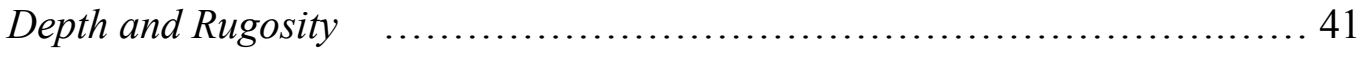


Proximity to Edge ................................................... 42

Patch Shape (P:A Ratio) $\quad$............................................. 44

Patch Size (Area) .................................................... 45

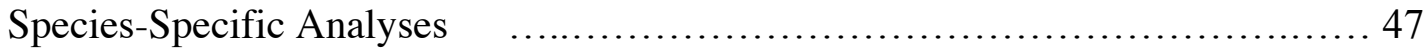

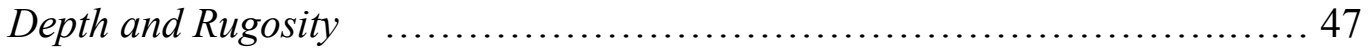

Proximity to Edge ................................................... 49

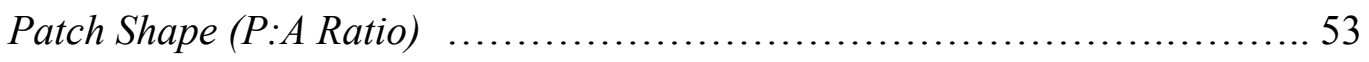

Patch Size (Area) ................................................... 55

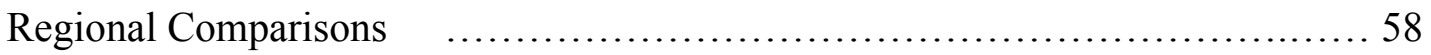

Proximity to Edge .................................................. 60

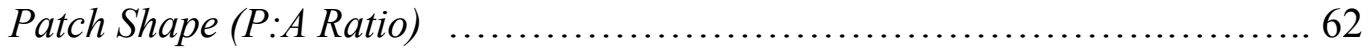

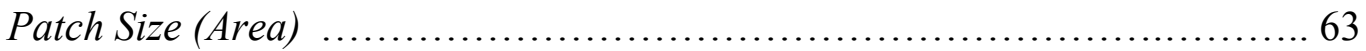

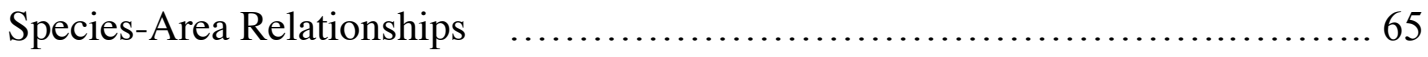

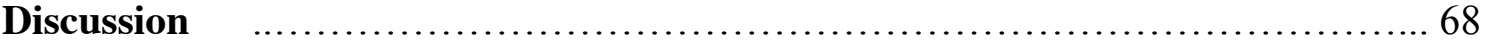

Does the abundance, diversity, or length frequency of fishes increase with depth?. 68

Does the abundance, diversity, or length frequency of fishes increase with rugosity? ........................................................... 71

Does the abundance, diversity, or length frequency of fishes increase with respect to the proximity of the edge of a rocky bank patch as would be by predicted the terrestrial landscape paradigm?

Does the abundance, diversity, or length frequency of fishes increase with respect to the shape of a rocky bank patch?

Does the abundance, diversity, or length frequency of fishes increase with respect to the size a rocky bank patch?

Are patterns in the nearshore fish assemblage with respect to independent habitat variables similar between regions of the central California coast? $\quad \ldots . .85$ What are the management implications of the observed patterns in nearshore fish assemblage with respect to landscape-scale habitat characteristics? $\quad \ldots 87$ 
References

Appendix A. Species observed near Point Lobos and Point Sur, by abundance and percentage abundance

Appendix B. Length-weight parameters obtained from published, peer-

reviewed literature that were used during this study 106

Appendix C. Equations and definitions of two diversity variables used in species composition calculations

Appendix D. Frequency histograms of the independent habitat variables per rocky bank patch near Point Lobos and Point Sur

Appendix E. Species-accumulation curves and comparisons of standard error and coefficient of variation of density

Appendix F. Biological response variables of nearshore fish assemblage with respect to depth and rugosity near Point Lobos

Appendix G. Species group goodness-of-fit analyses with respect to three landscape-scale independent habitat variables

Appendix H. Species observed in the edge zone, interior zone, or neither zone..... 128 


\section{LIST OF TABLES}

Page

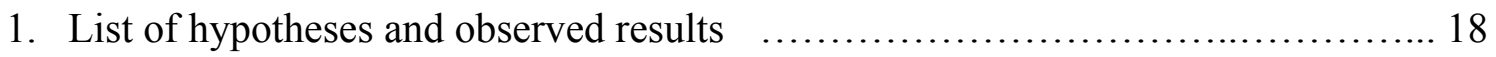

2. Species that comprise each of the four species groups used for the species -group analyses

3. Assemblage, species-groups, and species-specific relationships with respect to depth and rugosity near Point Lobos

4. Assemblage biological response variables (density, biomass, richness, evenness, and heterogeneity) with respect to distance from rocky bank patch edge near Point Lobos

5. Assemblage biological response variables (density, biomass, richness, evenness, and heterogeneity) with respect to patch shape of rocky bank patches near Point Lobos

6. Assemblage biological response variables (density, biomass, richness, evenness, and heterogeneity) with respect to patch size of rocky bank patches near Point Lobos

7. Biological response variables (density and length distributions) of the species groups with respect to distance from the rocky bank patch edge near Point Lobos

8. Biological response variables (density and length distributions) of the species groups with respect to patch shape of rocky bank patches near Point Lobos .... 45

9. Biological response variables (density and length distributions) of the species groups with respect to patch size of rocky bank patches near Point Lobos ..... 46

10. Biological response variables (density, biomass, mean length, and length distribution) of the specific species with respect to distance from rocky bank patch edge near Point Lobos

11. Biological response variables (density, biomass, mean length, and length distribution) of the specific species with respect to patch shape of rocky bank patches near Point Lobos 
12. Biological response variables (density, biomass, mean length, and length distribution) of the specific species with respect to patch size of rocky bank patches near Point Lobos

13. Assemblage biological response variables (density, biomass, richness, evenness, and heterogeneity) of shallow rocky bank patches near Point Lobos and Point Sur 


\section{LIST OF FIGURES}

Page

1. Map of the study region highlighting the two focus regions: Point Lobos and

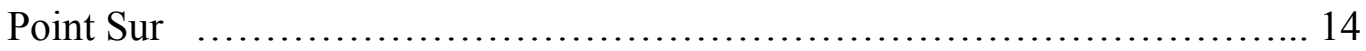

2. Distribution of selected rocky bank patches near Point Lobos and Point Sur $\quad \ldots . . .16$

3. Frequency histogram of rocky bank patch diameters near Point Lobos and

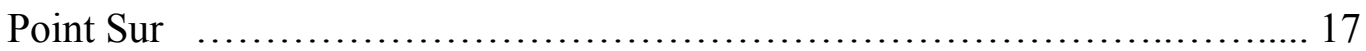

4. Assemblage density and richness per unit area surveyed at different widths of

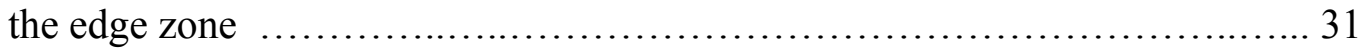

5. Species composition of the seven most abundant species by depth category near Point Lobos

6. Comparison of assemblage biological response variables (density and species richness) with respect to distance from rocky bank patch edge near Point Lobos 36

7. Species composition of the seven most abundant species by depth category and proximity to edge near Point Lobos

8. Comparison of assemblage biological response variables (density and richness) with respect to patch shape of rocky bank patches near Point Lobos

9. Comparison of assemblage biological response variables (density and richness) with respect to patch size of rocky bank patches near Point Lobos

10. Comparison of biological response variables (density and length distributions) of species groups with respect to distance from rocky bank patch edge near Point Lobos

11. Comparison of biological response variables (density, biomass, and mean length) of specific species with respect to distance from rocky bank patch

edge near Point Lobos .

12. Comparison of biological response variables (length distributions) of specific species with respect to patch shape of rocky bank patches near Point Lobos .... 54

13. Comparison of biological response variables (biomass, mean length, and 
length distributions) of specific species with respect to patch size of rocky

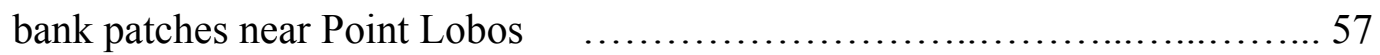

14. Species composition of the seven most abundant species for shallow rocky bank patches near Point Lobos and Point Sur...

15. Comparison of assemblage biological response variables (density and biomass) with respect to distance from rocky bank patch edge near Point Lobos and Point Sur

16. Comparison of assemblage biological response variables (density and biomass) with respect to patch shape of rocky bank patches near Point Lobos and Point Sur

17. Comparison of assemblage biological response variables (density and biomass) with respect to patch size of rocky bank patches near Point Lobos and Point Sur

18. Cumulative species richness with cumulative area surveyed and patch area near Point Lobos 66

19. Cumulative assemblage abundance with cumulative area surveyed and patch area near Point Lobos 


\section{Introduction}

The spatial scales at which ecological processes occur vary (Wiens 1989, Risser 1995), ranging from smaller than tens of centimeters (e.g., Eggleston et al. 1998) to larger than hundreds of kilometers (e.g., Woodroffe and Ginsberg 1998). At a fine-scale, the distribution of individuals can be driven by habitat selection, species mobility, and prey availability among other things (Wiens 1976). For example, aquatic and marine studies have demonstrated associations between species distribution and lithology for many fishes and invertebrates (Osman 1977, Vannote and Minshall 1982, Ault and Johnson 1998, Wang et al. 2003, Anderson et al. 2005b). At an intermediate-scale, intra- and inter-specific interactions (Gosz 1993, Turner 2005) or habitat types (Kareiva 1990, Ciannelli et al. 2008) also can drive patterns in the distribution of assemblages. Finally at a broad-scale, the movement of energy and matter, through air and water (Turner 2005, Genin 2004) and across landforms (MacArthur and Wilson 1967), influences the distribution of populations across ecosystems.

Ecological processes at fine and broad scales are well investigated, but few studies of factors influencing ecological processes at intermediate, or landscape, scales exist. The field of landscape ecology was developed to gain an understanding of the patterns and processes that occur across landscapes. A landscape is defined as a distinct spatial area that contains multiple patches of different habitat types (Forman and Godron 1986, Turner 2005). In landscape ecology, the unit of measure is a habitat patch. Research in landscape ecology is characterized by studies of patterns of biotic processes 
at the assemblage and species level with respect to the spatial distributions of habitat patches (Forman and Godron 1981, Turner et al. 2001, Turner 2005). The scale of a landscape is defined as the scale that is relevant to a species' distribution or ecological processes of interest (Wiens 1989, Gosz 1993).

A habitat patch is defined as an area that differs from its surroundings, is relatively homogeneous, and has a distinct boundary (Forman 1995, Fagan et al. 1999). The distribution, orientation, and shape of habitat patches have been shown to influence the distribution of organisms (Forman and Godron 1986). Within a habitat patch, finescale habitat type variation exists. For example within a stream, the streambed can contain pebble and sand substrates, which can influence the distribution of organisms (Hynes 1970). Thus, some researchers have used the term habitat patch to define these fine-scale habitat type variations (e.g., pebble, sand) rather than the larger-scale habitat (e.g., the stream). However, this study uses the convention in landscape ecology to refer to the larger-scale habitat as the habitat patch (Kotliar and Wiens 1990).

Clear patterns in the assemblage structure of organisms with respect to landscapescale habitat characteristics have been observed in terrestrial environments. For example, the density and diversity of the faunal assemblage in a habitat patch often correlates with three landscape-scale habitat characteristics: proximity to the edge of the habitat patch, habitat patch shape, and habitat patch size. First, species density and diversity have been shown to increase with proximity to the habitat patch edge, or at the ecotone (Odum 1958, Yahner 1988, Temple and Cary 1988). In addition, the abundance of larger individuals increases closer to the habitat patch edge (Connolly 1994). Second, habitat 
patches with more complex shapes have higher species density and diversity as well as a wider breadth of sizes of organisms (Kunin 1998, Fagan et al. 1999, Oksanen et al. 1992). Third, species density and diversity increase with increasing habitat patch area (van Dorp and Opdam 1987, Gosz 1993, Attrill et al. 2000).

Although these repeatable patterns between organisms and the environment are common on land, they have not been conclusively shown to occur in the marine environment. This is partially because ecological studies of species-habitat associations in the oceans have historically been focused at a smaller scale than in terrestrial studies. Most observations and experiments of marine species-habitat interactions have been conducted at the scale of centimeters to meters (e.g., Pearcy et al. 1989, Stein et al. 1992, Yoklavich et al. 2000, Heggenes and Saltveit 2007, Lindsay et al. 2008). Additionally, sub-tidal marine environments are remote and have been difficult to study. There is growing interest, however, in the value of understanding and quantifying the patterns in the distribution of organisms with respect to larger scale patches (hundreds of meters to kilometers; Kritzer and Sale 2006). Studies investigating the interactions between organisms and the marine environment across larger scales of the landscape are now being pursued more in the oceans (Wiens 1989, Irlandi 1994). Initial marine studies, though, have not shown a clear correspondence with terrestrial studies. Therefore, questions still remain about whether assemblage structures in the oceans are influenced by landscape-scale habitat characteristics in a similar manner as terrestrial assemblages. In addition, the majority of landscape-scale studies in the oceans has investigated patterns of distributions of invertebrates and fishes in seagrass meadows (e.g., Irlandi et al. 1999, 
Eggleston et al. 1999, Brooks and Bell 2001). Only a few studies have investigated patterns in invertebrate assemblage structure in temperate rocky bank habitats (e.g., Selgrath et al. 2007); no studies have examined patterns in fish assemblages with respect to landscape-scale habitat characteristics in temperate rocky bank habitats.

Rocky bank habitats are a common geological feature along the continental shelf of the US west coast in water depths of $0-200 \mathrm{~m}$ (Greene et al. 1999). Rocky habitats are comprised of fine-scale habitat types such as bedrock outcrops, pinnacles, rocky banks, and boulder fields. Unique assemblages of fishes are often observed in rocky bank habitats (Allen et al. 2006). These assemblages are primarily dominated by rockfish (Sebastes spp.) and have been described for central California by Love et al. (2002) and Love and Yoklavich (2006).

The objectives of this study were to determine if there are patterns in the assemblage structure of nearshore fishes with respect to landscape-scale habitat characteristics and whether or not these patterns persist across two regions of central California. In this study, the landscape-scale habitat patches investigated were rocky bank habitat patches (hereafter referred to as rocky bank patches), which occur at the scale of hundreds of meters in water depths of $30-100 \mathrm{~m}$. Data from multi-beam sonar surveys was used to identify rocky bank patches and used observational data from submersible surveys to analyze patterns in the nearshore fish assemblage with respect to the spatial distribution and patterns of the rocky bank patches. The biological response variables that investigated were species density and biomass, diversity of the assemblage, and size composition. Patterns in these biological response variables were analyzed with 
respect to five independent habitat variables of the rocky bank patch: proximity to the edge, shape (as measured by the perimeter-to-area ratio, see methods), area, depth, and rugosity. Additionally, patterns in the density and lengths of four species groups and the seven most abundant species within the assemblage with respect to the independent habitat variables were compared to determine if certain species groups or species are the most important in determining observed assemblage patterns. Finally, patterns of the biological response variables of the assemblage with respect to the independent habitat variables were compared between two distinct regions (near Point Lobos and near Point Sur).

\section{Background}

\section{Terrestrial Landscape Ecology}

During the early $20^{\text {th }}$ century, wildlife managers observed differences in species composition between the edge and the interior of habitat patches in terrestrial ecosystems (see summary by Turner 2005). The discovery of gradients in assemblage composition across a landscape resulted in an increased scientific interest in studying changes in ecological processes at the boundaries of habitat patches and the patterns of species distribution across landscapes. By the 1970s, terrestrial scientists had determined that the structure of the assemblage of organisms was a function of the type, availability, and spatial configuration of the habitat patches within the landscape (Forman and Godron 
1986). Subsequent ecological studies have shown, for example, that the configuration of habitat patches in a landscape influences patterns of processes related to gene flow (Manel et al. 2003), population dynamics (Kareiva 1990), and assemblage structure (Wiens et al. 1993). Both Wiens (1976) and Saunders et al. (1991) provide reviews of the responses of populations to the spatial structure of landscapes, including changes in predation, competition, dispersal, and movement. Additionally, published studies have demonstrated differences in species-specific size and ontogenetic differences in distribution with respect to habitat-characteristics across a landscape (as summarized by Turner et al. 2001).

Predictable patterns of species distributions across a landscape have been attributed to distance from the edge of a habitat patch, habitat patch shape, and habitat patch area. Field experiments and theoretical models have shown that species density and diversity increase with proximity to the habitat patch edge, or at the ecotone (Yahner 1988, Temple and Cary 1988, Connolly 1994, Risser 1995, Fagan et al. 1999, Lidicker 1999, Bolger et al. 2000). Ward et al. (1999) highlighted that the magnitude of this increase in density with proximity to the habitat patch edge varies among species. Overall, the species diversity of an assemblage is elevated at the edge in comparison with the interior of the habitat patch. Furthermore, different species occur at the edge than at the interior of the habitat patch (Yahner 1988, Oksanen et al. 1992, Lidicker 1995, With and Crist 1995). Also, individuals of larger size of individual species are more frequently observed closer to the habitat patch edge than within the interior of a habitat patch 
(Connolly 1994, Donovan et al. 1997, Yahner 1998, Tanner 2005, Turner 2005, Wilson et al. 2008).

Terrestrial studies also indicate that the shape of a habitat patch influences patterns in species distribution (Diamond 1975, Wilson and Willis 1975, Saunders et al. 1991, Golden and Crist 2000). Field experiments have illustrated that habitat patches with larger perimeter-to-area ratios have higher species density and diversity (Kunin 1998, Fagan et al. 1999, Bowden et al. 2001). These distributional patterns have been attributed to increases in foraging opportunities and other life history characteristics (Hawrot and Niemi 1996). Additionally, the size structures of different species vary with habitat patch shape. Habitat patches with greater perimeter-to-area ratios have a wider breadth of sizes of organisms than habitat patches with smaller ratios (Oksanen et al. 1992).

The area of a habitat patch also influences the density and diversity of an assemblage. Species diversity and richness increase with increases in habitat patch area (Gosz 1993, Attrill et al. 2000, Bolger et al. 2000, Hovel et al. 2002, Heegaard et al. 2007). However, not all species respond similarly to the change in habitat patch size. For example, Bender et al. (1998) summarized how different species respond to patch sizes; they reported that edge- and interior-specific species are more influenced by changes in patch size than generalist species. Additionally, the literature is currently divided about whether increases in patch size result in an increase or decrease in species density (see review by Bowman et al. 2002). In fact, Bowers and Matter (1997) determined that the density-area relationship was scale dependent; negative density-area 
relationships are observed in small-scale habitat patches whereas positive relationships occur in large-scale habitat patches.

Marine Landscape Ecology

Marine scientists have begun to ask landscape-scale ecological questions, especially related to assemblage structure in seagrass, coral reef, and rocky habitats (Wiens 1989, Irlandi 1994, García-Charton et al. 2004). The early studies, which described patterns in species distribution with respect to landscape-scale habitat characteristics, have shown evidence both in support of and in opposition to the patterns observed in terrestrial studies. A variety of studies has examined terrestrial paradigms in eelgrass patches. For example, species density and diversity increased both with edge proximity (Irlandi 1994, Friedlander and Parrish 1998, Bologna and Heck 2002) and increasing marine patch shape complexity (Irlandi 1997, Eggleston et al. 1999, Hovel and Lipcius 2001). Also, an investigation of the patterns of species distribution on reef patches described a positive correlation of species density and diversity to edge proximity and higher perimeter-to-area ratios (Selgrath et al. 2007). In one study, the size structure of fish assemblages also changed with habitat patch shape (Irlandi et al. 1995). Finally, Bowden et al. (2001) observed increases in the total number of taxa in seagrass patches of greater area.

Several other studies, however, have reported marine landscape patterns that contradict those predicted from terrestrial landscape ecology, indicating a need to 
investigate landscape-scale questions further in marine systems. Jelbart et al. (2006) determined that diversity of fishes decreased with proximity to the edge of an eelgrass patch due to increased predation rates. Hovel et al. (2002) observed no clear pattern in the relationship between species density and eelgrass patch shape. Similarly, GarcíaCharton et al. (2004) observed positive, negative, and non-linear relationships between fish species abundance and reef patch size as well as no relationship among species biomass and landscape-scale habitat characteristics. Additionally, Johnson et al. (1994) determined that suitable prey were substantially more abundant within the reef patch than in adjacent sand patches for four reef fishes in southern California, suggesting that the edge of a reef patch did not provide the presumed increase in foraging opportunities for predators. Baltz et al. (1993) and Eggleston et al. (1998) illustrated that the patterns of species density across a landscape were influenced by the size of the marsh fishes and macro-fauna sampled rather than the habitat characteristics of the landscape.

The ability to model marine systems using patterns observed in terrestrial systems is increasingly being questioned. For example, Hovel et al. (2002) observed that the distribution of faunal densities is influenced by many covarying environmental factors, at multiple spatial scales in eelgrass meadows, and these relationships change seasonally. They suggested that because the number of factors that vary are greater in marine environments than on land they were unable to replicate terrestrial patterns in their study. In addition, Carr et al. (2003) summarized differences between terrestrial and marine systems that result in altered patterns in the structure and dynamics (spatial, genetic, and trophic) of the biology of marine environments (see Table 1 in Carr et al. 2003). They 
attribute these differences in patterns at the assemblage, population, and ecosystem levels to the greater "openness" of marine systems. Hovel et al. (2002) and Carr et al. (2003) emphasized the need to investigate whether terrestrial paradigms are applicable to marine systems despite these differences.

To date, landscape-scale studies examining patterns of species distribution in marine landscapes have been focused on estuaries and tropical reefs. Ebeling and Hixon (1991) reviewed the differences in the structure of fish assemblages and causes for the differences between tropical and temperate reefs, indicating that patterns observed in tropical ecosystems may not apply to temperate ecosystems. Additionally, only a few studies have investigated questions regarding fish-habitat relationships with respect to landscape-scale habitat characteristics in the temperate, sub-tidal marine system. As Anderson et al. (2005a) and Anderson and Yoklavich (2007) identified, the lack of knowledge of the ecological processes at larger scales limits the effectiveness of local fisheries management in temperate regions because there is a disconnect between the scale of the data (tens of meters) and the scale needed for management (hundreds of meters to kilometers).

In situ Fish Surveys

Human-occupied submersible surveys have proven to be an effective technique for surveying nearshore fish populations in deep water (see Yoklavich and O'Connell 2008). The use of a submersible enables researchers to observe fishes in their natural 
habitat. From the data collected, scientists can calculate the density and diversity of demersal fishes (e.g., Stein et al. 1992, Yoklavich et al. 2000). Additionally, fine-scale habitat data can be recorded, often following the protocol proposed by Greene et al. (1999), thus enabling researchers to identify fish-habitat associations.

Data collected from in situ surveys also can be used for analyses of the assemblage structure of fishes and of the relationship between the fish assemblage and the surrounding habitat patch. By utilizing multiple surveys throughout an area that align with the scale of subpopulations or the home ranges of multiple species, researchers can describe relationships among the assemblage structure and the heterogeneity of the habitat patches at a landscape scale. In combination with current seafloor maps, data from a human-occupied submersible was used to quantify the assemblage structure and relevant landscape-scale habitat characteristics along the central coast of California. The data used included fish species' presence, abundance, and size as well as the geographic location of each observed fish. Using these techniques, this study provides the first indepth investigation of patterns in temperate sub-tidal fish assemblages with respect to the landscape-scale spatial structure of the rocky bank landscape. 


\section{Materials and Methods}

Submersible Surveys and Study Sites

Data for this study were collected in 2004, 2007, and 2008 using a humanoccupied submersible, the Delta. In 2004, surveys were conducted to develop a baseline assessment of the densities and species composition of rockfishes and other nearshore fishes within the newly established Rockfish Conservation Areas (PFMC 2009). During fall 2007 and 2008, submersible surveys were conducted to collect baseline assessments of nearshore fish and macro-invertebrate assemblages inside and adjacent to nine Marine Protected Areas (MPAs) in central California, which were established in September 2007 (Starr and Yoklavich 2008).

Data were collected following similar techniques as described in Yoklavich and O'Connell (2008). Ten-minute visual strip transects that were two meters wide and on average $236 \mathrm{~m}$ long (range $41-402 \mathrm{~m}$ ) were conducted to count fishes and invertebrates, characterize fine-scale habitat types, and collect video records. Fishes were identified to the lowest taxonomic level possible, most often to species. A few adjustments to the techniques described by Yoklavich and O'Connell (2008) were used to collect the data for this study. For example in 2007 and 2008, a Doppler Velocity Log was attached to the submersible, which provided a more accurate estimate of the distance traveled than that obtained from the Track-point and WinFrog navigation systems or the laser count methods previously used. Tissot (2008) provided a summary of the at-sea and land-based 
data preparation and processing techniques used for data collected from the 2007 and 2008 submersible surveys.

Data from these projects were opportunistically used for this study. All fish survey transects that occurred within the designated rocky bank patches were included in the study. When necessary, the original fish transects were truncated to remove portions outside of the rocky bank patches. Therefore, the mean fish transect distance used in this study was $199 \mathrm{~m}$ (range $8-351 \mathrm{~m}$ ). Each of the rocky bank patches contained between 3 and 9 fish transects.

In this study, the data used were collected from two regions of the central California coast: near Point Lobos (36³1'19.8” N 12157’9.0” W) and near Point Sur $\left(36^{\circ} 18^{\prime} 20.5^{\prime \prime} \mathrm{N} 121^{\circ} 53^{\prime} 57.0^{\prime \prime} \mathrm{W}\right.$; Fig. 1). Within these two regions, this study focused on the assemblage structure of fishes in the mid-depth rocky habitat from $30-100 \mathrm{~m}$. Allen et al. (2006) identified this depth zone as a faunal break for nearshore fish assemblages. ${ }^{1}$ While these two regions are in close proximity (roughly $50 \mathrm{~km}$ apart), each has distinct characteristics that may influence the habitats and fish distributions. For example, each region is composed of different bedrock types; Point Lobos is porphyritic granodiorite while Point Sur is metamorphic sandstone (Blake and Jones 1981, Norris and Webb 1990, Davidson et al. 2002). Point Lobos contains multiple canyon heads, whereas Point Sur is a large gradually slooping shelf (Fig. 1).

\footnotetext{
${ }^{1}$ Allen et al. (2006) describes this faunal assemblage within $30-100 \mathrm{~m}$ as the "mid-depth rocky habitat" group, whereas Love et al. (2002) classifies the species group of rockfishes in the same depth range as the "shallow shelf" assemblage.
} 


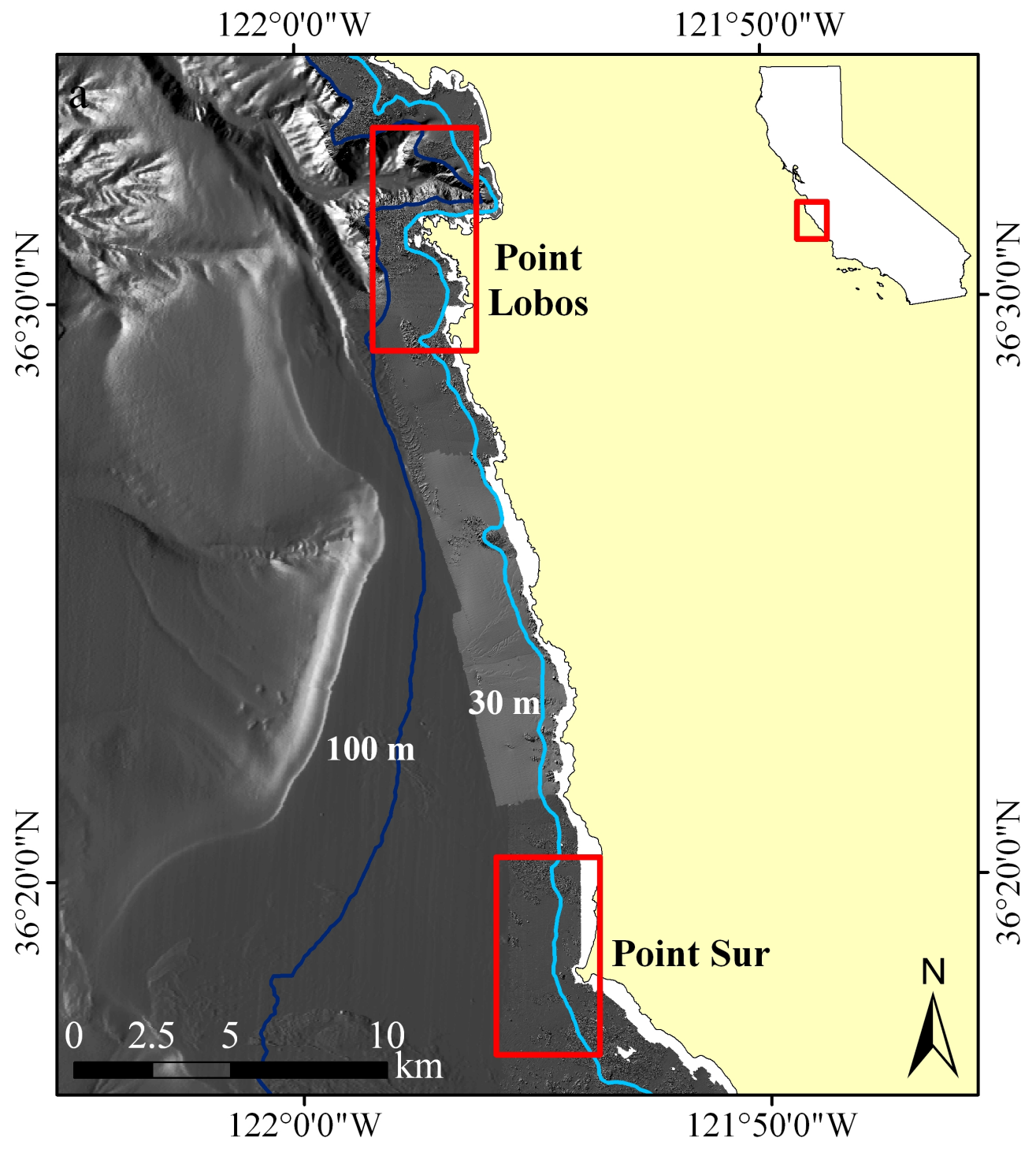

Fig. 1 Map of the study region highlighting the two focus regions: Point Lobos and Point Sur. The red boxes denote the regions in which the rocky bank patches included in this study occurred. The blue lines represent the $30 \mathrm{~m}$ (light blue) and $100 \mathrm{~m}$ (dark blue) isobaths. The seafloor bottom topography is depicted based on the 2-m side scan sonar images 
Independent Habitat Variables

This study investigated landscape patterns at 37 rocky bank patches across the central coast: 24 near Point Lobos and 13 near Point Sur. Two criteria were used to classify a rocky bank patch: the amount of fine-scale habitat and the sharpness of habitat changes at the boundary. For the first criterion, only rocky bank patches that were predominantly $(>80 \%$ ) rocky habitat (e.g., rock outcrop, boulder) were used. Second, at least $75 \%$ of the boundary of each patch had to abut a major change in habitat type (e.g., the habitat changed abruptly from rock to sand). Following these criteria, 2-m resolution side-scan sonar images loaded into ArcGIS were used to define and delineate the rocky bank patches within the study sites (Fig. 2a-b). All the rocky bank patches contained similar fine-scale habitat types. Rocky bank patches were distributed throughout the selected 30 - $100 \mathrm{~m}$ depth range near Point Lobos, but were restricted to shallow depths near Point Sur $(<55 \mathrm{~m})$. The mean rocky bank patch diameter was $288 \mathrm{~m}$ (range $114-$ 714 m; Fig. 3). 

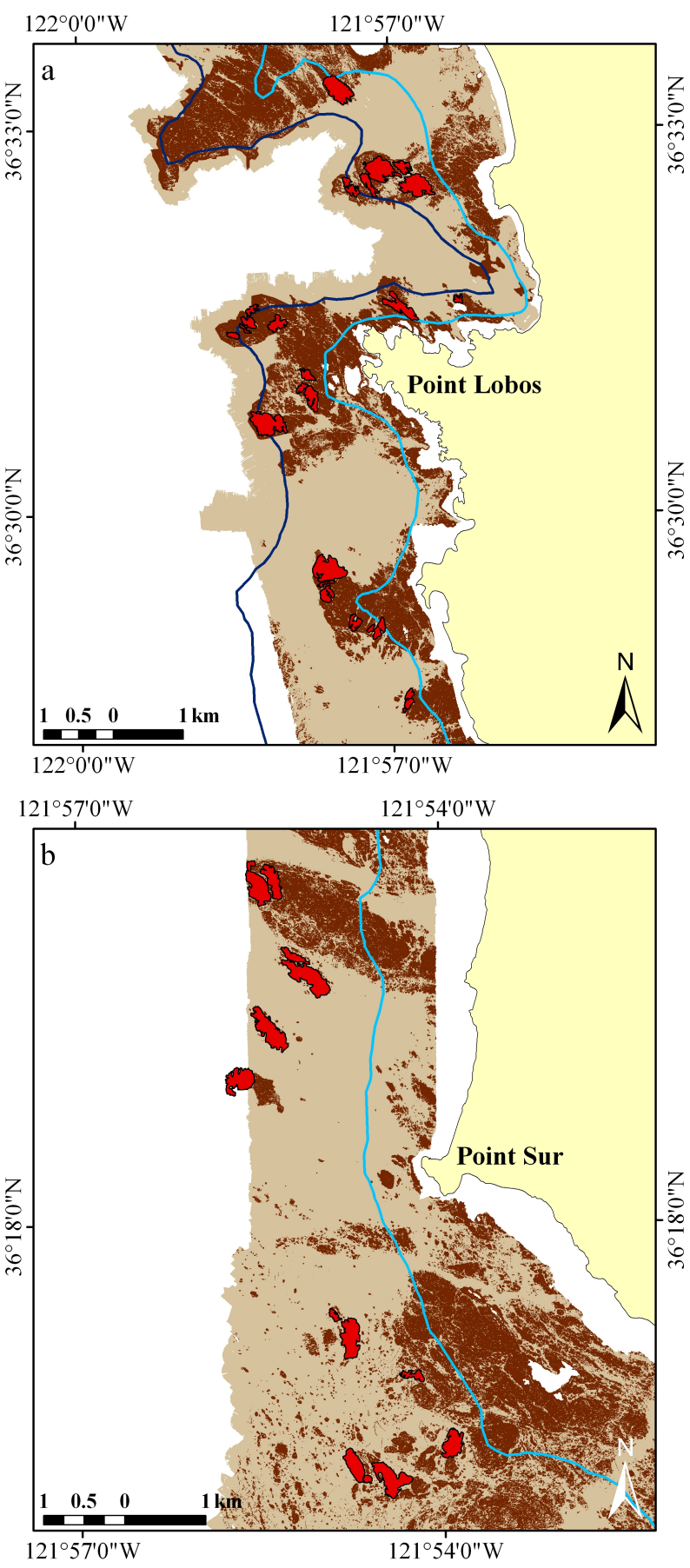

Fig. 2 Distribution of selected rocky bank patches near Point Lobos and Point Sur. The red polygons represent the rocky bank patches analyzed in this study $(n=37)$. The blue lines represent the $30 \mathrm{~m}$ (light blue) and $100 \mathrm{~m}$ (dark blue) isobaths. Areas in light tan represent soft sediment and dark brown areas represent hard bottom habitat based upon GIS substrate layers from CSUMB Seafloor Mapping Lab 


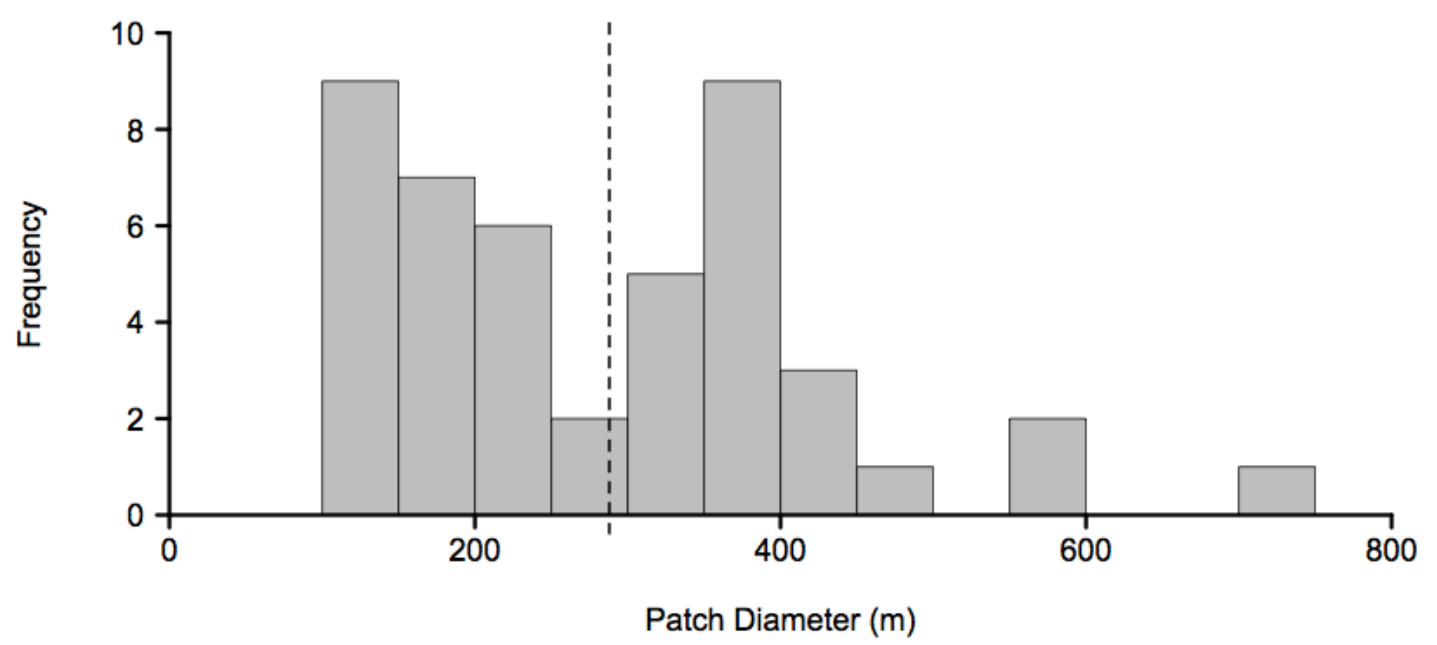

Fig. 3 Frequency histogram of rocky bank patch diameters near Point Lobos and Point Sur. Dotted line denotes the mean rocky bank patch diameter $(228 \mathrm{~m})$

The five independent habitat variables that this study evaluated for the selected rocky bank patches were: proximity to the edge of a patch, patch shape, patch size, patch depth, and patch rugosity (Table 1). The edge of the rocky bank patch was defined as a zone containing rock at the outer perimeter of the rocky habitat, thus excluding soft sediment habitats adjacent to the rocky bank patch. To determine an appropriate width for the edge zone, sections of fish transects were assigned as edge or non-edge iteratively using $2 \mathrm{~m}$ increments between 2 and $40 \mathrm{~m}$ from the rocky bank patch boundary. For each width of edge zone, the density and richness per unit area of fishes along fish transects were calculated. A natural break point in the data, as defined by a change in the slope, was used as an objective measure to determine an appropriate edge zone width. To quantify differences between edge and interior areas of a rocky bank patch, a buffer between the edge and interior zones was used to separate them in space, thus reducing 
spatial autocorrelation. To be conservative, a buffer width that was twice the width of the edge zone was used. Data along fish transects that occurred within the buffer were removed from proximity to edge analyses.

Table 1 List of hypotheses and observed results. The hypotheses and observed results are for assemblage level analyses (a), species-group analyses (b), species-specific analyses (c), and regional comparison assemblage analyses (d). Hyp are the hypotheses and Obs are the observed results. The + represents a positive relationship, - represents a negative relationship, ns means there was no significant relationship, $\mathrm{S}$ denotes shallow patches, and D denotes deep rocky bank patches

\begin{tabular}{|c|c|c|c|c|c|c|c|c|c|c|}
\hline \multirow[t]{2}{*}{ a - Assemblage } & \multicolumn{2}{|c|}{ Depth } & \multicolumn{2}{|c|}{ Rugosity } & \multicolumn{2}{|c|}{ Distance to Edge } & \multicolumn{2}{|c|}{ Patch Shape } & \multicolumn{2}{|c|}{ Patch Size } \\
\hline & Hyp & Obs & Hyp & Obs & Hyp & $O b s$ & Hyp & Obs & Hyp & Obs \\
\hline Density & + & + & + & ns & + & ns (S \& D) & + & ns & + & ns \\
\hline Biomass & + & + & + & ns & + & ns (S \& D) & + & ns & + & ns \\
\hline Richness & + & ns & + & ns & + & + & + & - & + & + \\
\hline Evenness & + & - & + & ns & + & $+(\mathrm{S} \& \mathrm{D})$ & + & ns & + & ns \\
\hline Heterogeneity & + & - & + & ns & + & $+(\mathrm{S} \& \mathrm{D})$ & + & ns & + & ns \\
\hline \multirow[t]{2}{*}{ b - Species Groups } & \multicolumn{2}{|c|}{ Depth } & \multicolumn{2}{|c|}{ Rugosity } & \multicolumn{2}{|c|}{ Distance to Edge } & \multicolumn{2}{|c|}{ Patch Shape } & \multicolumn{2}{|c|}{ Patch Size } \\
\hline & Hyp & $\mathrm{Obs}$ & Hyp & Obs & Hyp & $O b s$ & Hyp & $O b s$ & Hyp & $O b s$ \\
\hline \multicolumn{11}{|l|}{ Density } \\
\hline large rockfishes & + & + & + & ns & + & $\mathrm{ns}(\mathrm{S}),+(\mathrm{D})$ & + & ns & + & ns \\
\hline dwarf rockfishes & + & + & + & ns & + & $\mathrm{ns}(\mathrm{S}),+(\mathrm{D})$ & + & ns & + & ns \\
\hline large non-rockfishes & + & ns & + & ns & + & ns & + & ns & + & ns \\
\hline other benthic fishes & - & + & + & + & + & $+(\mathrm{S}), \mathrm{ns}(\mathrm{D})$ & + & ns & + & ns \\
\hline \multicolumn{11}{|l|}{ Length Distribution } \\
\hline large rockfishes & + & ns & + & ns & + & ns & + & ns & + & ns \\
\hline dwarf rockfishes & + & + & + & $-(S),+(D)$ & - & $-(S),+(D)$ & - & $+(\mathrm{S} \& \mathrm{D})$ & + & $-(\mathrm{S}),+(\mathrm{D})$ \\
\hline large non-rockfishes & + & ns & + & N/A & + & ns & + & ns & + & ns \\
\hline other benthic fishes & + & ns & + & ns & + & ns & + & ns & + & ns \\
\hline
\end{tabular}


Table 1 cont.

\begin{tabular}{|c|c|c|c|c|c|c|c|c|c|c|}
\hline \multirow[t]{2}{*}{ c - Specific Species } & \multicolumn{2}{|c|}{ Depth } & \multicolumn{2}{|c|}{ Rugosity } & \multicolumn{2}{|c|}{ Distance to Edge } & \multicolumn{2}{|c|}{ Patch Shape } & \multicolumn{2}{|c|}{ Patch Size } \\
\hline & Hyp & Obs & Hyp & $O b s$ & Hyp & $O b s$ & Hyp & $O b s$ & Hyp & $O b s$ \\
\hline \multicolumn{11}{|l|}{ Density } \\
\hline Blackeye Goby & - & - & - & ns & + & $\mathrm{ns}(\mathrm{S}),+(\mathrm{D})$ & + & ns & + & ns \\
\hline Blue Rockfish & + & - & + & - & + & $\mathrm{ns}$ & + & ns & + & ns \\
\hline Painted Greenling & - & - & + & + & + & ns & + & ns & + & ns \\
\hline Pygmy Rockfish & + & + & - & ns & + & ns & + & ns & + & ns \\
\hline Rosy Rockfish & + & + & + & ns & + & ns & + & ns & + & ns \\
\hline Squarespot Rockfish & + & + & + & ns & + & ns & + & ns & + & ns \\
\hline Starry Rockfish & + & + & + & ns & + & ns & + & ns & + & ns \\
\hline \multicolumn{11}{|l|}{ Biomass } \\
\hline Blackeye Goby & - & - & - & ns & + & $\mathrm{ns}(\mathrm{S}),+(\mathrm{D})$ & + & ns & + & ns \\
\hline Blue Rockfish & + & $\mathrm{ns}$ & + & ns & + & ns & + & ns & + & + \\
\hline Painted Greenling & - & - & + & + & + & ns & + & ns & + & ns \\
\hline Pygmy Rockfish & + & + & - & + & + & ns & + & ns & + & ns \\
\hline Rosy Rockfish & + & + & + & ns & + & ns & + & ns & + & ns \\
\hline Squarespot Rockfish & + & + & + & ns & + & ns & + & ns & + & + \\
\hline Starry Rockfish & + & + & + & ns & + & ns & + & ns & + & + \\
\hline \multicolumn{11}{|l|}{ Mean Length } \\
\hline Blackeye Goby & - & - & - & ns & + & $+(\mathrm{S} \& \mathrm{D})$ & + & ns & + & $\mathrm{ns}$ \\
\hline Blue Rockfish & - & ns & + & ns & + & ns & + & ns & + & ns \\
\hline Painted Greenling & - & - & + & + & + & ns & + & ns & + & ns \\
\hline Pygmy Rockfish & + & + & - & ns & + & $\mathrm{ns}(\mathrm{S}),+(\mathrm{D})$ & + & ns & + & ns \\
\hline Rosy Rockfish & + & + & + & ns & + & $+(\mathrm{S} \& \mathrm{D})$ & + & ns & + & ns \\
\hline Squarespot Rockfish & + & + & + & ns & + & $\mathrm{ns}(\mathrm{S}),+(\mathrm{D})$ & + & ns & + & + \\
\hline Starry Rockfish & + & + & + & ns & + & $\mathrm{ns}(\mathrm{S}),+(\mathrm{D})$ & + & ns & + & + \\
\hline \multicolumn{11}{|l|}{ Length Distribution } \\
\hline Blackeye Goby & - & ns & - & ns & + & ns & + & ns & + & ns \\
\hline Blue Rockfish & - & ns & + & ns & + & ns & + & ns & + & ns \\
\hline Painted Greenling & - & ns & + & ns & + & ns & + & ns & + & ns \\
\hline Pygmy Rockfish & + & + & - & $+(\mathrm{S} \& \mathrm{D})$ & + & ns & + & $\mathrm{ns}(\mathrm{S}),+(\mathrm{D})$ & + & $\mathrm{ns}(\mathrm{S}),+(\mathrm{D})$ \\
\hline Rosy Rockfish & + & ns & + & ns & + & ns & + & ns & + & ns \\
\hline Squarespot Rockfish & + & ns & + & ns & + & ns & + & + & + & + \\
\hline Starry Rockfish & + & ns & + & ns & + & ns & + & ns & + & ns \\
\hline
\end{tabular}


Table 1 cont.

\begin{tabular}{lcccccccc}
\hline d - Regional Comparison & \multicolumn{3}{c}{ Distance to Edge } & \multicolumn{2}{c}{ Patch Shape } & \multicolumn{2}{c}{ Patch Size } \\
\hline \multirow{2}{*}{ Density } & & Hyp & Obs & Hyp & Obs & Hyp & Obs \\
& Point Lobos & + & $\mathrm{ns}$ & + & $\mathrm{ns}$ & + & $\mathrm{ns}$ \\
\multirow{5}{*}{ Biomass } & Point Sur & + & $\mathrm{ns}$ & + & $\mathrm{ns}$ & + & $\mathrm{ns}$ \\
& Point Lobos & + & $\mathrm{ns}$ & + & $\mathrm{ns}$ & + & $\mathrm{ns}$ \\
& Point Sur & + & $\mathrm{ns}$ & + & $\mathrm{ns}$ & + & $\mathrm{ns}$ \\
Richness & & & & & & & \\
& Point Lobos & + & $\mathrm{ns}$ & + & - & + & + \\
\multirow{5}{*}{ Evenness } & Point Sur & + & $\mathrm{ns}$ & + & $\mathrm{ns}$ & + & $\mathrm{ns}$ \\
& & & & & & & \\
& Point Lobos & + & + & + & $\mathrm{ns}$ & + & $\mathrm{ns}$ \\
Heterogeneity & Point Sur & + & $\mathrm{ns}$ & + & $\mathrm{ns}$ & + & $\mathrm{ns}$ \\
& & & & & & & \\
& Point Lobos & + & + & + & $\mathrm{ns}$ & + & $\mathrm{ns}$ \\
& Point Sur & + & $\mathrm{ns}$ & + & $\mathrm{ns}$ & + & $\mathrm{ns}$ \\
\hline
\end{tabular}

The second and third independent habitat variables were the rocky bank patch shape and patch size. Using ArcGIS Hawth's Tools extension the perimeter and area for each rocky bank patch was deteremined. The perimeter-to-area (P:A) ratio was calculated for each rocky bank patch by dividing the perimeter by the area. This ratio measurement was used as a quantitative proxy for the patch shape. When necessary, area and $\mathrm{P}: \mathrm{A}$ ratio data were binned to create two discrete categories using the mean value as the break point for both area and $\mathrm{P}:$ A ratio.

The fourth and fifth habitat characteristics of the rocky bank patches analyzed were patch depth and patch rugosity. Mean depth per rocky bank patch was calculated from the Seabird SBE19 Plus Seacat Profiler instrument attached to the submersible. For some analyses, depth was used to separate the data into two categories. Shallow patches included rocky bank patches in less than $55 \mathrm{~m}$ of water depth and deep rocky bank 
patches in waters greater than $65 \mathrm{~m}$ deep. These depth bins were chosen to ensure equal sample size between the shallow and deep portions of the data set. ArcGIS data layers of rugosity, from the CSUMB Seafloor Habitat Mapping Lab, were used to determine the rugosity value for each position along the fish transects and for the rocky bank patches as a whole. Rugosity is often calculated as the non-dimensional relationship between the surface area of the seafloor and the linear surface area (Luckhurst and Luckhurst 1978); CSUMB uses digital elevation models to calculate the rugosity from high-resolution multi-beam bathymetry. Rugosity levels in the rocky bank patches range from $1.025-$ 1.364; low rugosity was defined as values that ranged from 0 to 1.182 and high rugosity as values greater than 1.182. These divisions of low and high rugosity categories were chosen because they correspond with the rugosity values of fine-scale habitat types observed during the submersible surveys.

\section{Biological Response Variables}

Patterns of the fish assemblage were analyzed at three different levels of biological organization: all fishes combined to represent the entire assemblage, fishes separated into four species groups, and individual patterns for the seven most abundant species. Assemblage analyses were evaluated for all species observed on fish transects. A subset of species was assigned to the four species groups by a combination of taxonomy, size, and habitat association. The species groups include: "large" rockfishes (Sebastes spp.), dwarf rockfishes (Sebastes spp.), "large" non-rockfishes, and other 
benthic fishes (see Table 2 for list of the species comprising each group). The seven most abundant fishes observed on transects were used for species-specific analyses. These seven species were chosen because they individually comprised more than $1 \%$ of the total abundance of all fishes observed (Appendix A). Although the independent habitat variables used in this study may influence common and rare species differently (Wiens 1976), there were insufficient data to test patterns of rare species with respect to the independent habitat variables.

Table 2 Species that comprise each of the four species groups used for the species-group analyses. The published maximum total length per species is reported. Species were chosen based upon a similarity of taxonomy, size, and habitat associations

\begin{tabular}{cllc}
\hline Species Group & \multicolumn{1}{c}{ Scientific Name } & \multicolumn{1}{c}{ Common Name } & Maximum Total Length \\
\hline large rockfishes & Sebastes caurinus & Copper Rockfish & $66 \mathrm{~cm}$ \\
& Sebastes constellatus & Starry Rockfish & $46 \mathrm{~cm}$ \\
& Sebastes miniatus & Vermilion Rockfish & $76 \mathrm{~cm}$ \\
& Sebastes paucispinis & Bocaccio & $91 \mathrm{~cm}$ \\
& Sebastes pinniger & Canary Rockfish & $76 \mathrm{~cm}$ \\
& Sebastes ruberrimus & Yelloweye Rockfish & $91 \mathrm{~cm}$ \\
dwarf rockfishes & Sebastes hopkinsi & Sqaurespot Rockfish & $29 \mathrm{~cm}$ \\
& Sebastes rosaceus & Rosy Rockfish & $58 \mathrm{~cm}$ \\
& Sebastes semicinctus & Halfbanded Rockfish & $25 \mathrm{~cm}$ \\
& Sebastes wilsoni & Pygmy Rockfish & $23 \mathrm{~cm}$ \\
large non-rockfishes & Hydrolagus colliei & Pacific Ratfish & $97 \mathrm{~cm}$ \\
& Ophiodon elongatus & Lingcod & $152 \mathrm{~cm}$ \\
other benthic fishes & Hexagrammos decagrammus & Kelp Greenling & $61 \mathrm{~cm}$ \\
& Oxylebius pictus & Painted Greenling & $25 \mathrm{~cm}$ \\
& Scorpaena guttata & California Scorpionfish & $43 \mathrm{~cm}$ \\
& Sebastes atrovirens & Kelp Rockfish & $42.5 \mathrm{~cm}$ \\
& Sebastes carnatus & Gopher Rockfish & $42.5 \mathrm{~cm}$ \\
\hline
\end{tabular}

Seven biological response variables were used to define the structure of the nearshore fish assemblage: richness, evenness, heterogeneity, density, biomass, mean length, and length frequency distribution (Table 2). The assemblage diversity indices 
(richness, evenness, and heterogeneity) were only calculated for the assemblage. For the diversity indices, the species richness, evenness (Pielou's evenness index), and heterogeneity (Shannon-Wiener diversity index; Appendix C) were calculated. Density was calculated for the assemblage, species groups, and seven specific species. Density was calculated as the mean number of fishes per $10 \mathrm{~m}^{2}$ of area surveyed along each fish transect. Fish biomass of the assemblage and seven specific species, which also was averaged along each fish transect, was calculated using the Fish Biomass Conversion Equation $\left(\mathrm{W}=\mathrm{a}^{*} \mathrm{~L}^{\mathrm{b}}\right.$; Anderson and Gutreuter 1983) and the collected size and frequency data. Published total length and total weight parameters ( $a$ and $b$ ) for each species, or the most closely related species available, were used (Appendix B). Finally, the size structure of fishes was investigated using the both the mean length (seven specific species) and length frequency distributions (species groups and seven specific species). The length data were originally collected in $5 \mathrm{~cm}$ bins of the total lengths of fishes, thus the length frequency analyses were conducted in $5 \mathrm{~cm}$ increments.

Analytical Techniques

First, patterns among the biological response variables were investigated at the assemblage level with respect to the independent habitat variables near Point Lobos. To determine if these assemblage patterns were driven by specific species within the assemblage, patterns in the biological response variables were then investigated for the four species groups and seven specific species with respect to the independent habitat 
variables. Finally, a comparison of the observed patterns in the structure of the nearshore fish assemblages near Point Lobos with those observed near Point Sur was conducted. All analyses were conducted using the software package R.

Analyses were made using rocky bank patches as the sample unit, with individual fish transects within a patch as the subsamples of the rocky bank patch. Fish density, biomass, and mean length data were averaged across the subsamples. The richness, evenness, heterogeneity, and length frequency data were cumulative calculations among the subsamples. Analyses of patterns among the biological response variables and all independent habitat variables followed these methods. For all analyses an alpha of 0.05 was used to determine statistical significance.

Previous studies have reported that the structure of fish assemblages correlates with depth and rugosity. Therefore, the relationship among the biological response variables with depth and then rugosity was investigated prior to analyzing the other independent habitat variables. If there was a significant relationship among a biological response variable with depth this relationship was accounted for in further analyses. These analyses were either conducted by comparing the biological response variable data in bins, shallow and deep categories, or the residuals of depth and the biological response variable with the independent habitat variable. Additionally, prior to analyzing the patterns of the biological response variable with respect to the proximity to edge, patch shape, or patch size, the relationship between the biological response variable and rugosity was analyzed, after accounting for depth. Using binned or residual data it was possible to ensure that the effect of depth did not mask the effects of other independent 
habitat variables on the biological response variables. Appendix D includes the distribution of rocky bank patches across depth zones and rugosity levels.

Density, Biomass, and Abundance Analyses. Linear regressions and ANOVAs were performed to investigate the relationships among the density of fishes (dependent variable) and each independent habitat variable. All of the following analyses were repeated for each independent habitat variable. Linear regressions were used to test for a relationship between the continuous habitat data (depth, rugosity, patch shape, and patch size) and fish density and biomass. For these analyses, the density data, or when necessary, the residuals of depth with density, was used to test the relationship with each independent habitat variable. ANOVAs were used to investigate patterns in density with respect to proximity to the edge of a rocky bank patch. If necessary, the data were split for each biological response variable by depth category. Then the analyses were conducted on the relationship between proximity to edge and density separately for each depth zone. A significant difference in density between the edge and interior zones of a rocky bank patch would indicate the presence of an edge effect.

Patterns in density at the assemblage level could mask more detailed responses of specific species density with respect to each independent habitat variable. Therefore, regression and ANOVA analyses were repeated for both the four species groups and then the seven most abundant species to compare the species group and species-specific patterns of density with respect to each independent habitat variable. All of the above 
analyses were repeated for biomass of the assemblage and the seven most abundant species.

To determine if the abundances of the four species groups were distributed proportionally with respect to the independent habitat variables, a Preference Index (Krebs 1999) and Goodness-of-Fit (Quinn and Keough 2002) analyses were used. The Preference Index estimated the expected abundance, which was set at an equal distribution between the independent habitat variable categories. This represents the utilization of habitat by fishes, rather than a true test of the preference of a species for a specific habitat type. The Goodness-of-Fit analyses compared the observed and expected abundances against the categories of proximity to edge, rocky bank patch shape, and rocky bank patch size. The independent habitat variables were binned into two categories based upon the mean value. These tests were used to determine if the species groups were proportionally distributed across each independent habitat variable category, i.e., if species associated more strongly with certain habitat characteristics.

Assemblage Diversity Analyses (Richness, Evenness, and Heterogeneity). Statistical tests similar to those described above were used to compare species composition of the assemblage, in terms of richness, evenness, and heterogeneity, to the independent habitat variables. The Bray-Curtis Index of Similarity was used to determine the similarity matrix among the species composition across depth categories, proximity to edge categories, and locations. This metric is not sensitive to sample size, species diversity, or proportional differences in abundance but is able to detect additive changes to the species 
composition of an assemblage (Krebs 1999). The index ranges from 0, which is no similarity, to 1 , which is complete similarity; for this study 0.6 was used as the threshold for similarity between assemblages, based off of the upper similarity range reported by Cailliet and Barry (1979).

Mean Length and Length Frequency Distribution Analyses. The final biological response variable investigated was the length of individuals for the species groups and the seven specific species. Both the mean length and length frequency distributions were used for analyses of the seven specific species, but only the length frequency distributions for the species groups. Linear regressions were used to determine if there were relationships between the mean lengths of fishes and each independent habitat variable. ANOVAs were used to investigate patterns in the mean length of each species between the edge and interior zones of a rocky bank patch. Also, the length frequency distributions in relation to each independent habitat variable were compared using Kolmogorov-Smirnov tests. These values were calculated by determining the cumulative length frequencies of each species within a rocky bank patch across transects. The cumulative values then were averaged across rocky bank patches for each independent habitat variable.

Regional Comparison Analyses. All of the statistical analyses conducted for the biological response variables of the assemblage in shallow rocky bank patches near Point Lobos were repeated for the assemblage data near Point Sur. Only the shallow rocky bank patches were used for the regional comparisons due to sample size constraints. The 
same edge distance as defined for Point Lobos was used in Point Sur. The results and patterns in the biological response variables with respect to the independent habitat variables were compared between the locations to determine if patterns were consistent between two regions in central California.

Other Analyses. Species accumulation curves were compiled for each depth category near Point Lobos and for shallow rocky bank patches near Point Sur (Appendix E). Additionally, the standard error and coefficient of variation for assemblage fish density with respect to sample size were analyzed to further ensure a robust sample size (Appendix E). Using the method described by Bizzarro et al. (2007), the slope among the final four points of each curve was calculated to determine if an asymptote was reached (Appendix E). Numerous studies have documented species-area relationships; therefore, the data were resampled to calculate the cumulative number of species $(\mathrm{S})$ across fish transects as well as among the rocky bank patches. Results from the resampling analyses were compared with predicted values derived from the species-area relationship equation, $\mathrm{S}=\mathrm{c}^{*} \mathrm{~A}^{\mathrm{z}}$ (Arrhenius 1921 summarized in Gotelli 2001), where $\mathrm{A}$ is area, and $\mathrm{c}$ and $\mathrm{z}$ are fitted coefficients. Additionally, the data were resampled to calculate the cumulative abundance of species observed across fish transects as well as among the rocky bank patches. 


\section{Results}

Species Abundance and Composition

During the fish transects used for this study, 38,845 fishes were identified and enumerated. A total of 68 fish taxa was recorded within the sample area and 58 of those were identified to the species level (Appendix A). Of the observed fishes, Sebastes was the dominant genus within the assemblage (representing $50 \%$ of the taxa and $79.4 \%$ of the total abundance). A total of 8,156 fishes (26.3\% of the total abundance) was recorded in the generic "rockfish", sub-generic "Sebastomus", or the "unidentified" categories. These fishes were used for the assemblage analyses but not for the species groups or species-specific analyses. Near Point Lobos, 11 taxa accounted for $>1 \%$ of the total abundance; near Point Sur, 13 taxa accounted for $>1 \%$ (Appendix A). To compare species-specific patterns, the most abundant species from Point Lobos were used. The species, in descending order, included Pygmy Rockfish (Sebastes wilsoni, Gilbert 1915), Blackeye Goby (Rhinogobiops nicholsii, Bean 1882), Squarespot Rockfish (S. hopkinsi, Cramer 1895), Rosy Rockfish (S. rosaceus, Girard 1854), Blue Rockfish (S. mystinus, Jordan and Gilbert 1881), Widow Rockfish (S. entomelas, Jordan and Gilbert 1880), Painted Greenling (Oxylebius pictus, Gill 1862), Starry Rockfish (S. constellatus, Jordan and Gilbert 1880), and Olive Rockfish (S. serranoides, Eigenmann and Eigenmann

\footnotetext{
${ }^{2}$ Following data collection protocols fish are included in the "rockfish" category if they are from the genus Sebastes but the observer is unable to identify the species or if the defining markings of the subgenus Sebastomus were not visible.
} 
1890). Widow and Olive Rockfish were not included in the analyses of the most abundant species because they are mid-water species that are less associated with the bottom habitats included in the submersible surveys. Therefore, only 7 species were used for the species-specific analyses.

\section{Defining the Edge Width}

The density of all fishes per unit area surveyed decreased rapidly with increasing edge widths until around $12 \mathrm{~m}$; adding additional edge width did not result in a substantial change in the density per unit area surveyed (Fig. 4a). Similarly, the richness per unit area surveyed decreased rapidly with increasing edge width until it leveled off around $12 \mathrm{~m}$ (Fig. 4b). Additionally, the mean richness per unit area surveyed was 0.028 , which occurred at $12 \mathrm{~m}$. Therefore, the edge width zone was defined as the first $12 \mathrm{~m}$ from the rocky bank patch boundary. Data for the interior zone included fishes that were observed at distances greater than $36 \mathrm{~m}$ from the rocky bank patch boundary. All fishes observed between $12 \mathrm{~m}$ and $36 \mathrm{~m}$ from the rocky bank patch boundary were removed from analyses to spatially separate the edge and interior zones of the rocky bank patch. ${ }^{3}$

\footnotetext{
${ }^{3}$ Forty-two percent of the observed fish on fish transects were observed within the buffer zone of rocky bank patches.
} 

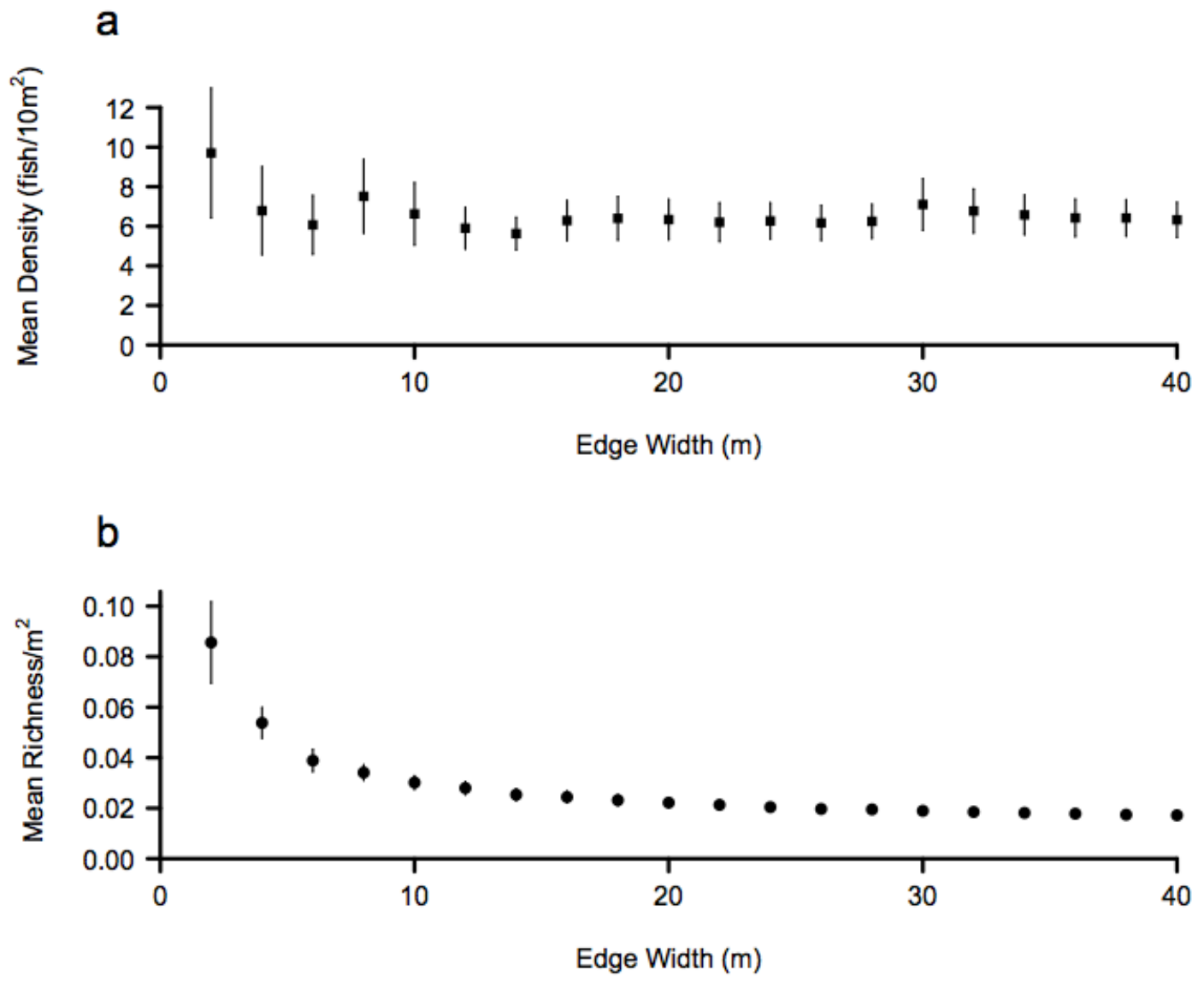

Fig. 4 Assemblage density and richness per unit area surveyed at different widths of the edge zone. Density (a) and richness (b) per unit area surveyed of the nearshore fish assemblage were calculated for each incremental cumulative $2 \mathrm{~m}$ width of edge zone from $2-40 \mathrm{~m}$. Standard error is plotted as vertical bars

Assemblage Analyses

Depth and Rugosity. The fish assemblage structure varied with respect to depth. The overall species composition similarity index between shallow and deep patches near Point Lobos was only 0.493 (Fig. 5). 

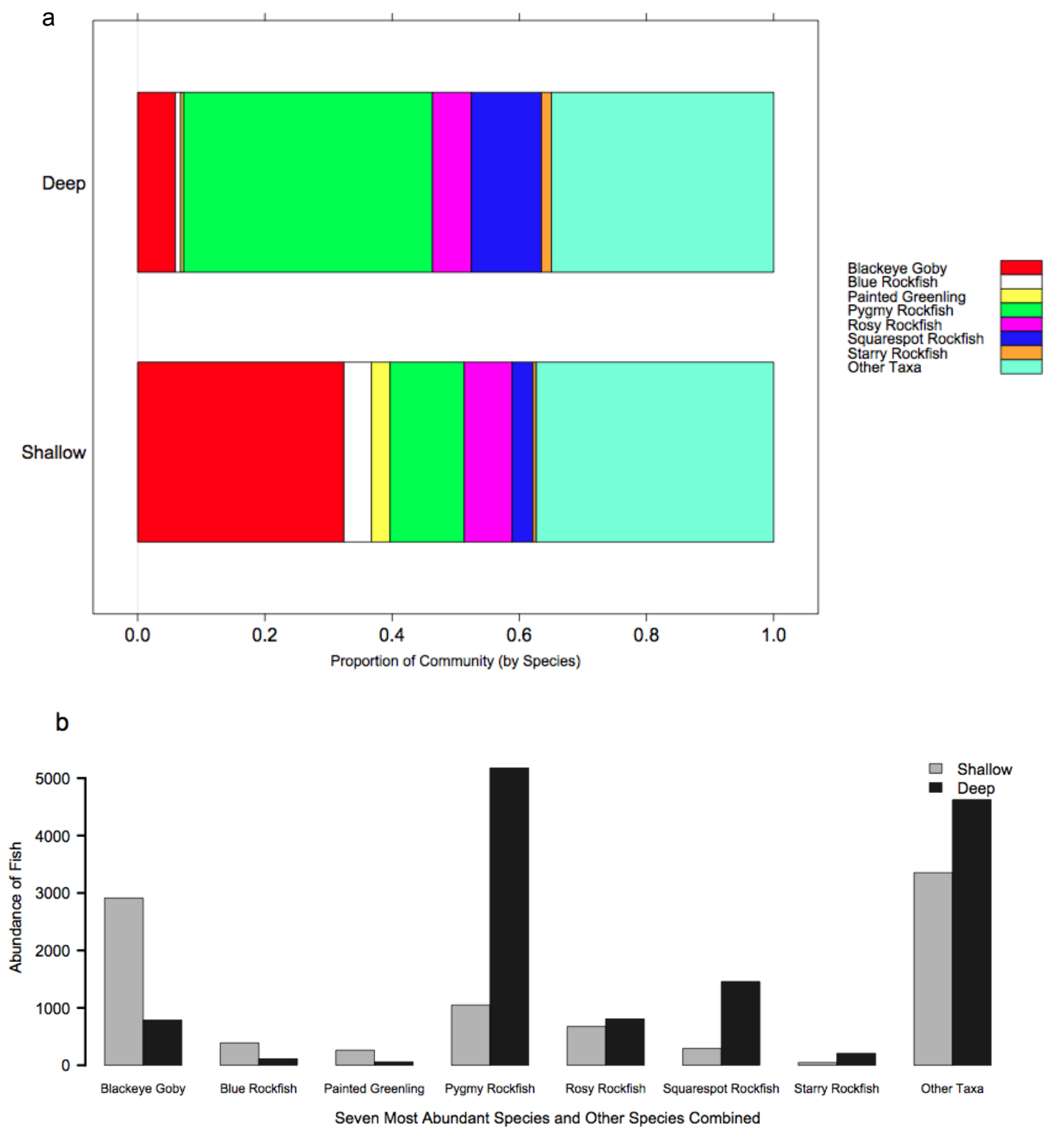

Fig. 5 Species composition of the seven most abundant species by depth category near Point Lobos. The assemblage composition in proportional abundance (a) and the observed abundance (b) are reported. The unidentified fishes, those not identified to the species level, and the 51 less-abundant species (whose abundance was less than $1 \%$ of the total abundance) are pooled into the "other" category. Depth classifications were defined as shallow $(<55 \mathrm{~m})$ and deep $(>65 \mathrm{~m})$ 
Additionally, the density and biomass of all fishes significantly increased with increasing depth $(p=0.001, p=0.019$, respectively), whereas the evenness $(p=0.019)$ and heterogeneity $(p=0.007)$ significantly decreased with increasing depth (Table $3 a$, Appendix G). These significant relationships with depth were accounted for in subsequent analyses by comparing the regression residuals of depth and the biological response variable (density, biomass, evenness, or heterogeneity) with the subsequent independent habitat variable. There was no significant relationship between richness and depth; therefore, subsequent analyses used the original data for this biological response variable. After accounting for the effect of depth on the biological response variables at the assemblage level, there was no significant relationship among any of the biological response variables and rugosity (Appendix G).

Table 3 Assemblage, species-groups, and species-specific relationships with respect to depth and rugosity near Point Lobos. Results are grouped by analyses: assemblage indices with respect to depth and rugosity (a), species-group density and length distributions with respect to depth (b) and rugosity (c), and species-specific relationships with depth (d) and rugosity (e). Statistically significant relationships are in bold

\begin{tabular}{llllllc}
\hline a - Assemblage & \multicolumn{3}{l}{ Depth } & \multicolumn{3}{c}{ Rugosity } \\
\hline Density $\left(\right.$ fish $\left./ 10 \mathrm{~m}^{2}\right)$ & $\mathbf{p}$ & $\mathbf{r}^{2}$ & Direction & $\mathbf{p}$ & $\mathbf{r}^{2}$ & Direction \\
Biomass $\left(\mathrm{g} / \mathrm{cm} / 10 \mathrm{~m}^{2}\right)$ & $\mathbf{0 . 0 0 1}$ & 0.419 & Positive & 0.811 & 0.003 & No \\
Richness & $\mathbf{0 . 0 1 9}$ & 0.224 & Positive & 0.552 & 0.016 & No \\
Evenness & 0.408 & 0.031 & No & 0.142 & 0.095 & Negative \\
Heterogeneity & $\mathbf{0 . 0 1 9}$ & 0.225 & Negative & 0.899 & 0.001 & No \\
\hline
\end{tabular}

\begin{tabular}{lrccrcc}
\hline b - Species Groups (Depth) & \multicolumn{3}{c}{ Density $\left(\mathbf{f i s h} / \mathbf{1 0 \mathbf { m } ^ { 2 } )}\right.$} & \multicolumn{3}{c}{ Length Distribution } \\
\hline & \multicolumn{1}{c}{$\mathbf{p}$} & \multicolumn{1}{c}{$\mathbf{r}^{2}$} & Direction & \multicolumn{1}{c}{ p } & \multicolumn{1}{c}{ D } & Direction \\
\hline large rockfishes & $\mathbf{0 . 0 0 2}$ & 0.354 & Positive & 0.993 & 0.130 & No \\
dwarf rockfishes & $<\mathbf{0 . 0 0 1}$ & 0.670 & Positive & $<\mathbf{0 . 0 0 1}$ & 0.215 & Positive \\
large non-rockfishes & 0.287 & 0.051 & No & 1.000 & 0.139 & No \\
other benthic fishes & $<\mathbf{0 . 0 0 1}$ & 0.497 & Positive & 1.000 & 0.099 & No \\
\hline
\end{tabular}


Table 3 cont.

\begin{tabular}{|c|c|c|c|c|c|c|}
\hline \multirow[t]{2}{*}{ c - Species Groups (Rugosity) } & \multicolumn{3}{|c|}{ Density (fish/10m²) } & \multicolumn{3}{|c|}{ Length Distribution } \\
\hline & $\mathbf{p}$ & $\mathbf{r}^{2}$ & Direction & $\mathbf{p}$ & D & Direction \\
\hline large rockfishes & 0.793 & 0.003 & No & 1.000 & 0.087 & No \\
\hline dwarf rockfishes & 0.278 & 0.053 & No & & & \\
\hline Shallow & & & & $<0.001$ & 0.317 & Negative \\
\hline Deep & & & & $<0.001$ & 0.127 & Positive \\
\hline large non-rockfishes & 0.688 & 0.007 & No & 1.000 & 0.139 & No \\
\hline other benthic fishes & 0.032 & 0.192 & Positive & 1.000 & 0.035 & No \\
\hline \multirow[t]{2}{*}{ d - Specific Species (Depth) } & \multicolumn{3}{|c|}{ Density (fish/10m²) } & \multicolumn{3}{|c|}{ Biomass $\left(\mathrm{g} / \mathrm{cm} / \mathbf{1 0 m ^ { 2 } )}\right.$} \\
\hline & p & $\mathbf{r}^{2}$ & Direction & $p$ & $\mathbf{r}^{2}$ & Direction \\
\hline Blackeye Goby & 0.006 & 0.295 & Negative & 0.022 & 0.215 & Negative \\
\hline Blue Rockfish & 0.047 & 0.168 & Negative & 0.059 & 0.152 & No \\
\hline Painted Greenling & $<0.001$ & 0.439 & Negative & 0.001 & 0.404 & Negative \\
\hline Pygmy Rockfish & $<0.001$ & 0.533 & Positive & 0.001 & 0.418 & Positive \\
\hline Rosy Rockfish & 0.008 & 0.278 & Positive & 0.001 & 0.428 & Positive \\
\hline Squarespot Rockfish & 0.001 & 0.382 & Positive & $<0.001$ & 0.559 & Positive \\
\hline \multirow[t]{3}{*}{ Starry Rockfish } & $<0.001$ & 0.539 & Positive & 0.001 & 0.419 & Positive \\
\hline & \multicolumn{3}{|c|}{ Mean Length $(\mathrm{cm})$} & \multicolumn{3}{|c|}{ Length Distribution } \\
\hline & p & $\mathbf{r}^{2}$ & Direction & $\mathbf{p}$ & D & Direction \\
\hline Blackeye Goby & 0.045 & 0.170 & Negative & 0.998 & 0.057 & No \\
\hline Blue Rockfish & 0.063 & 0.148 & No & 0.282 & 0.324 & No \\
\hline Painted Greenling & $<0.001$ & 0.694 & Negative & 0.999 & 0.167 & No \\
\hline Pygmy Rockfish & $<0.001$ & 0.874 & Positive & $<0.001$ & 0.296 & Positive \\
\hline Rosy Rockfish & 0.001 & 0.404 & Positive & 0.085 & 0.222 & No \\
\hline Squarespot Rockfish & $<0.001$ & 0.720 & Positive & 0.248 & 0.207 & No \\
\hline Starry Rockfish & 0.024 & 0.210 & Positive & 1.000 & 0.071 & No \\
\hline
\end{tabular}


Table 3 cont.

\begin{tabular}{|c|c|c|c|c|c|c|}
\hline e - Specific Species (Rugosity) & \multicolumn{3}{|c|}{ Density (fish/10m²) } & \multicolumn{3}{|c|}{ Biomass $\left(\mathrm{g} / \mathrm{cm} / 10 \mathrm{~m}^{2}\right)$} \\
\hline & p & $\mathbf{r}^{2}$ & Direction & p & $\mathbf{r}^{2}$ & Direction \\
\hline Blackeye Goby & 0.459 & 0.025 & No & 0.460 & 0.025 & No \\
\hline Blue Rockfish & 0.023 & 0.213 & Negative & 0.116 & 0.108 & No \\
\hline Painted Greenling & 0.014 & 0.243 & Positive & 0.013 & 0.248 & Positive \\
\hline Pygmy Rockfish & 0.242 & 0.062 & No & 0.024 & 0.212 & Positive \\
\hline Rosy Rockfish & 0.589 & 0.014 & No & 0.718 & 0.006 & No \\
\hline Squarespot Rockfish & 0.839 & 0.002 & No & 0.982 & 0.000 & No \\
\hline \multirow[t]{3}{*}{ Starry Rockfish } & 0.661 & 0.009 & No & 0.817 & 0.002 & No \\
\hline & \multicolumn{3}{|c|}{ Mean Length (cm) } & \multicolumn{3}{|c|}{ Length Distribution } \\
\hline & p & $\mathbf{r}^{2}$ & Direction & $\mathrm{p}$ & D & Direction \\
\hline Blackeye Goby & 0.947 & 0.000 & No & 0.994 & 0.048 & No \\
\hline Blue Rockfish & 0.057 & 0.155 & No & 0.807 & 0.205 & No \\
\hline Painted Greenling & $\mathbf{0 . 0 3 3}$ & 0.191 & Positive & 0.998 & 0.145 & No \\
\hline \multicolumn{7}{|l|}{ Pygmy Rockfish } \\
\hline Shallow & 0.994 & 0.000 & No & $<0.001$ & 0.749 & Positive \\
\hline Deep & 0.136 & 0.098 & No & $<0.001$ & 0.147 & Positive \\
\hline Rosy Rockfish & 0.243 & 0.061 & No & 1.000 & 0.030 & No \\
\hline Squarespot Rockfish & 0.118 & 0.107 & No & 0.347 & 0.157 & No \\
\hline Starry Rockfish & 0.927 & 0.417 & No & 0.996 & 0.167 & No \\
\hline
\end{tabular}

Proximity to Edge. Total density of fishes was not significantly different between the edge and interior zones in shallow rocky bank patches $(p=0.627$; Fig. 6a, Table 4$)$.

Although the mean density of fishes in deep rocky bank patches was somewhat greater in the edge than in the interior, it was not significantly different $(p=0.099$; Fig. 6a). The fish assemblage biomass did not differ between the edge and interior zones in shallow rocky bank patches $(\mathrm{p}=0.463$; Table 4$)$, but was significantly greater in the edge than the interior zones in deep patches $(\mathrm{p}=0.036)$. 

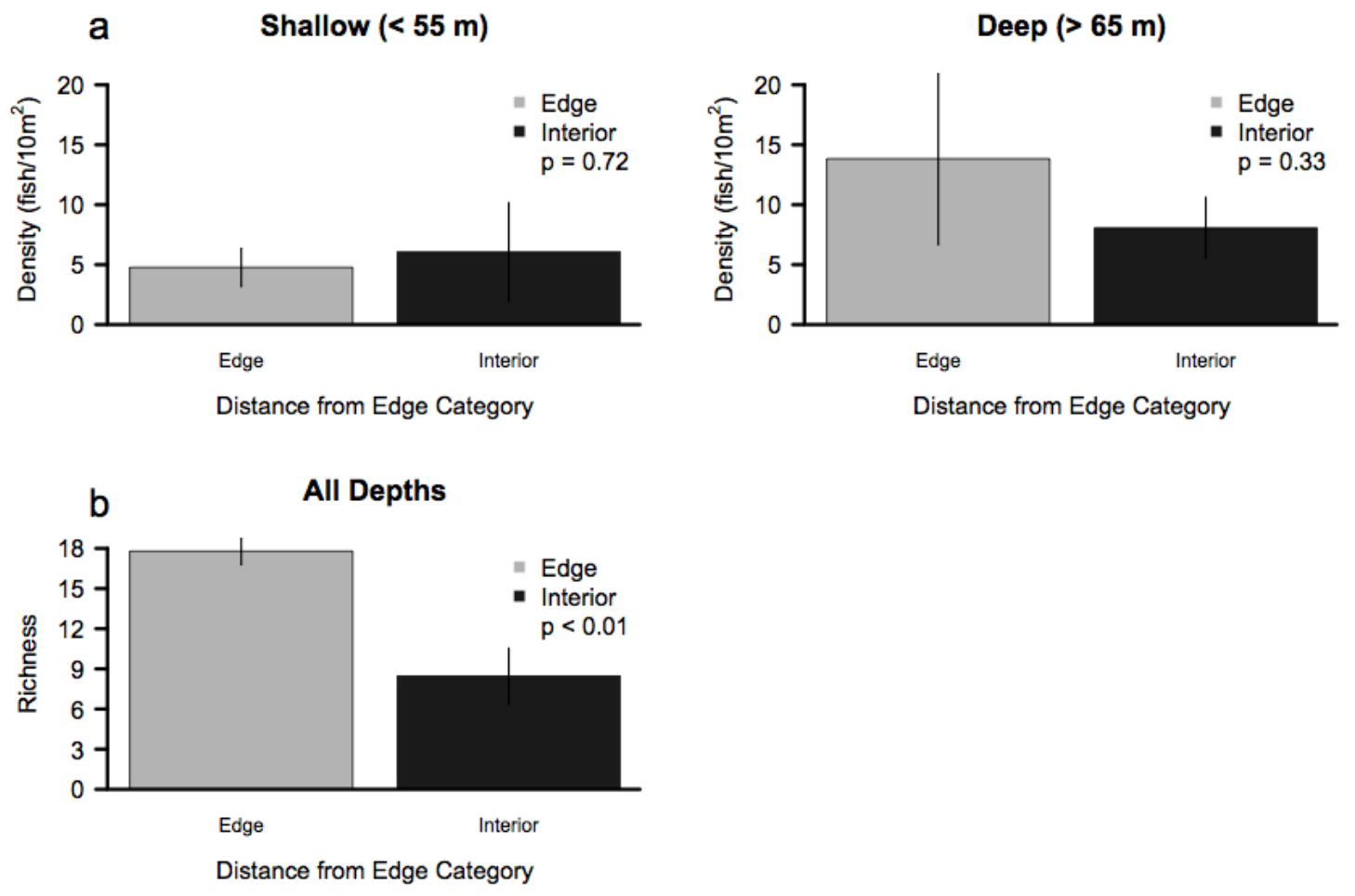

Fig. 6 Comparison of assemblage biological response variables (density and species richness) with respect to distance from rocky bank patch edge near Point Lobos. The results are of the density (a) and species richness (b). If the assemblage index was significantly correlated with depth, the analysis was run with binned data. Gray denotes the edge zone and black denotes the interior zone. Standard error is plotted as vertical bars. P-values are included in the legends

Table 4 Assemblage biological response variables (density, biomass, richness, evenness, and heterogeneity) with respect to distance from rocky bank patch edge near Point Lobos. If the assemblage index was significantly correlated with depth, the analysis was run with binned data. Statistically significant relationships are in bold

\begin{tabular}{lrccccccc}
\hline & \multicolumn{4}{c}{ Shallow or Pooled } & \multicolumn{4}{c}{ Deep } \\
\hline & \multicolumn{1}{c}{$\mathbf{p}$} & df & F-ratio & Direction & $\mathbf{p}$ & df & F-ratio & Direction \\
\hline Density $\left(\mathrm{fish} / 10 \mathrm{~m}^{2}\right)$ & 0.627 & 2 & 0.242 & No & 0.099 & 2 & 3.000 & No \\
Biomass $\left(\mathrm{g} / \mathrm{cm} / 10 \mathrm{~m}^{2}\right)$ & 0.463 & 2 & 0.555 & No & 0.036 & 2 & 5.058 & Edge \\
Richness & $<\mathbf{0 . 0 0 1}$ & 2 & 14.904 & Edge & & & & \\
Evenness & $\mathbf{0 . 0 0 8}$ & 2 & 8.484 & Edge & $\mathbf{0 . 0 2 6}$ & 2 & 5.786 & Edge \\
Heterogeneity & $\mathbf{0 . 0 2 7}$ & 2 & 5.584 & Edge & $\mathbf{0 . 0 0 7}$ & 2 & 9.043 & Edge \\
\hline
\end{tabular}


The number of observed species was significantly greater in the edge than the interior zones near Point Lobos ( $\mathrm{p}<0.001$; Fig. 6b). Similarly, evenness was significantly greater in the edge than the interior zones in both shallow $(p=0.008)$ and deep $(p=0.026)$ sections near Point Lobos (Table 4), meaning there were fewer dominant species in the assemblage at the edge of rocky bank patches than in the interior. Therefore, heterogeneity also was significantly greater in the edge than the interior zones across the depth range $(p=0.008, p=0.026$; Table 4$)$. The species composition between the edge and interior zones in shallow patches was 0.713 similar, but only 0.424 similar in deep patches (Fig. 7). This indicates a difference in edge effects of assemblage diversity between the shallow and deep patches similar to those observed in the density and biomass results. 


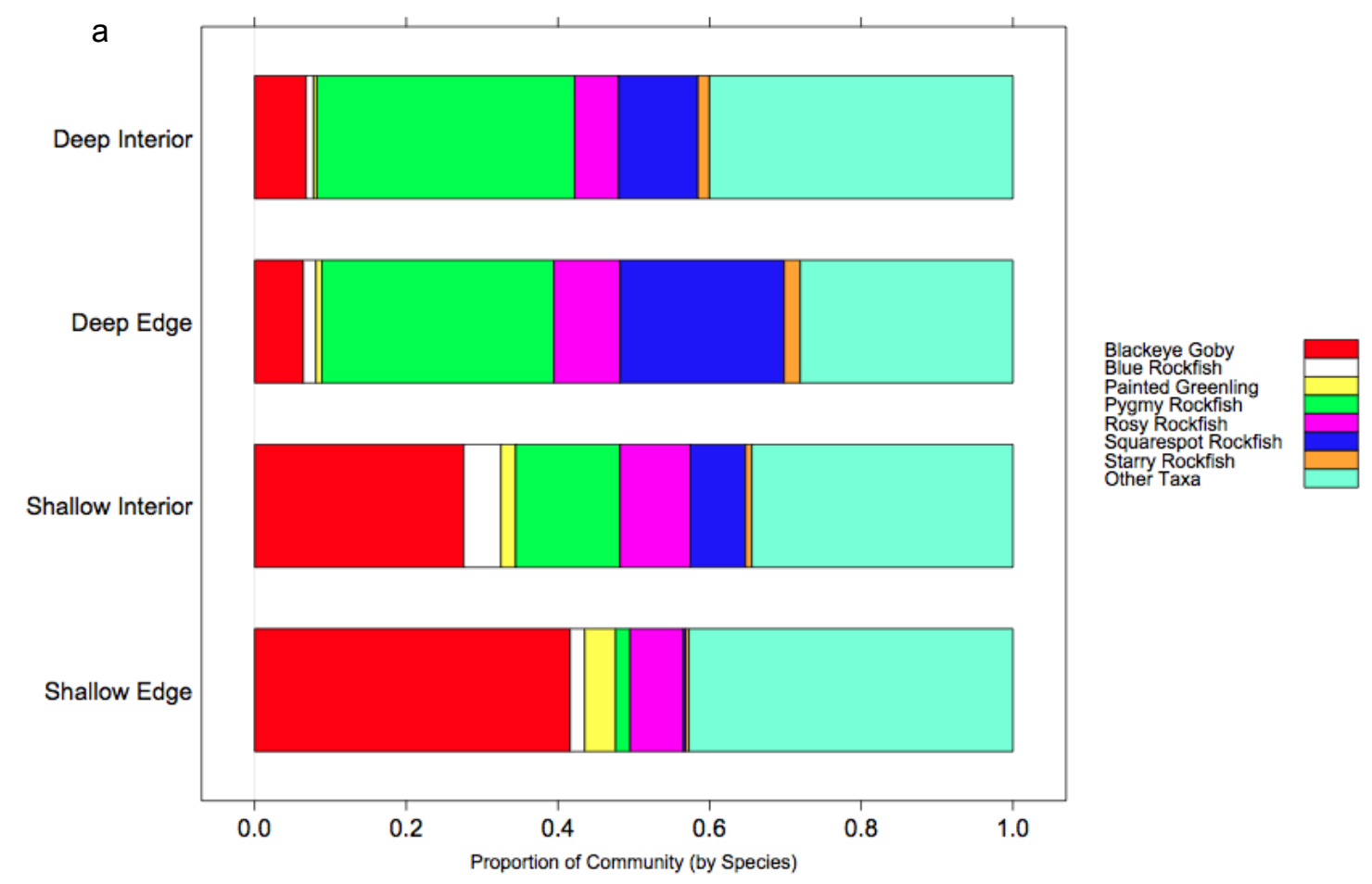

b

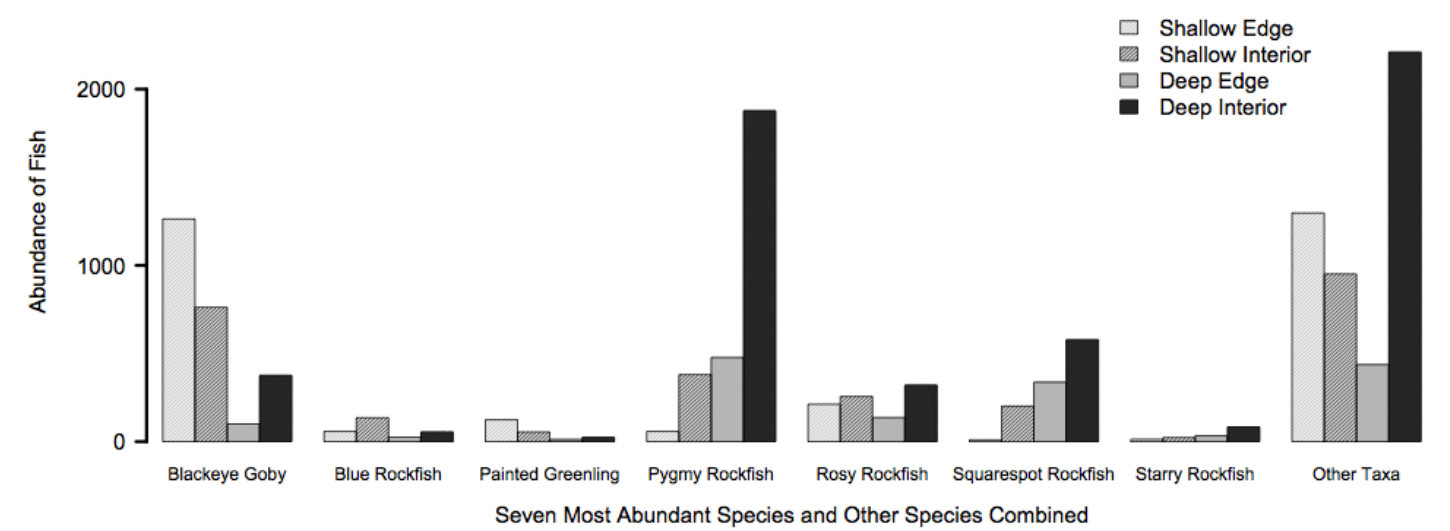

Fig. 7 Species composition of the seven most abundant species by depth category and proximity to edge near Point Lobos. The assemblage composition in proportional abundance (a) and the observed abundance (b) are reported. The unidentified fishes, those not identified to the species level, and the 51 less-abundant species (whose abundance was less than $1 \%$ of the total abundance) are pooled into the "other" category. Depth classifications were defined as shallow $(<55 \mathrm{~m})$ and deep $(>65 \mathrm{~m})$ 
Patch Shape (P:A Ratio). Neither the density nor biomass of all fishes combined was significantly correlated with the P:A ratio $(p=0.559$ and $p=0.192$ respectively; Table 5, Fig. 8a). However, there was a significant negative relationship between richness and rocky bank patch shape $(\mathrm{p}=0.012 ;$ Fig. $8 \mathrm{~b})$. Fewer species were observed in rocky bank patches with more complex boundaries. In fact, rocky bank patch shape explained $25.4 \%$ of the variability in richness in the nearshore fish assemblage. However, there was no significant relationship between assemblage evenness or heterogeneity and $\mathrm{P}: \mathrm{A}$ ratio $(\mathrm{p}=$ $0.362, \mathrm{p}=0.742)$.
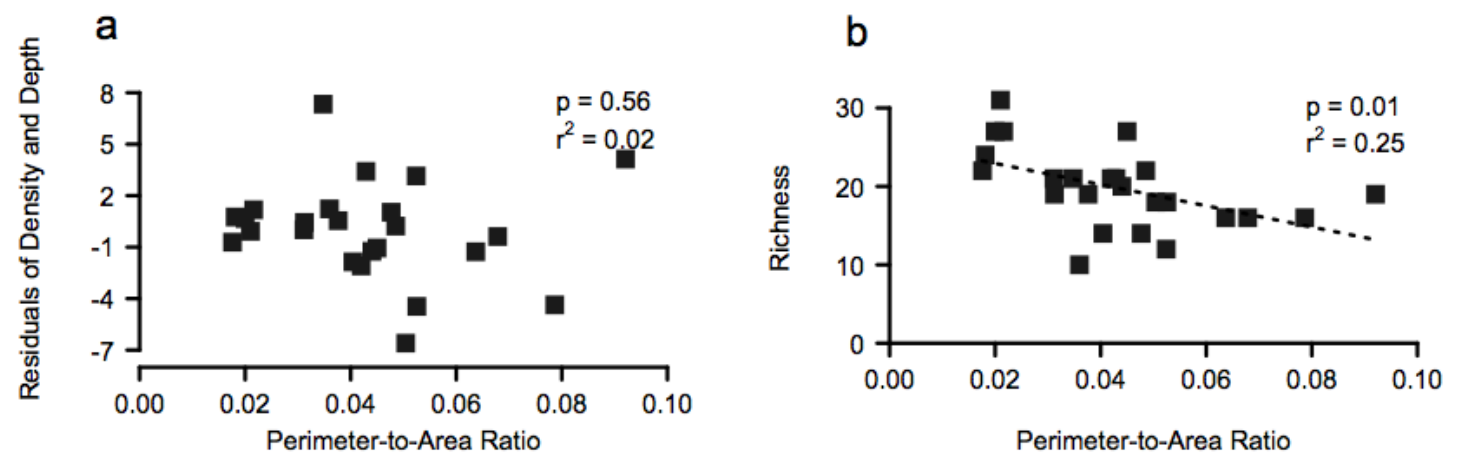

Fig. 8 Comparison of assemblage biological response variables (density and richness) with respect to patch shape of rocky bank patches near Point Lobos. Results are of the density (a) and richness (b). If the assemblage index was significantly correlated with depth, the analysis was run against the residuals data. Significant relationships are denoted by a dotted regression line. P-values and $\mathrm{r}^{2}$ values are included in the legends 
Table 5 Assemblage biological response variables (density, biomass, richness, evenness, and heterogeneity) with respect to patch shape of rocky bank patches near Point Lobos. If the assemblage index was significantly correlated with depth, the analysis was run against the residuals data. Statistically significant relationships are in bold

\begin{tabular}{lccc}
\hline & $\mathbf{p}$ & $\mathbf{r}^{2}$ & Direction \\
\hline Density $\left(\mathrm{fish} / 10 \mathrm{~m}^{2}\right)$ & 0.559 & 0.016 & No \\
Biomass $\left(\mathrm{g} / \mathrm{cm} / 10 \mathrm{~m}^{2}\right)$ & 0.192 & 0.076 & No \\
Richness & $\mathbf{0 . 0 1 2}$ & 0.254 & Negative \\
Evenness & 0.362 & 0.038 & No \\
Heterogeneity & 0.742 & 0.005 & No \\
\hline
\end{tabular}

Patch Size (Area). Neither the density nor biomass of all fishes was significantly correlated with rocky bank patch size $(p=0.483, p=0.064$; Fig. 9a, Table 6). However, there was a significant positive relationship between richness and area $(\mathrm{p}<0.001$; Fig. 9b). In fact, rocky bank patch size explained $48.2 \%$ of the variability in species richness. But there was no relationship between the dominance of species within the assemblage or the overall diversity and area $(\mathrm{p}=0.895, \mathrm{p}=0.082$, Table 6$)$.
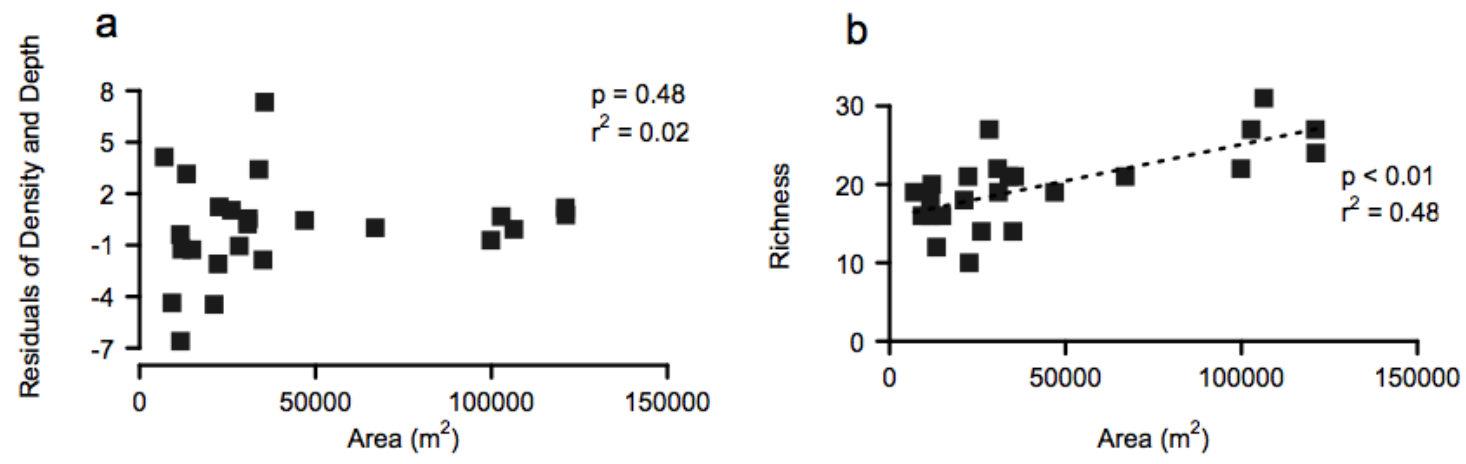

Fig. 9 Comparison of assemblage biological response variables (density and richness) with respect to patch size of rocky bank patches near Point Lobos. Results are of the density (a) and richness (b). If the assemblage index was significantly correlated with depth, the analysis was run against the residuals data. Significant relationships are denoted by a dotted regression line. P-values and $\mathrm{r}^{2}$ values are included in the legends 
Table 6 Assemblage biological response variables (density, biomass, richness, evenness, and heterogeneity) with respect to patch size of rocky bank patches near Point Lobos. If the assemblage index was significantly correlated with depth, the analysis was run against the residuals data. Statistically significant relationships are in bold

\begin{tabular}{lrcc}
\hline & \multicolumn{1}{c}{$\mathbf{p}$} & $\mathbf{r}^{2}$ & Direction \\
\hline Density $\left(\mathrm{fish} / 10 \mathrm{~m}^{2}\right)$ & 0.483 & 0.023 & No \\
Biomass $\left(\mathrm{g} / \mathrm{cm}^{2} / 10 \mathrm{~m}^{2}\right)$ & 0.064 & 0.147 & No \\
Richness & $<\mathbf{0 . 0 0 1}$ & 0.482 & Positive \\
Evenness & 0.895 & 0.001 & No \\
Heterogeneity & 0.082 & 0.131 & No \\
\hline
\end{tabular}

Species Group Analyses

Depth and Rugosity. The density and length distribution of the four species groups varied with respect to depth. The density of large rockfishes, dwarf rockfishes, and other benthic fishes significantly increased with increasing depth $(p=0.002, p<0.001, p<$ 0.001 respectively; Table 3b, Appendix F). Additionally, the length distribution of dwarf rockfishes increased significantly with depth $(\mathrm{p}<0.001)$. These significant relationships with depth for the density and length distributions of different species groups were accounted for in subsequent analyses by using the regression residuals of depth and the biological response variable for the appropriate species group (i.e., density of large rockfishes, dwarf rockfishes, and other benthic fishes) and by binning the length distribution data by depth categories for dwarf rockfishes. There were no significant relationships among the remaining species groups' density or length distributions with respect to depth, therefore subsequent analyses used the original data for these two biological response variables. 
Although the assemblage indices did not correlate with rugosity, there were significant relationships between rugosity and some of the species groups' density and length distributions (Table 3c, Appendix F). For example, the density of other benthic fishes was positively correlated with rugosity $(\mathrm{p}=0.032)$. In addition, the length distribution of dwarf rockfishes significantly decreased with increasing rugosity $(\mathrm{p}=$ 0.004). The density and length distribution for the other species groups did not significantly vary with changes in rugosity; therefore, the original, or depth-adjusted, data were used for further analyses with the remaining independent habitat variables.

Proximity to Edge. As expected, positive edge effects were observed in some of the assemblage indices investigated (e.g., diversity indices and biomass, see above). Therefore, this study investigated if these trends of the assemblage structure could be explained by patterns of the four species groups. The relative abundance of each species group was proportionally distributed between the edge and interior zones of rocky bank patches. This means that the observed abundance in the edge and interior zones did not differ from the expected abundance based on the available area of the edge and interior zones (Appendix G). However, differences in densities were detected between the edge and interior zones (Table 7). For example, the density of large rockfishes and other benthic fishes were both significantly greater in the edge zone as compared to the interior zones $(p=0.046, p=0.013 ;$ Fig. 10a). The densities of the dwarf rockfishes and large non-rockfishes were not significantly different $(p>0.05)$ with respect to proximity to the edge for either shallow or deep rocky bank patches. 
Table 7 Biological response variables (density and length distributions) of the species groups with respect to distance from the rocky bank patch edge near Point Lobos. The results are for the density (a) and the length distributions (b). If the species-group index was significantly correlated with depth, the analysis was run with binned data. Statistically significant relationships are in bold

\begin{tabular}{|c|c|c|c|c|c|c|c|c|}
\hline \multirow[t]{2}{*}{ a - Density (fish/10m²) } & \multicolumn{4}{|c|}{ Shallow } & \multicolumn{4}{|c|}{ Deep } \\
\hline & $\mathbf{p}$ & df & F-ratio & Direction & $\mathbf{p}$ & df & F-ratio & Direction \\
\hline large rockfishes & 0.286 & 2 & 1.19 & Edge & 0.046 & 2 & 4.547 & Edge \\
\hline dwarf rockfishes & 0.383 & 2 & 0.788 & Core & 0.550 & 2 & 0.369 & Edge \\
\hline large non-rockfishes & 0.511 & 2 & 0.438 & Edge & & & & \\
\hline other benthic fishes & 0.013 & 2 & 7.216 & Edge & 0.552 & 2 & 0.365 & No \\
\hline b - Length Distribution & & $\mathbf{p}$ & D & Direction & & & & \\
\hline large rockfishes & & 0.574 & 0.244 & No & & & & \\
\hline \multirow[t]{2}{*}{ dwarf rockfishes } & & 0.001 & 0.787 & Core & & & & \\
\hline & & 0.021 & 0.286 & Edge & & & & \\
\hline large non-rockfishes & & 0.574 & 0.244 & No & & & & \\
\hline other benthic fishes & & 0.964 & 0.167 & No & & & & \\
\hline
\end{tabular}

The length distribution of dwarf rockfishes was significantly different between the edge and interior zones. In shallow rocky bank patches, longer dwarf rockfishes were observed in the interior zone $(\mathrm{p}<0.001$; Fig. 10b). Whereas in deep rocky bank patches, dwarf rockfishes of longer lengths were observed in the edge zone rather than the interior zone $(\mathrm{p}=0.021 ;$ Fig. $10 \mathrm{~b})$. There was no relationship among the length distribution of large rockfishes, large non-rockfishes, or other benthic fishes and the proximity to the edge for either shallow or deep rocky bank patches (Table 7). 

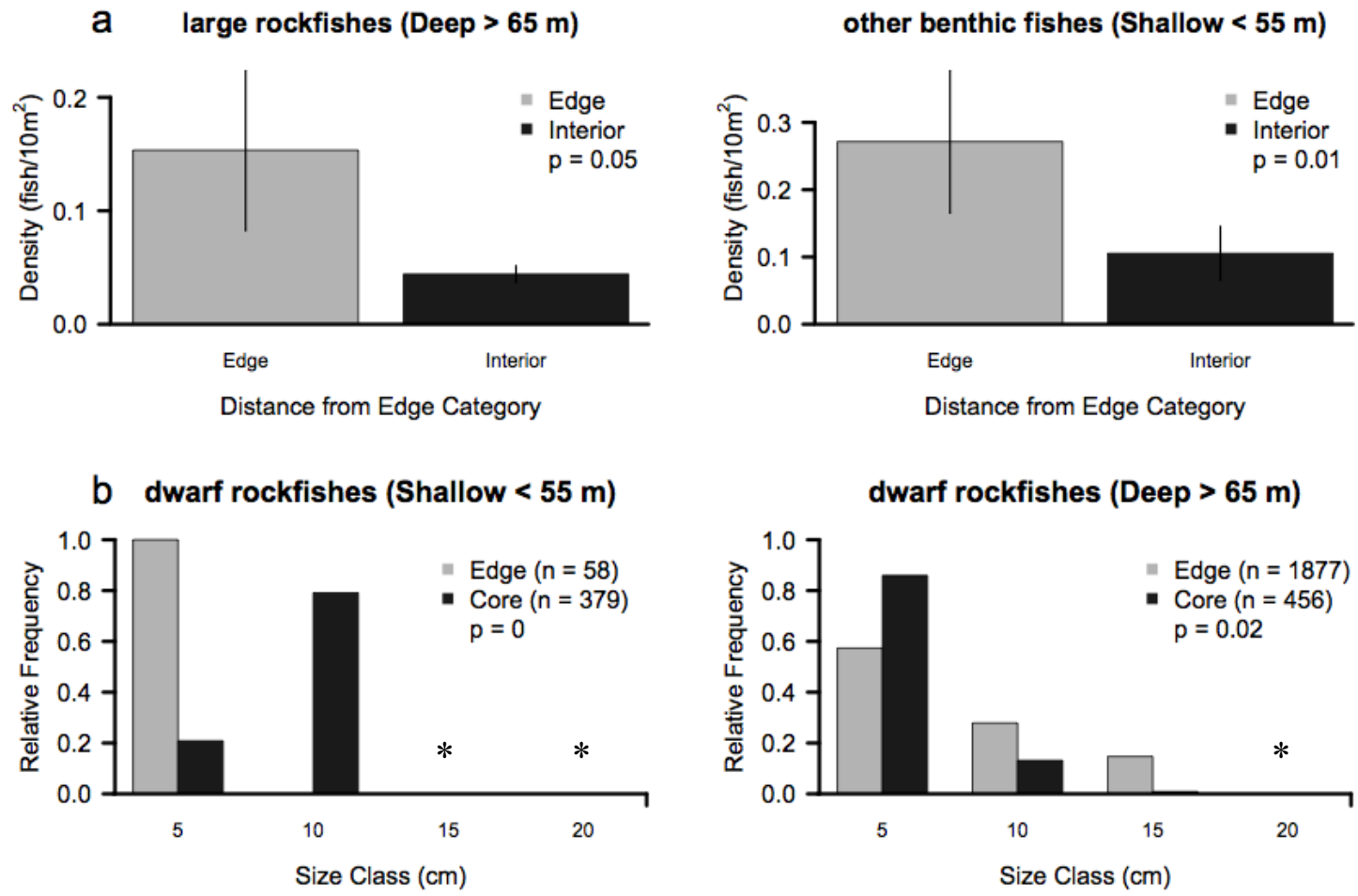

Fig. 10 Comparison of biological response variables (density and length distributions) of species groups with respect to distance from the rocky bank patch edge near Point Lobos. $\mathrm{A}$ is the density of large rockfishes and other benthic fishes; $\mathrm{b}$ is the length distributions of dwarf rockfishes in shallow and deep rocky bank patches. If the species-group index was significantly correlated with depth, the analysis was run with binned data. Gray denotes the edge zone and black denotes the interior zone. Asterisks indicate size classes in which fish were observed in abundances too small to be observed on the relative frequency histograms. Standard error is plotted as vertical bars. P-values are included in the legends

Patch Shape (P:A Ratio). Rocky bank patch shape displayed a significant correlation with the number of species within the nearshore fish assemblage. These results are opposite of what the edge results for the assemblage demonstrated. The relationship between patch shape and the fish assemblage may be species-specific, and thus patterns between the four species groups and patch shape were investigated. 
Similar to the assemblage results, there was no significant relationship between the density of each species group and the P:A ratio (Table 8). Whereas three of the species groups were not significantly correlated with the P:A ratio, individuals of dwarf rockfishes were longer in rocky bank patches with greater P:A ratios in both shallow and deep rocky bank patches $(\mathrm{p}=0.001$ and $\mathrm{p}<0.001$ respectively; Table 8). Additionally, the goodness-of-fit results indicated that while the abundances of three of the four species groups were proportionally distributed between rocky bank patches of greater and lesser P:A ratios, the abundances of dwarf rockfishes were not evenly distributed between rocky bank patches of different P:A ratios (Appendix G). Instead, the observed abundance of dwarf rockfishes was greater than expected in patches of greater P:A ratios based on the available area in the rocky bank patches $\left(x^{2}=6.247, p=0.012\right.$; Appendix $\left.G\right)$.

Table 8 Biological response variables (density and length distributions) of the species groups with respect to patch shape of rocky bank patches near Point Lobos. If the species-group index was significantly correlated with depth, the analysis was run against the residuals or the binned data. Statistically significant relationships are in bold

\begin{tabular}{lcccccc}
\hline & \multicolumn{3}{c}{ Density $\left(\mathbf{f i s h} / \mathbf{1 0 \mathbf { m } ^ { 2 }}\right)$} & \multicolumn{3}{c}{ Length Distribution } \\
\hline & $\mathbf{p}$ & $\mathbf{r}^{2}$ & Direction & $\mathbf{p}$ & $\mathbf{D}$ & Direction \\
\hline large rockfishes & 0.923 & 0.000 & No & 0.681 & 0.220 & Negative \\
dwarf rockfishes & 0.130 & 0.101 & No & $\mathbf{0 . 0 0 1}$ & 0.346 & Positive \\
& & & & $<\mathbf{0 . 0 0 1}$ & 0.214 & Positive \\
large non-rockfishes & 0.961 & 0.000 & No & 0.889 & 0.300 & No \\
other benthic fishes & 0.901 & 0.001 & No & 0.999 & 0.110 & No \\
\hline
\end{tabular}

Patch Size (Area). To determine if the patterns of the assemblage with respect to patch size were driven by species groups within the assemblage, the relationship of the density and length distributions of the species groups was examined with respect to area. 
However, there was no significant relationship between the density of any species group and patch area (Table 9). Similar to the patch shape results, dwarf rockfishes was the only species group in which a significant relationship between the length distribution and patch area was observed. Dwarf rockfishes were significantly longer in rocky bank patches of greater area for both shallow and deep rocky bank patches $(p=0.001$ and $p<$ 0.001 respectively; Table 9).

Table 9 Biological response variables (density and length distributions) of the species groups with respect to patch size of rocky bank patches near Point Lobos. If the speciesgroup index was significantly correlated with depth, the analysis was run against the residuals or the binned data. Statistically significant relationships are in bold

\begin{tabular}{lcccccc}
\hline & \multicolumn{3}{c}{ Density $\left(\mathbf{f i s h} / \mathbf{1 0 m}^{2}\right)$} & \multicolumn{3}{c}{ Length Distribution } \\
\hline & $\mathbf{p}$ & $\mathbf{r}^{2}$ & Direction & $\mathbf{p}$ & $\mathbf{D}$ & Direction \\
\hline large rockfishes & 0.398 & 0.033 & No & 0.990 & 0.131 & No \\
dwarf rockfishes & 0.053 & 0.159 & Positive & $\mathbf{0 . 0 0 1}$ & 0.351 & Negative \\
& & & & $<\mathbf{0 . 0 0 1}$ & 0.222 & Positive \\
large non-rockfishes & 0.412 & 0.031 & No & 1.000 & 0.139 & No \\
other benthic fishes & 0.539 & 0.017 & No & 0.995 & 0.118 & No \\
\hline
\end{tabular}

The abundance of the different species groups varied between rocky bank patches of lesser and greater area. The abundances of two of the four species groups (dwarf rockfishes and other benthic fishes) were not proportionally distributed between patches of lesser and greater area. Instead the observed abundances of dwarf rockfishes was greater than expected in patches of lesser area $\left(x^{2}=12.914, p<0.001\right)$, whereas the observed abundance of other benthic fishes was greater in patches of greater area based on the available area in the rocky bank patches $\left(\mathrm{x}^{2}=6.465, \mathrm{p}=0.011\right.$; Appendix $\left.\mathrm{G}\right)$. This indicated that the size of a rocky bank patch affected the relative abundances of these species groups. 
Species-Specific Analyses

Depth and Rugosity. The density of all of the seven most abundant species varied with respect to depth (Table 3d, Appendix F). The density of Blackeye Goby $(p=0.006)$, Blue Rockfish ( $p=0.047)$, and Painted Greenling $(p<0.001)$ significantly decreased with increasing depth, whereas the density of Pygmy $(p<0.001)$, Rosy $(p=0.008)$, Squarespot $(\mathrm{p}=0.001)$, and Starry Rockfish $(\mathrm{p}<0.001)$ significantly increased with increasing depth. Patterns in fish biomass were the same as those observed for speciesspecific density, except there was no significant difference in biomass of Blue Rockfish with depth (Table 3d, Appendix F). The biomass of Blackeye Goby $(p=0.022)$ and Painted Greenling $(p=0.001)$ significantly decreased with increasing depth, whereas the biomass of Pygmy $(p=0.001)$, Rosy $(p=0.001)$, Squarespot $(p<0.001)$, and Starry Rockfish $(p=0.001)$ significantly increased with increasing depth.

As expected, the patterns in mean length for all seven species were the same as those observed for biomass for each species (Table 3d, Appendix F). The mean length of Blackeye Goby $(\mathrm{p}=0.045)$ and Painted Greenling $(\mathrm{p}<0.001)$ significantly decreased with increasing depth, whereas the mean length of Pygmy $(p<0.001)$, Rosy $(p=0.001)$, Squarespot $(p<0.001)$, and Starry Rockfish $(p=0.024)$ significantly increased with increasing depth. Pygmy rockfish, however, was the only species whose length frequency distribution significantly varied with depth (Table 3d, Appendix F). Pygmy Rockfish of longer size were observed in deeper rocky bank patches $(\mathrm{p}<0.001)$. 
Whenever a biological response variable was significantly correlated with depth, the data were either split into shallow and deep depth bins (length frequency distribution) or the regression residuals of depth and the biological response variable (density, biomass, and mean length) was used for the subsequent analyses. When the speciesspecific biological response variables did not significantly correlate with depth (e.g., Blue Rockfish biomass) the original data was used to analyze patterns with respect to other independent habitat variables.

Similar to the relationships between species groups and rugosity, there were significant relationships between rugosity and biological response variables for some of the seven most abundant species (Table 3e, Appendix F). For example, the density of Blue Rockfish was negatively correlated with rugosity $(p=0.023)$, whereas the density of Painted Greenling was positively correlated $(\mathrm{p}=0.014)$. There was no significant difference in the density of the remaining species with respect to rugosity. There was a significant increase in the biomass of both Painted Greenling $(p=0.013)$ and Pygmy Rockfish $(p=0.024)$ with increasing rugosity (Table 3e, Appendix G), but no significant relationship for biomass of the other five species. Also, significant changes in the lengths of Painted Greenling and Pygmy Rockfish were observed (Table 3e, Appendix F). The mean length of Painted Greenling was significantly longer in rocky bank patches with greater rugosity $(\mathrm{p}=0.033)$. Although the mean length for Pygmy Rockfish was similar with respect to rugosity, the length frequency distributions significantly differed in both shallow and deep patches $(\mathrm{p}<0.001, \mathrm{p}<0.001)$. 
Proximity to Edge. Knowing that the species groups responded differently to the edge and interior zones of rocky bank patches, whether the seven most abundant species also varied with respect to the edge of a rocky bank patch was investigated. Blackeye Goby, which was not included in any of the species groups, was the only species whose density and size correlated with the edge or interior zone (Table 10). The density $(p=0.046)$ and biomass $(\mathrm{p}=0.001)$ of the Blackeye Goby were significantly greater in the edge zone than the interior zone in deep patches (Fig. 11a-b). The mean lengths of Blackeye Goby $(p=0.021, p=0.003 ;$ Fig. 11c $)$ and Rosy Rockfish $(p=0.031, p=0.005 ;$ Fig. 11e $)$ were significantly longer in the edge zone in both shallow and deep patches. Additionally, the mean lengths of Pygmy ( $p=0.002$; Fig. 11d), Squarespot $(p=0.003$; Fig. 11f), and Starry Rockfishes ( $p=0.014$; Fig. $11 \mathrm{~g}$ ) also were significantly longer in the edge zone of the rocky bank patch, but only in deep patches. There was no relationship among density, biomass, mean length, or length frequency distributions for either Blue Rockfish or Painted Greenling with respect to proximity to rocky bank patch edge (Table 10). 
Table 10 Biological response variables (density, biomass, mean length, and length distributions) of the specific species with respect to distance from rocky bank patch edge near Point Lobos. The results are for density (a), biomass (b), mean length (c), and length distributions (d). If the species-group index was significantly correlated with depth, the analysis was run against the residuals or binned data. Statistically significant relationships are in bold

\begin{tabular}{|c|c|c|c|c|c|c|c|c|}
\hline \multirow[t]{2}{*}{ a - Density (fish/10m²) } & \multicolumn{4}{|c|}{ Shallow } & \multicolumn{4}{|c|}{ Deep } \\
\hline & p & df & F-ratio & Direction & p & dff & F-ratio & Direction \\
\hline Blackeye Goby & 0.182 & 2 & 1.886 & Edge & 0.007 & 2 & 8.953 & Edge \\
\hline Blue Rockfish & 0.827 & 2 & 0.049 & Edge & 0.312 & 2 & 1.076 & Edge \\
\hline Painted Greenling & 0.074 & 2 & 3.492 & Edge & 0.543 & 2 & 0.382 & Edge \\
\hline Pygmy Rockfish & 0.389 & 2 & 0.770 & Core & 0.188 & 2 & 1.860 & Edge \\
\hline Rosy Rockfish & 0.913 & 2 & 0.012 & No & 0.063 & 2 & 3.889 & Edge \\
\hline Squarespot Rockfish & 0.533 & 2 & 0.401 & Core & 0.600 & 2 & 0.283 & Core \\
\hline Starry Rockfish & 0.627 & 2 & 0.242 & No & 0.099 & 2 & 3.000 & Edge \\
\hline \multirow[t]{2}{*}{$\mathrm{b}$ - Biomass $\left(\mathrm{g} / \mathrm{cm} / \mathbf{1 0 m ^ { 2 } )}\right.$} & \multicolumn{4}{|c|}{ Shallow } & \multicolumn{4}{|c|}{ Deep } \\
\hline & p & df & F-ratio & Direction & p & df & F-ratio & Direction \\
\hline Blackeye Goby & 0.563 & 2 & 0.345 & Edge & 0.001 & 2 & 14.142 & Edge \\
\hline Blue Rockfish & 0.553 & 2 & 0.358 & Edge & & & & \\
\hline Painted Greenling & 0.238 & 2 & 1.466 & Edge & 0.515 & 2 & 0.440 & Edge \\
\hline Pygmy Rockfish & 0.340 & 2 & 0.949 & Core & 0.093 & 2 & 3.129 & Edge \\
\hline Rosy Rockfish & 0.594 & 2 & 0.291 & No & 0.116 & 2 & 2.703 & Edge \\
\hline Squarespot Rockfish & 0.491 & 2 & 0.489 & Core & 0.191 & 2 & 1.831 & Edge \\
\hline Starry Rockfish & 0.672 & 2 & 0.184 & Core & 0.307 & 2 & 1.098 & Edge \\
\hline \multirow[t]{2}{*}{ c - Mean Length (cm) } & \multicolumn{4}{|c|}{ Shallow } & \multicolumn{4}{|c|}{ Deep } \\
\hline & p & df & F-ratio & Direction & p & dff & F-ratio & Direction \\
\hline Blackeye Goby & 0.021 & 2 & 6.073 & Edge & 0.003 & 2 & 11.015 & Edge \\
\hline Blue Rockfish & 0.058 & 2 & 3.750 & No & & & & \\
\hline Painted Greenling & 0.166 & 2 & 2.042 & No & 0.462 & 2 & 0.561 & No \\
\hline Pygmy Rockfish & 0.337 & 2 & 0.961 & No & 0.002 & 2 & 13.146 & Edge \\
\hline Rosy Rockfish & 0.031 & 2 & 5.245 & Edge & 0.005 & 2 & 10.143 & Edge \\
\hline Squarespot Rockfish & 0.790 & 2 & 0.073 & No & 0.003 & 2 & 11.703 & Edge \\
\hline Starry Rockfish & 0.833 & 2 & 0.045 & No & 0.014 & 2 & 7.298 & Edge \\
\hline
\end{tabular}

\begin{tabular}{lllllll}
\hline d - Length Distribution & \multicolumn{3}{c}{ Shallow } & \multicolumn{2}{c}{ Deep } \\
\hline & p & D & Direction & p & D & Direction \\
\hline Blackeye Goby & 1.000 & 0.031 & No & & & \\
Blue Rockfish & 1.000 & 0.125 & No & & & \\
Painted Greenling & 1.000 & 0.045 & No & & & \\
Pygmy Rockfish & 1.000 & 0.100 & No & 1.000 & 0.000 & No \\
Rosy Rockfish & 1.000 & 0.200 & No & & & \\
Squarespot Rockfish & 1.000 & 0.171 & No & & & \\
Starry Rockfish & 0.999 & 0.400 & No & & & \\
\hline
\end{tabular}




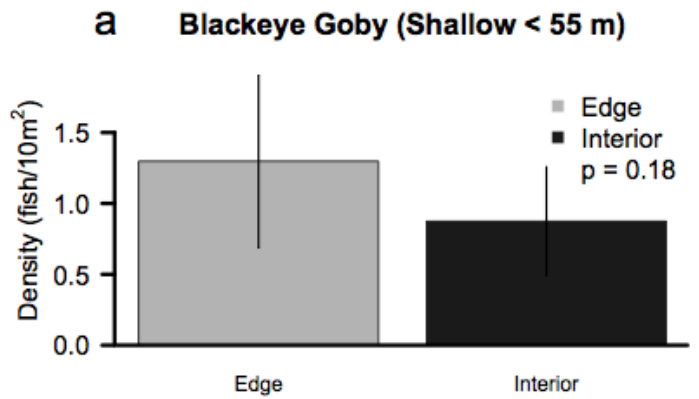

Distance from Edge Category

b Blackeye Goby (Shallow $<55 \mathrm{~m}$ )

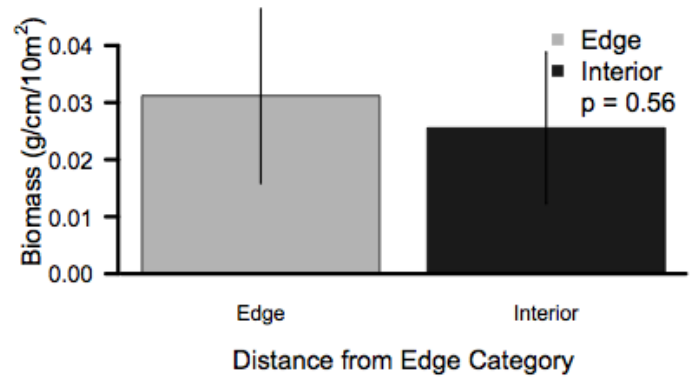

C Blackeye Goby (Shallow $<55 \mathrm{~m}$ )

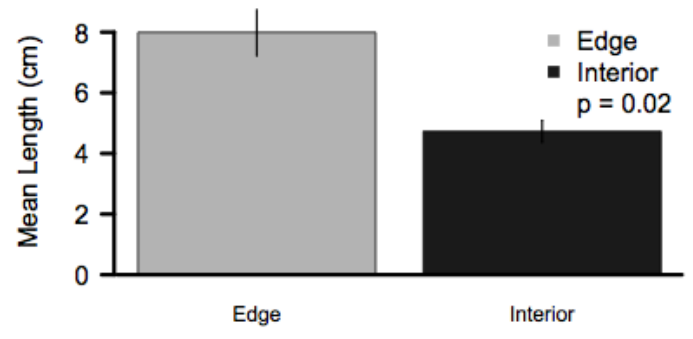

Distance from Edge Category

Pygmy Rockfish (Shallow $<55$ m)

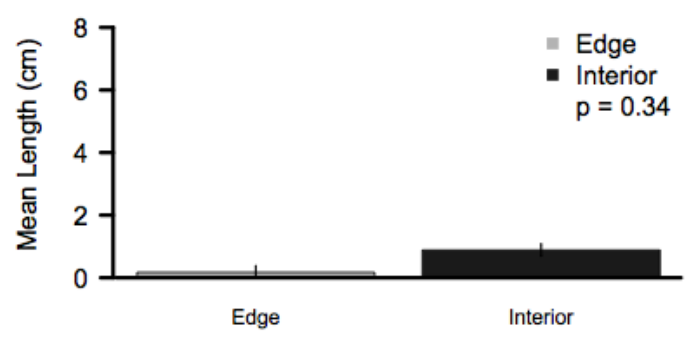

Distance from Edge Category
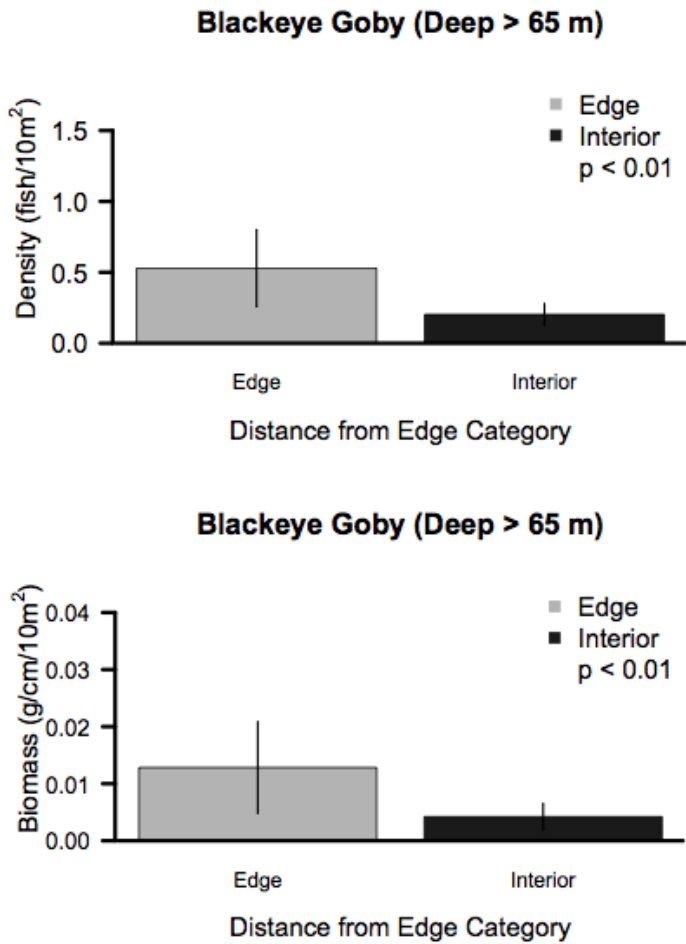

Blackeye Goby (Deep > $65 \mathrm{~m}$ )

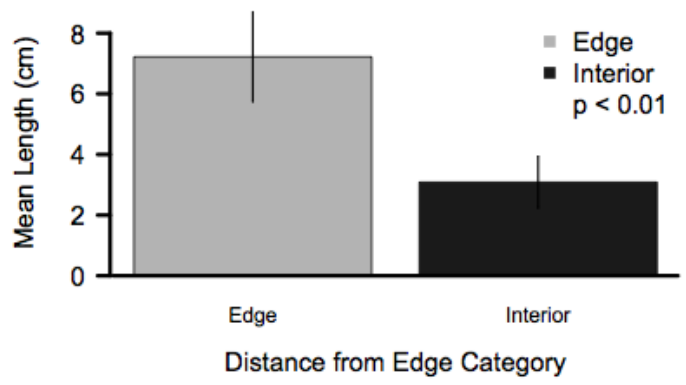

Pygmy Rockfish (Deep > 65 m)

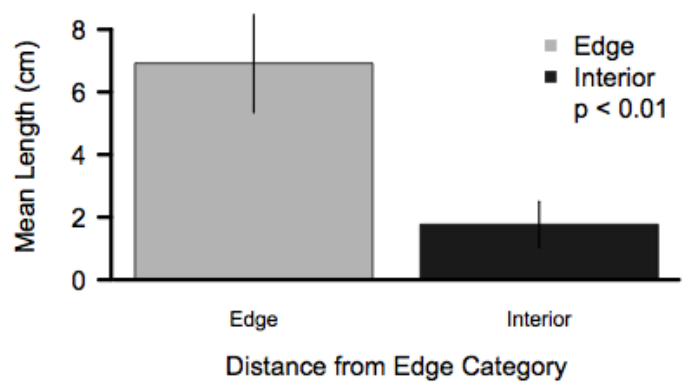



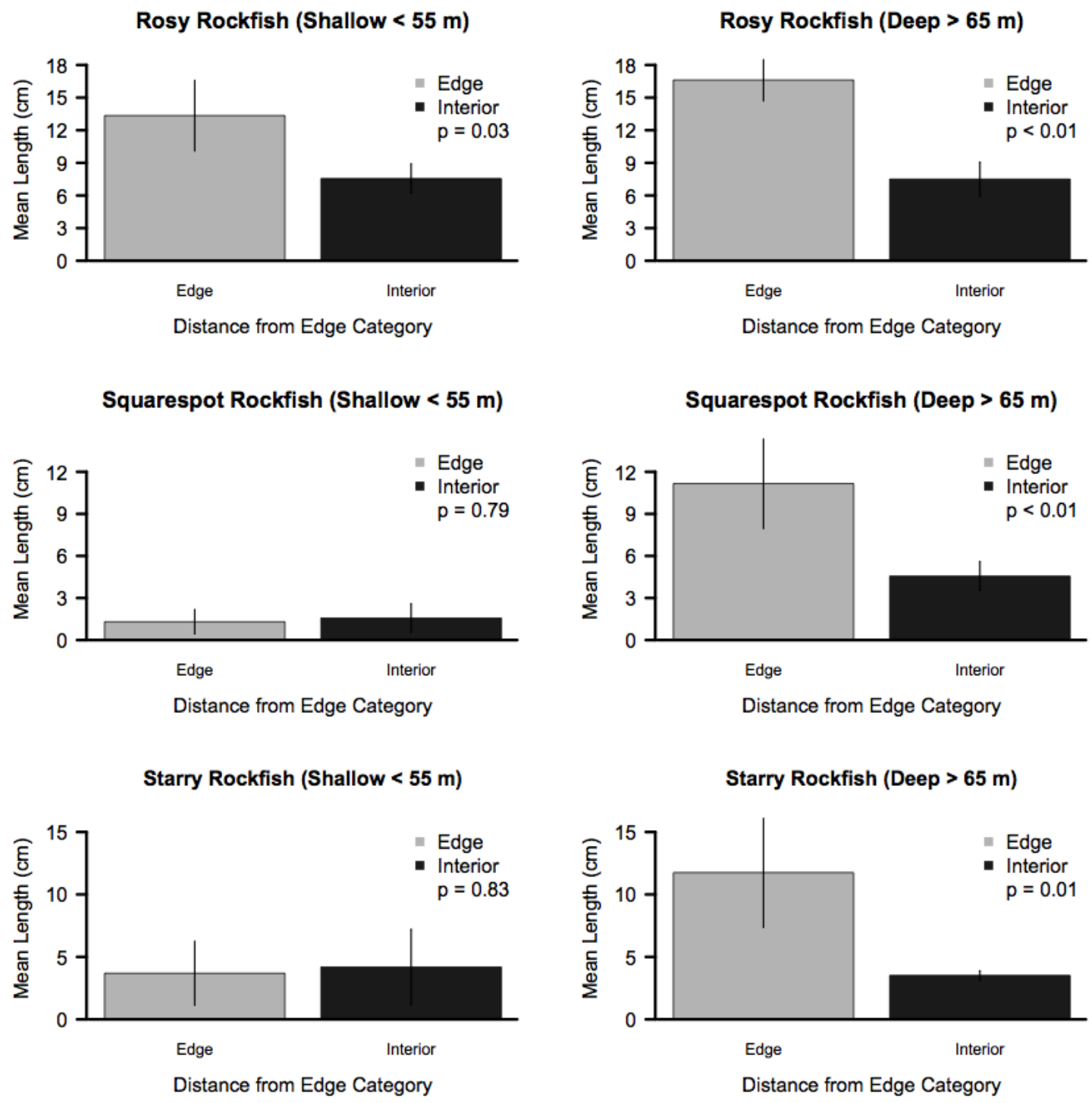

Fig. 11 Comparison of biological response variables (density, biomass, and mean length) of specific species with respect to distance from rocky bank patch edge near Point Lobos. $\mathrm{A}$ is the density and $\mathrm{b}$ is the biomass of Blackeye Goby. The mean length of Blackeye Goby as well as Pygmy, Rosy, Squarespot, and Starry Rockfish (c) are also reported. If the species index was significantly correlated with depth, the analysis was run with binned data. Gray denotes the edge zone and black denotes the interior zone. Standard error is plotted as vertical bars. P-values are included in the legends 
Patch Shape (P:A Ratio). Results from the four species groups did not further explain the relationship between assemblage biological response variables and patch shape. However, significant patterns among species-specific biological response variables and P:A ratio were observed. These patterns, especially those observed in length frequency distributions, could be driving the assemblage response of length frequencies to patch shape. For example, the length frequency distributions of Pygmy and Squarespot Rockfish were significantly different between patches with lesser and greater P:A ratios, respectively ( $p<0.001, p=0.045 ;$ Fig. 12a-b). For both of these species, individuals in patches with more complex shapes (greater P:A ratio) had longer mean lengths than patches with less complex shapes (lesser P:A ratio). The relationship between Pygmy Rockfish and patch shape was only significant for deep patches because none were observed in shallow patches of high P:A ratio near Point Lobos (Fig. 12a). However, the density, biomass, and mean length of Pygmy and Squarespot Rockfish did not vary significantly with respect to patch shape (Table 11). Additionally, none of the other five species demonstrated significant patterns with respect to P:A ratio for density, biomass, mean length, or length frequency distributions (Table 8). 
a Pygmy Rockfish (Shallow $<55 \mathrm{~m}$ )

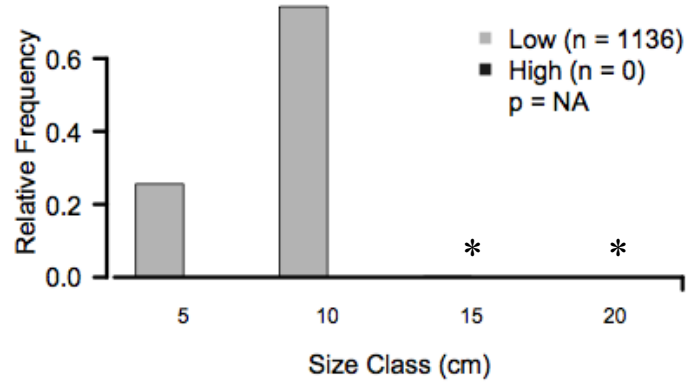

\section{b Squarespot Rockfish (All Depths)}

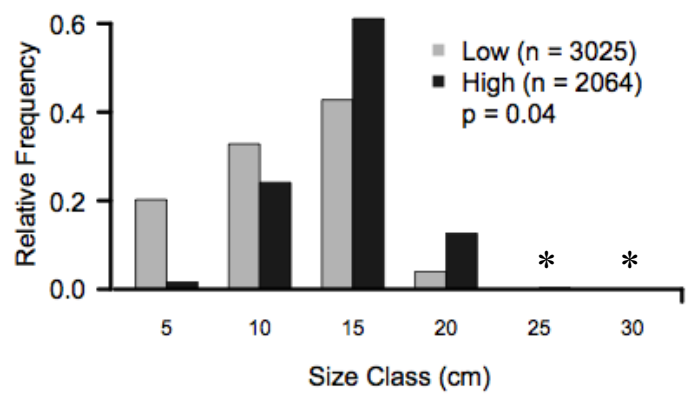

Pygmy Rockfish (Deep > $65 \mathrm{~m}$ )

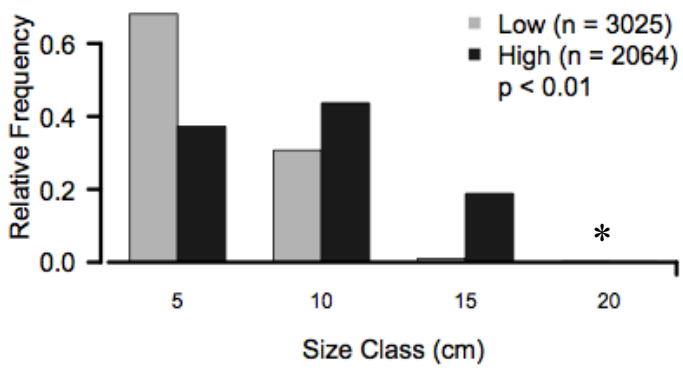

Fig. 12 Comparison of biological response variables (length distributions) of specific species with respect to patch shape of rocky bank patches near Point Lobos. Results are for Pygmy (a) and Squarespot Rockfish (b). If the species index was significantly correlated with depth, the analysis was run with binned data. Gray denotes the low perimeter-to-area ratio category and black denotes the high perimeter-to-area ratio category. Asterisks indicate size classes in which fish were observed in abundances too small to be observed on the relative frequency histograms. P-values are included in the legends; NA means that statistical tests were not possible due to lack of data in a category 
Table 11 Biological response variables (density, biomass, mean length, and length distributions) of the specific species with respect to patch shape of rocky bank patches near Point Lobos. The results are for density, biomass, mean length, and length distributions. If the species-specific index was significantly correlated with depth, the analysis was run against the residuals or with binned data. Statistically significant relationships are in bold; N/A denotes analyses that could not be tested due to insufficient data

\begin{tabular}{|c|c|c|c|c|c|c|}
\hline & \multicolumn{3}{|c|}{ Density (fish/10m²) } & \multicolumn{3}{|c|}{ Biomass $\left(\mathrm{g} / \mathrm{cm} / 10 \mathrm{~m}^{2}\right)$} \\
\hline & $\mathbf{p}$ & $\mathbf{r}^{2}$ & Direction & p & $\mathbf{r}^{2}$ & Direction \\
\hline Blackeye Goby & 0.414 & 0.031 & No & 0.471 & 0.024 & No \\
\hline Blue Rockfish & 0.387 & 0.034 & No & 0.071 & 0.140 & Negative \\
\hline Painted Greenling & 0.879 & 0.001 & No & 0.579 & 0.014 & No \\
\hline Pygmy Rockfish & 0.591 & 0.013 & No & 0.341 & 0.041 & No \\
\hline Rosy Rockfish & 0.160 & 0.088 & No & 0.118 & 0.107 & No \\
\hline Squarespot Rockfish & 0.075 & 0.137 & Negative & 0.113 & 0.110 & No \\
\hline \multirow[t]{3}{*}{ Starry Rockfish } & 0.734 & 0.005 & No & 0.097 & 0.120 & No \\
\hline & \multicolumn{3}{|c|}{ Mean Length (cm) } & \multicolumn{3}{|c|}{ Length Distribution } \\
\hline & $\mathbf{p}$ & $\mathbf{r}^{2}$ & Direction & $\mathbf{p}$ & D & Direction \\
\hline Blackeye Goby & 0.621 & 0.011 & No & 1.000 & 0.009 & No \\
\hline Blue Rockfish & 0.325 & 0.044 & No & 1.000 & 0.108 & No \\
\hline Painted Greenling & 0.161 & 0.087 & No & 1.000 & 0.114 & No \\
\hline Pygmy Rockfish & 0.672 & 0.008 & No & & & \\
\hline Shallow & & & & N/A & N/A & $\mathrm{N} / \mathrm{A}$ \\
\hline Deep & & & & $<0.001$ & 0.308 & Positive \\
\hline Rosy Rockfish & 0.647 & 0.010 & No & 1.000 & 0.053 & No \\
\hline Squarespot Rockfish & 0.503 & 0.021 & No & 0.035 & 0.273 & Positive \\
\hline Starry Rockfish & 0.078 & 0.134 & No & 0.845 & 0.252 & No \\
\hline
\end{tabular}

Patch Size (Area). Similar to the species groups, there was no significant relationship between the species-specific density and area (Table 12). However, there was a positive relationship between patch area and the biomass of Blue, Squarespot, and Starry Rockfish $(\mathrm{p}=0.041, \mathrm{p}=0.025$, and $\mathrm{p}=0.005$, respectively; Fig. 13). As the patch size increased, the biomass of each of the observed species increased. There was a significant relationship between the patch area and mean length of Squarespot and Starry Rockfish $(p=0.033, p=0.002 ;$ Fig. 13). Not only did the mean length of Squarespot Rockfish 
increase with patch size, but the length frequency distributions also were significantly different between patches with longer fishes observed in higher frequencies in patches of greater area $(p=0.027$; Fig. 13). The length frequency distribution of the Pygmy

Rockfish population also varied with respect to patch size $(\mathrm{p}<0.001$; Fig. 13). For both of these species, patches of greater area had increased proportions of longer individuals. These patterns aligned with the positive relationship between length frequencies of the dwarf rockfish species group and patch area.

Table 12 Biological response variables (density, biomass, mean length, and length distributions) of the specific species with respect to patch size of rocky bank patches near Point Lobos. The results are for density, biomass, mean length, and length distributions. If the species-specific index was significantly correlated with depth, the analysis was run against the residuals or with binned data. Statistically significant relationships are in bold; N/A denotes analyses were not be tested due to insufficient data

\begin{tabular}{|c|c|c|c|c|c|c|}
\hline & \multicolumn{3}{|c|}{ Density (fish/10m²) } & \multicolumn{3}{|c|}{ Biomass $\left(\mathrm{g} / \mathrm{cm} / \mathbf{1 0 m ^ { 2 }}\right)$} \\
\hline & $\mathbf{p}$ & $\mathbf{r}^{2}$ & Direction & $\mathbf{p}$ & $\mathbf{r}^{2}$ & Direction \\
\hline Blackeye Goby & 0.306 & 0.048 & No & 0.678 & 0.008 & No \\
\hline Blue Rockfish & 0.215 & 0.069 & No & 0.041 & 0.176 & Positive \\
\hline Painted Greenling & 0.600 & 0.013 & No & 0.658 & 0.009 & No \\
\hline Pygmy Rockfish & 0.221 & 0.067 & Positive & 0.308 & 0.047 & Positive \\
\hline Rosy Rockfish & 0.299 & 0.049 & No & 0.364 & 0.038 & No \\
\hline Squarespot Rockfish & 0.211 & 0.070 & Positive & 0.025 & 0.208 & Positive \\
\hline \multirow[t]{3}{*}{ Starry Rockfish } & 0.176 & 0.082 & Positive & 0.005 & 0.309 & Positive \\
\hline & \multicolumn{3}{|c|}{ Mean Length (cm) } & \multicolumn{3}{|c|}{ Length Distribution } \\
\hline & $\mathbf{p}$ & $\mathbf{r}^{2}$ & Direction & $\mathbf{p}$ & D & Direction \\
\hline Blackeye Goby & 0.716 & 0.006 & No & 0.812 & 0.073 & No \\
\hline Blue Rockfish & 0.212 & 0.070 & No & 0.718 & 0.205 & No \\
\hline Painted Greenling & 0.080 & 0.133 & Positive & 1.000 & 0.131 & No \\
\hline Pygmy Rockfish & 0.721 & 0.006 & No & & & \\
\hline Shallow & & & & N/A & N/A & N/A \\
\hline Deep & & & & $<0.001$ & 0.140 & Positive \\
\hline Rosy Rockfish & 0.275 & 0.054 & Positive & 1.000 & 0.043 & No \\
\hline Squarespot Rockfish & $\mathbf{0 . 0 3 3}$ & 0.191 & Positive & $\mathbf{0 . 0 3 3}$ & 0.232 & Positive \\
\hline Starry Rockfish & 0.002 & 0.358 & Positive & 0.959 & 0.209 & No \\
\hline
\end{tabular}



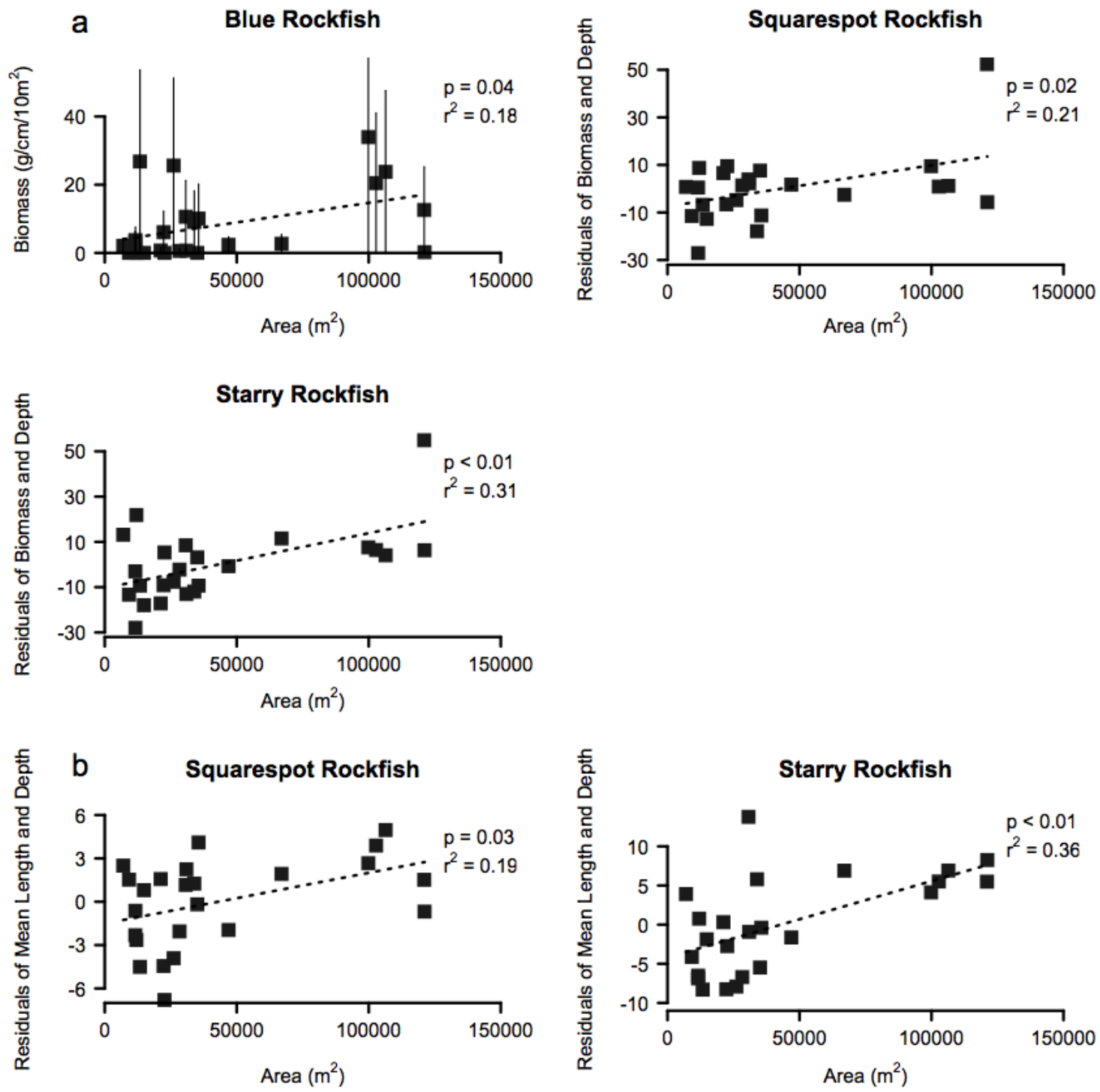

\section{Pygmy Rockfish (Shallow $<55$ m)}
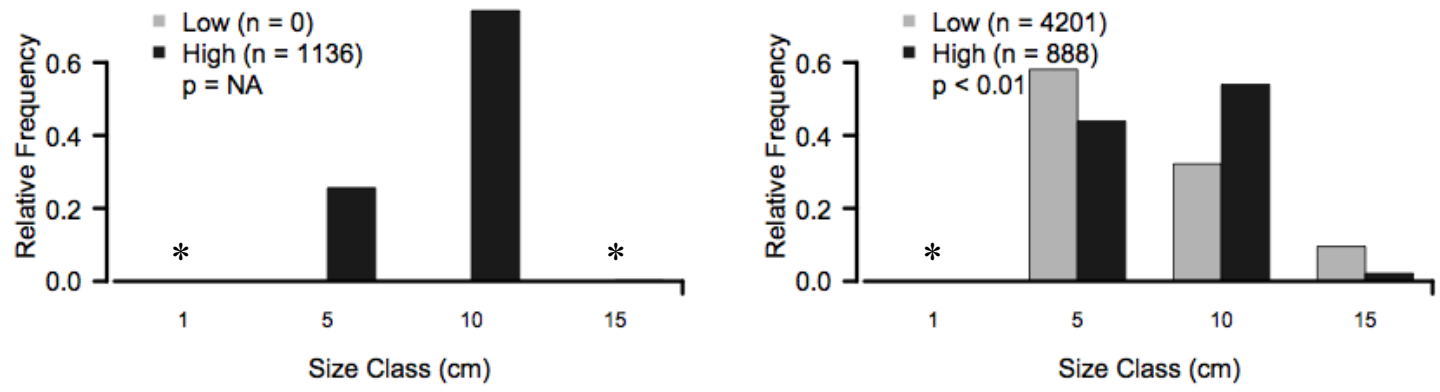


\section{Squarespot Rockfish (All Depths)}

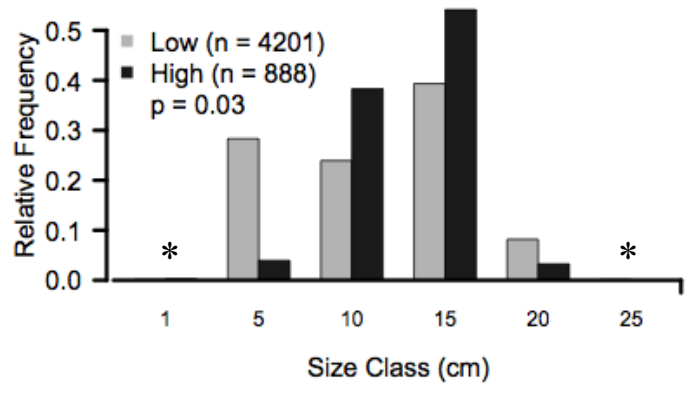

Fig. 13 Comparison of biological response variables (biomass, mean length, and length distributions) of specific species with respect to patch size of rocky bank patches near Point Lobos. Results of biomass analyses are for Blue, Squarespot, and Starry Rockfish (a), the mean length of Squarespot and Starry Rockfish (b), and the length distributions of Pygmy and Squarespot Rockfish (c). If the species index was significantly correlated with depth, the analysis was run with the residuals or the binned data. Gray denotes the low area category and black denotes the high area category. Significant linear relationships are denoted by a dotted regression line. Standard error is plotted as vertical bars. Asterisks indicate size classes in which fish were observed in abundances too small to be observed on the relative frequency histograms. P-values, and where applicable $\mathrm{r}^{2}$ values, are included in the legends

\section{Regional Comparisons}

The similarity of the species composition between Point Lobos and Point Sur was 0.638 (Fig. 14). Although there were regional differences in the specific species present and their proportional abundances, the assemblage composition within central California was similar between these two regions. For most of the assemblage indices, the significance and direction of the relationship between the biological response variables, at the assemblage level, and the independent habitat variables were similar between regions. However, regional differences with respect to edge proximity and patch shape were observed. 

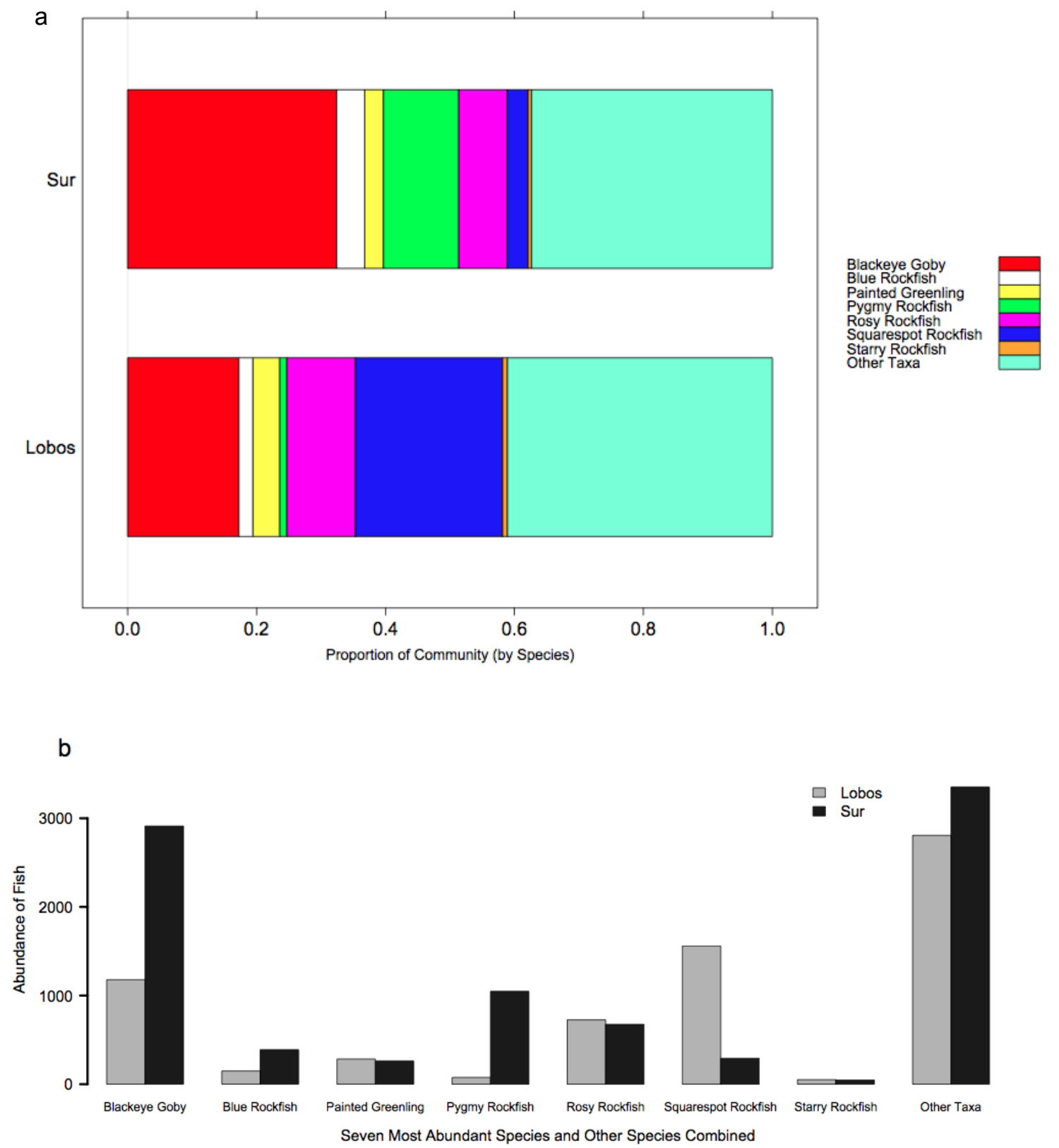

Fig. 14 Species composition of the seven most abundant species for shallow rocky bank patches near Point Lobos and Point Sur. The assemblage composition in proportional abundance (a) and the observed abundance (b) are reported. The unidentified fishes, those not identified to the species level, and the 51 less-abundant species (whose abundance was less than $1 \%$ of the total abundance) are pooled into the "other" category 
Proximity to Edge. The density of all fishes was not significantly different between the edge and interior zones near Point Lobos (Tables 4 and 13) or near Point Sur ( $p=0.753$; Fig. 15a). Mean biomass was not significantly different between the edge and interior zones near Point Lobos $(p=0.463$; Fig. 15a) or near Point Sur ( $p=0.958$; Fig. 15b). Similar to the density and biomass results, patterns in the species richness in the nearshore fish assemblage near Point Lobos and Point Sur were not significantly different between the edge and interior zones $(p=0.061$ and $p=0.888$; Table 13). However, the observed patterns of the remaining assemblage diversity indices varied between near Point Sur and those observed near Point Lobos. The evenness and heterogeneity near Point Lobos were significantly greater in the edge zone than the interior near Point Lobos (Table 4). Near Point Sur there was no significant difference in evenness $(p=0.155)$ or heterogeneity $(p=0.465)$ between the edge and interior zones of the rocky bank patches. 
a

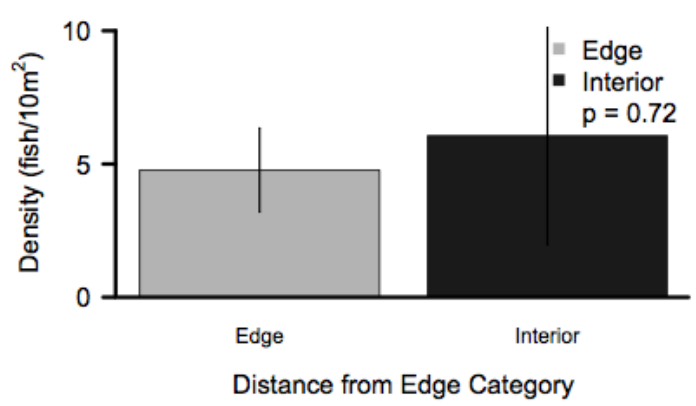

b

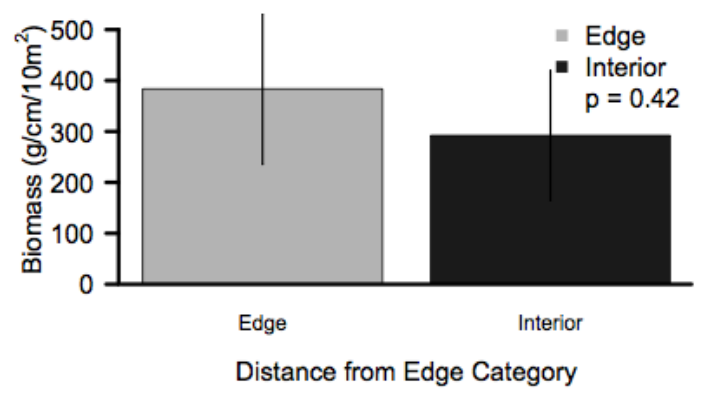

Point Sur

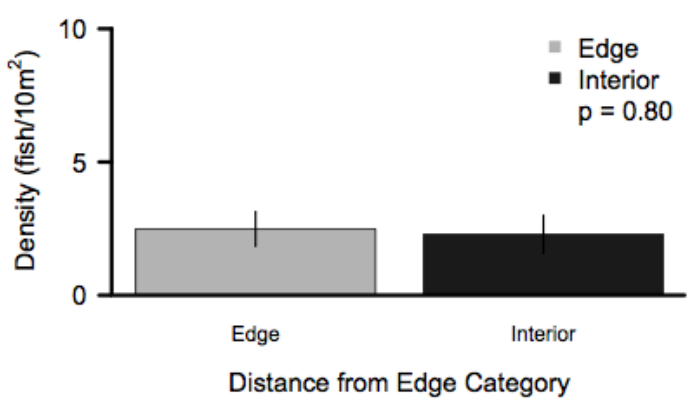

Point Sur

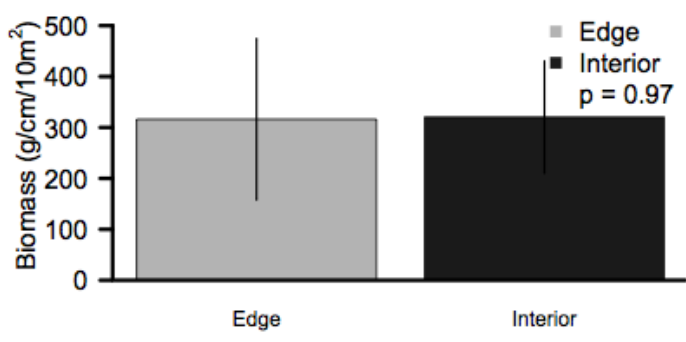

Distance from Edge Category

Fig. 15 Comparison of assemblage biological response variables (density and biomass) with respect to distance from rocky bank patch edge near Point Lobos and Point Sur. The results include the assemblage density (a) and biomass (b) between the edge and interior zones of shallow rocky bank patches near Point Lobos and Point Sur. Gray denotes the edge zone and black denotes the interior zone. Standard error is plotted as vertical bars. $\mathrm{P}$-values are included in the legends 
Table 13 Assemblage biological response variables (density, biomass, richness, evenness, and heterogeneity) of shallow rocky bank patches near Point Lobos and Point Sur. The results are with respect to proximity to edge (a), patch shape (b), and patch size (c). If the assemblage index was significantly correlated with depth, the analysis was run against the residuals. Statistically significant relationships are in bold

\begin{tabular}{|c|c|c|c|c|c|c|c|c|}
\hline \multirow[t]{2}{*}{ a } & \multicolumn{4}{|c|}{ Point Lobos } & \multicolumn{4}{|c|}{ Point Sur } \\
\hline & p & df $F-$ & F-ratio & Direction & p & df & F-ratio & Dire \\
\hline Density (fish/10m2) & 0.989 & 2 & 0.000 & No & 0.753 & 2 & 0.101 & $\mathrm{~N}$ \\
\hline Biomass $(\mathrm{g} / \mathrm{cm} / 10 \mathrm{~m} 2)$ & 0.463 & 2 & 0.555 & No & 0.958 & 2 & 0.003 & $\mathrm{~N}$ \\
\hline Richness & 0.061 & 2 & 3.865 & No & 0.888 & 2 & 0.020 & $\mathrm{~N}$ \\
\hline Evenness & 0.008 & 2 & 8.484 & Edge & 0.155 & 2 & 2.156 & $\mathrm{~N}$ \\
\hline Heterogeneity & 0.027 & 2 & 5.584 & Edge & 0.465 & 2 & 0.552 & $\mathrm{~N}$ \\
\hline \multirow[t]{2}{*}{ b } & \multicolumn{4}{|c|}{ Point Lobos } & \multicolumn{4}{|c|}{ Point Sur } \\
\hline & p & $\mathbf{r}^{2}$ & \multicolumn{2}{|c|}{ Direction } & $\mathbf{p}$ & $\mathbf{r}^{2}$ & \multicolumn{2}{|c|}{ Direction } \\
\hline \multirow{2}{*}{$\begin{array}{l}\text { Density }\left(\text { fish } / 10 \mathrm{~m}^{2}\right) \\
\text { Biomass }\left(\mathrm{g} / \mathrm{cm} / 10 \mathrm{~m}^{2}\right)\end{array}$} & 0.393 & 0.001 & \multicolumn{2}{|c|}{ No } & 0.441 & 0.055 & \multicolumn{2}{|c|}{ No } \\
\hline & 0.616 & 0.024 & \multicolumn{2}{|c|}{ No } & 0.185 & 0.154 & \multicolumn{2}{|c|}{ No } \\
\hline Richness & 0.024 & 0.385 & \multicolumn{2}{|c|}{ Negative } & 0.169 & 0.165 & \multicolumn{2}{|c|}{ No } \\
\hline Evenness & 0.981 & $<0.001$ & \multicolumn{2}{|c|}{ No } & 0.169 & 0.165 & \multicolumn{2}{|c|}{ No } \\
\hline Heterogeneity & 0.080 & 0.252 & \multicolumn{2}{|c|}{ No } & 0.848 & 0.004 & \multicolumn{2}{|c|}{ No } \\
\hline \multirow[t]{2}{*}{ c } & \multicolumn{4}{|c|}{ Point Lobos } & \multicolumn{4}{|c|}{ Point Sur } \\
\hline & $\mathbf{p}$ & $\mathbf{r}^{2}$ & Dir & ction & $\mathbf{p}$ & $\mathbf{r}^{2}$ & Direct & ion \\
\hline Density (fish/10m²) & 0.674 & 0.017 & & No & 0.533 & 0.036 & No & \\
\hline Biomass $\left(\mathrm{g} / \mathrm{cm} / 10 \mathrm{~m}^{2}\right)$ & 0.206 & 0.141 & & No & 0.214 & 0.137 & No & \\
\hline Richness & 0.012 & 0.447 & & itive & 0.070 & 0.268 & No & \\
\hline Evenness & 0.860 & 0.003 & & No & 0.554 & 0.033 & No & \\
\hline Heterogeneity & 0.088 & 0.242 & & No & 0.793 & 0.007 & $\mathrm{No}$ & \\
\hline
\end{tabular}

Patch Shape (P:A Ratio). The density and biomass of the nearshore fish assemblage did not vary with respect to the P:A ratio near Point Lobos $(p=0.939, p=0.616$; Table 13) or near Point Sur $(\mathrm{p}=0.441, \mathrm{p}=0.185$; Fig. 16a-b). The significant decrease in the number of species observed in rocky bank patches of greater shape complexity near Point Lobos (Table 12) was not observed in the number of species with respect to patch shape near Point Sur $(\mathrm{p}=0.169$; Table 13). The remaining assemblage diversity indices 
(evenness and heterogeneity) were not statistically related to patch shape either near Point Lobos or Point Sur (Table 13). However, the range of P:A ratios of the rocky bank patches near Point Sur was smaller than near Point Lobos (Appendix D).
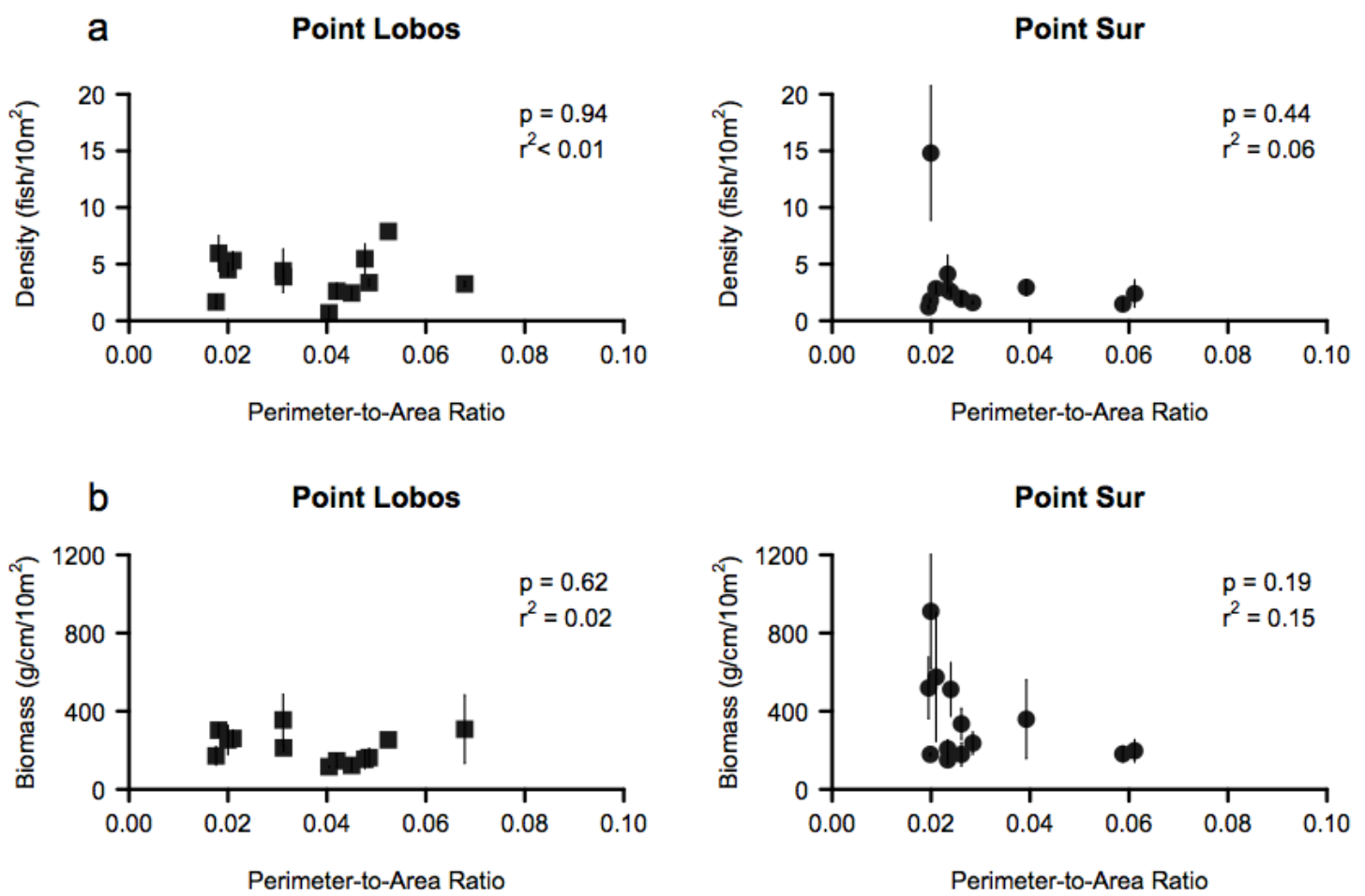

Fig. 16 Comparison of assemblage biological response variables (density and biomass) with respect to patch shape of rocky bank patches near Point Lobos and Point Sur. Results include the assemblage density (a) and biomass (b). Standard error is plotted as vertical bars. P-values and $\mathrm{r}^{2}$ values are included in the legends

Patch Size (Area). Similar to the relationships among the biological response variables and patch shape, the density and biomass of fishes did not vary significantly with patch area. Similar to the patch shape comparisons, there was no difference in the density or biomass of the assemblage with respect to patch size near Point Lobos $(\mathrm{p}=0.674, \mathrm{p}=$ $0.206)$ or near Point Sur $(\mathrm{p}=0.533, \mathrm{p}=0.214$; Fig. 17a-b, Table 13). Additionally, a 
significant relationship between species richness and patch size was only observed near Point Lobos (Table 13). Both near Point Lobos and Point Sur there were no significant relationships among evenness or heterogeneity and patch size (Table 13). The range of areas of the rocky bank patches near Point Sur was similar to near Point Lobos (Appendix D).
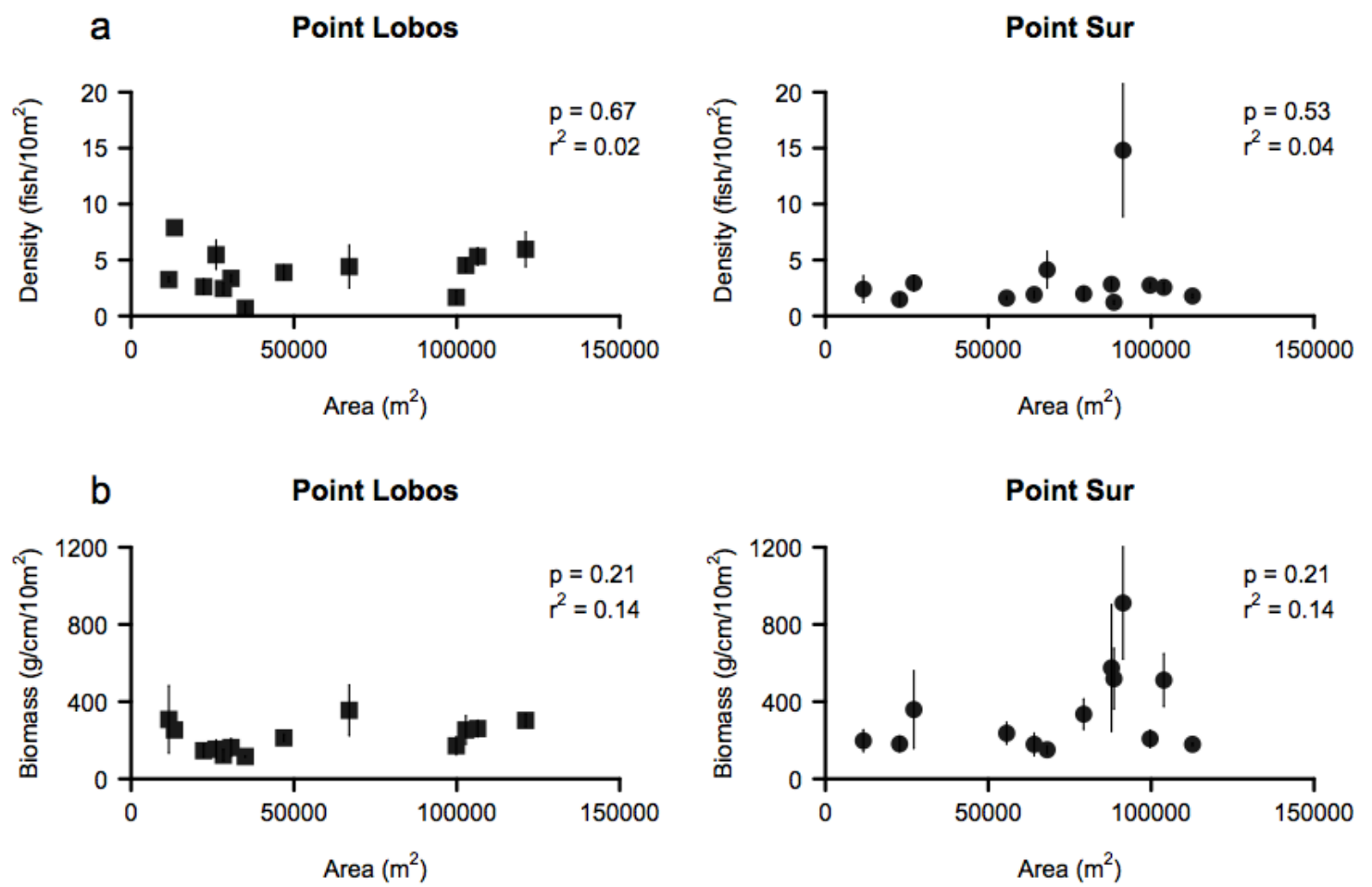

Fig. 17 Comparison of assemblage biological response variables (density and biomass) with respect to patch size of rocky bank patches near Point Lobos and Point Sur. Results include the assemblage density (a) and biomass (b). Standard error is plotted as vertical bars. P-values and $r^{2}$ values are included in the legends 


\section{Species-Area Relationships}

As the rocky bank patch area increased, the number of species increased proportionally. The results of Resampling Statistics indicated that the cumulative number of species observed and the area of fish transects surveyed were similar to that which the species-area relationship equation $\left(S=c^{*} A^{z}\right)$ would predict $(c=159.0, z=0.3$; Fig. 18a). Similarly, results of resampling the cumulative number of species observed and the rocky bank patch area also were similar to those predicted by the species-area relationship equation $(\mathrm{c}=57.87, \mathrm{z}=0.25$; Fig. 18b). Additionally the cumulative abundance of the assemblage showed a positive relationship with cumulative area surveyed (Fig. 19a) and rocky bank patch area (Fig. 19b). These results are consistent with the previously mentioned lack of a significant relationship between assemblage density and area, as density is an area-standardized measure of abundance. These results demonstrate that the richness and abundance increases with area within the dataset of this study. 


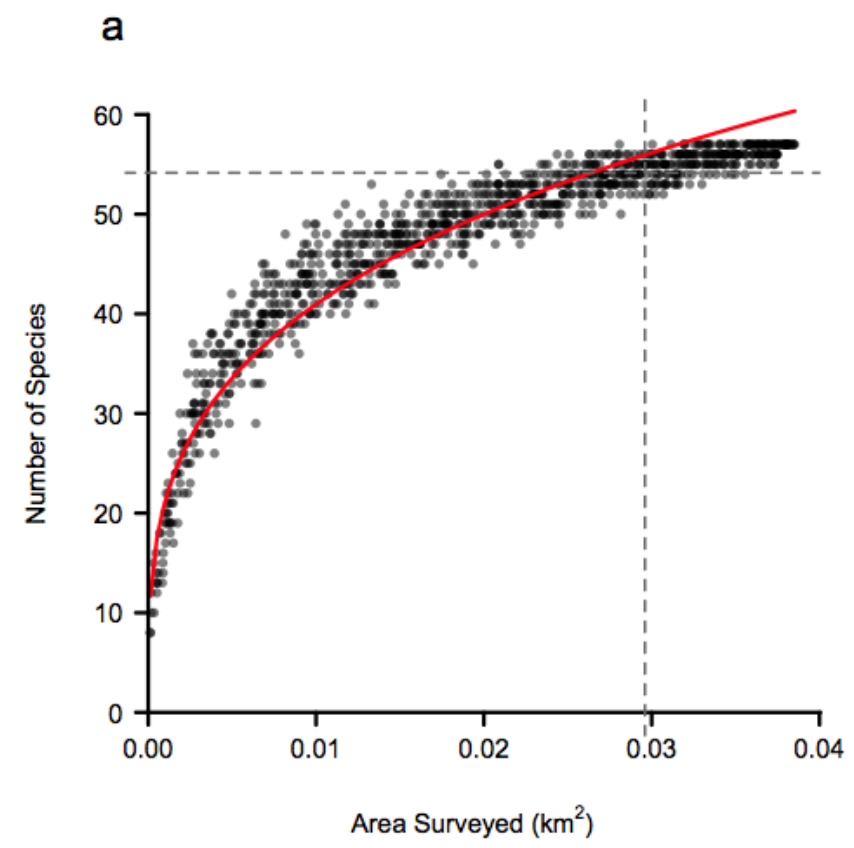

b

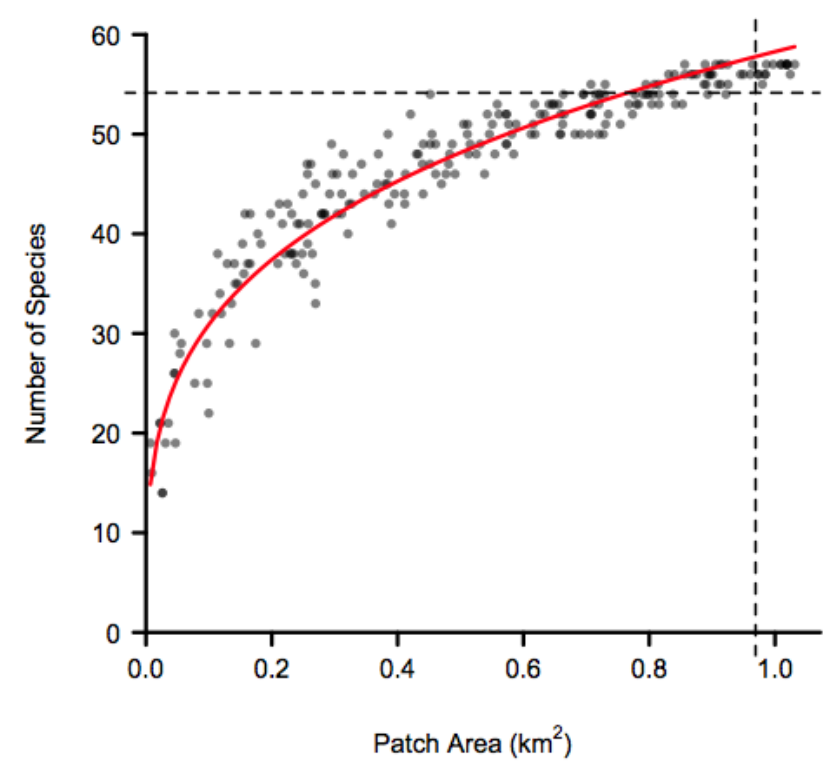

Fig. 18 Cumulative species richness with cumulative area surveyed and patch area near Point Lobos. Results of the resampling analyses of the cumulative species richness with respect to cumulative area surveyed (a) and cumulative patch area (b). The weight of the dot color denotes the frequency of the value in the resampling results. The predicted species-area relationship is superimposed in red. The dotted lines denote $90 \%$ of the total number of species and corresponding area surveyed or patch area 

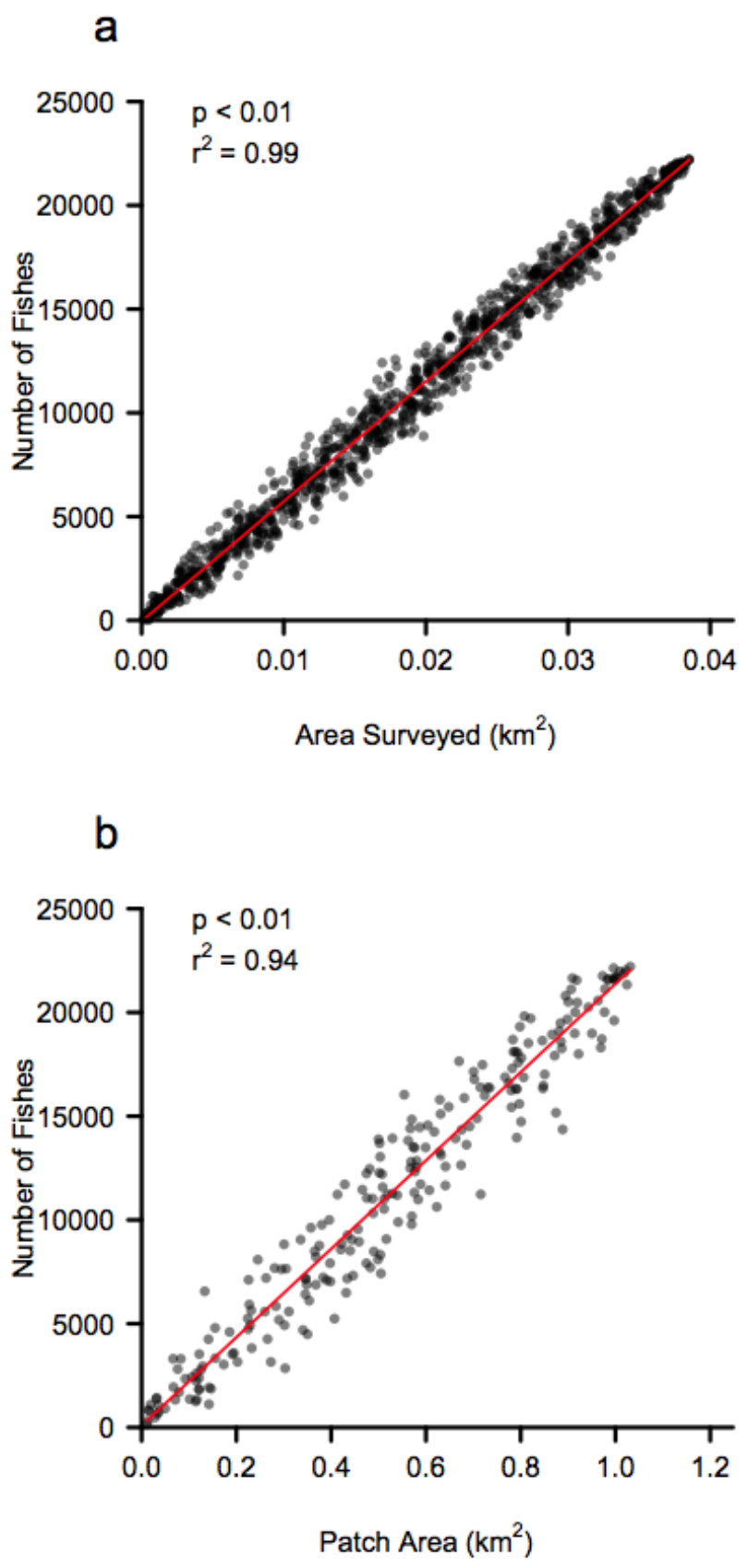

Fig. 19 Cumulative assemblage abundance with cumulative area surveyed and patch area near Point Lobos. Results of the resampling analyses of the cumulative assemblage abundance with respect to cumulative area surveyed (a) and cumulative patch area (b). The weight of the dot color denotes the frequency of the value in the resampling results. The linear relationship of the results is superimposed in red. P-values and $\mathrm{r}^{2}$ values are included in the legends 


\section{Discussion}

Does the abundance, diversity, or length frequency of fishes increase with depth?

Previous studies of fish-habitat relationships along the west coast of the United States have highlighted the importance of depth as a factor that explains the presence and abundance of specific species and thus the assemblage composition. My results indicated that there are species-specific differences with respect to depth, yet overall assemblage abundance and diversity increase with increasing depth. This means that more fishes and higher species counts were observed at greater depths. Faunal breaks along the California coast are largely defined by latitude and depth (as reviewed by Allen et al. 2006). This study was limited to the central California coast, and thus there was no effect of latitude on the species assemblage. For central and northern California, the peak fish abundance usually occurs in deep reefs and on the continental slope (Allen et al. 2006), which occur at the deepest limit of the present study region. Therefore, even though this study was constrained to the mid-depth rocky habitat zone $(30-100 \mathrm{~m})$, significant relationships between assemblage density and biomass with depth were observed. The response of each of the four species groups to depth aligned with previous findings (Miller and Lea 1976, Love et al. 2002, Allen et al. 2006).

Patterns in the species-specific density with respect to depth also aligned with previous research. For example, Blue Rockfish often are found in sub-tidal reefs and rocky habitats in less than $90 \mathrm{~m}$ depth (Love et al. 2002). In this study, Blue Rockfish 
were more abundant in shallow rocky bank patches, and density decreased with depth towards $100 \mathrm{~m}$, which is outside of the habitable depth of the species. In contrast, Starry Rockfish are typically found between 60 and $150 \mathrm{~m}$ of water (Love et al. 2002) and thus would, on average, peak in abundance around $100 \mathrm{~m}$ of depth. In this study, the density of Starry Rockfish significantly increased with depth toward the $100 \mathrm{~m}$ depth range of the study.

Assemblage composition naturally varies with depth due to individual speciesspecific depth ranges. As with fish abundance, there is a positive relationship between richness and depth across the continental slope (Allen et al. 2006). Therefore, it was expected to observe a positive relationship between the number of species and depth near Point Lobos. However, this kind of relationship was not observed. Perhaps the depth range of this study was not wide enough to observe the depth ranges of highest species richness, or the topography of Point Lobos may limit the overlap of species depth ranges. Most of the deep rocky bank patches within this study were located at the top of canyon walls. Rather than a gradual decrease in depth that fosters species overlap, the canyon walls might act as a barrier to the overlap of species or our ability to observe the overlap from the submersible.

Fish assemblage diversity often increases with increasing depth (Chittaro et al. 2010). However, this pattern was not observed within the mid-depth rocky habitat zone, which again could be due to the narrow depth range of this study. Evenness decreased with depth, meaning that a few species were more dominant in the deeper rocky bank patches. For a similar reason, the overall diversity of the assemblage decreased with 
depth. The difference in these results versus previous studies investigating the assemblage structure across the continental shelf could be because the depth range in this study was shallower than in previous studies of the nearshore fish assemblage.

The relationships among mean length and depth observed for the specific species supported previous findings. The increase in mean lengths of the dwarf rockfishes (Pygmy, Rosy, and Squarespot Rockfish) with depth is consistent with observations of younger rockfishes inhabiting shallow waters and moving to deeper habitats with age (Love et al. 2002). These ontogenetic shifts with depth are well documented for species within the large rockfish and non-rockfish species group: Yelloweye Rockfish $(S$. ruberrimus, Cramer 1895; Richards 1986, O’Connell and Carlile 1993), Bocaccio (S. paucispinus, Ayres 1854; Allen et al. 2006), and Lingcod (Ophiodon elongatus, Girard 1854; Fields 2005). However, the length distributions of these species groups in this study did not vary with respect to depth. This may be due to the $100 \mathrm{~m}$ depth restriction. The submersible transects analyzed covered the shallower portions of the depth range of these species and most likely the smaller lengths of the individuals for many of these species. For example, Love et al. (2002) reported that Yelloweye Rockfish were most abundant between 90 and $180 \mathrm{~m}$ and Bocaccio between 50 and $250 \mathrm{~m}$; thus, it was expected to see individuals of shorter lengths at the shallow end of their range, which was the deeper portion of the depth range in the present study.

The increase in the density of the assemblage and the decrease in the diversity with respect to depth support the previous conclusions that habitat depth strongly influences assemblage composition in California (Allen et al. 2006). Although a large 
portion of the variability ( 22 to $42 \%$ ) is explained by depth, this study was interested in what other variables could be influencing the variation in the nearshore fish assemblage. An additional factor that previous researchers have correlated with species composition of the fish assemblage is the complexity of the fine-scale habitat.

Does the abundance, diversity, or length frequency of fishes increase with rugosity?

Previous investigations of the nearshore fish assemblage have illustrated a relationship between fine-scale habitat types and the abundance and presence of specific species within the mid-depth rocky habitat zone (Ralston et al. 1986, Pearcy et al. 1989, Stein et al. 1992, Yoklavich et al. 2000, Anderson and Yoklavich 2007). Gratwicke and Speight (2005) used rugosity as a quantifiable metric to investigate the relationship between fine-scale habitat types and the fish assemblage. As a habitat type becomes more complex, the surface area of the seafloor increases and provides increased refuge from predators (Hixon and Beets 1989, Irlandi et al. 1995, Wilson et al. 2008), increased foraging opportunities (García-Charton et al. 2004), and increased niche partitioning (MacArthur and Levins 1964). Therefore, this study expected to observe a positive relationship among all of the biological response variables and rugosity.

The importance of fine-scale habitat type complexity is evident in the relationships this study observed among length frequency distributions of the species groups and specific species and rugosity. These results indicated that the length distribution of fishes was skewed towards shorter individuals in less complex habitat and 
longer individuals in more complex habitat. Previous studies have shown that Atlantic Cod (Gadus marhua, Linnaeus 1758) and Nassau Grouper (Epinephelus striatus, Bloch 1792) demonstrate ontogenetic shifts in the complexity of habitats they use (Gotceitas and Brown 1993, Gotceitas et al. 1995, Dahlgren and Eggleston 2000). Additionally, work with Atlantic Cod demonstrated that juveniles and adults rely on different defense mechanisms within soft sediment and complex rocky habitats, which could explain the pattern of longer individuals using more complex habitat (Gregory and Anderson 1997). However, there was no relationship among the other assemblage indices (density, biomass, or species composition) and rugosity. Therefore, fine-scale variation of the habitat does not appear to be a major factor affecting assemblage structure across the landscape of this study area.

Although rugosity was not correlated with many of the assemblage indices, significant relationships among density and length distributions of fishes were observed in the four species groups and species-specific analyses. In other studies, species within the other benthic species group have shown a positive correlation with rugosity (Yoklavich et al. 2002). Whereas the density dwarf rockfishes did not correlate with rugosity in this study, a previous study reported a positive association of abundance with rock, boulder, and cobble substrata (O'Farrell et al. 2009). Additionally the abundance of Blue Rockfish, which are semi-pelagic but have been previously reported to associate with rock pinnacles (Jorgensen et al. 2006), negatively correlated with rugosity. Although these results seem to counter those of Jorgensen et al. (2006), no pinnacles were included in this study. 
The significant relationships among the species groups and specific species with respect to rugosity support previous findings that rugosity is an important factor in species-specific responses to habitats. When there was a significant relationship, rugosity only explained $19 \%$ to $24 \%$ of the variability. However, these results also suggest that the assemblage as a whole is not strongly affected by rugosity across a landscape scale. Therefore, less than $50 \%$ of the variability in assemblage structure was explained by depth and rugosity in this study. Other observable factors, such as the independent habitat variables of the rocky bank patches, may account for the remaining variation in the nearshore fish assemblage.

Does the abundance, diversity, or length frequency of fishes increase with respect to the proximity of the edge of a rocky bank patch as would be predicted by the terrestrial landscape paradigm?

There is no standard ecological method for choosing the width of an edge zone. Previous landscape-scale investigations have defined the edge zone based upon the highest observed density (Peterson and Turner 1994), by using what other studies have used (Bologna and Heck 1999, Tanner 2003), or by slightly increasing the distance used by other studies (Jelbart et al. 2006). Therefore, designing an objective method for defining the edge zone for the rocky bank patches was a priority of this study. This study investigated both species-specific and assemblage responses to the edge, and thus the movement patterns of individual species could not be used to define the edge zone, as 
home range varies with body size (Kramer and Chapman 1999) and across species (NOAA 2004). Using the edge-width distance from previous studies would have enabled comparisons of the results from this study with those studies. However, most marine studies have used a distance that was defined by the distribution of epifaunal invertebrates in seagrass meadows (Peterson and Turner 1994, Bell et al. 1995). Therefore, assemblage density and the richness per unit area surveyed was used, two metrics that had been used previously to define the edge zone width, to look objectively for break points in the data. Both of these variables suggested a similar edge width zone. This width resulted in a similar percentage of the patch area being defined as the edge as compared to a previous seagrass study of fishes (Jelbart et al. 2006). In addition, the edge width used was at a similar scale to the estimated horizontal foraging range of Señorita (Oxyjulis californica, Günther 1861), another temperate fish (Bernstein and Jung 1979).

Terrestrial studies have reported increases in density and biomass of individuals along the edges of habitat patches within a landscape (Lidicker 1999, Bolger et al. 2000, Golden and Crist 2000). However, to date, marine studies have shown conflicting results with respect to the density of organisms at a patch edge. Changes in density at the edge of a habitat patch could be due to niche overlap of species at the edge or predator distribution and movements. For example, some researchers have observed an increase in total density of species due to a decrease in susceptibility to predators along edges (Gotceitas and Brown 1993, Fraser et al. 1995, Gotceitas et al. 1995, Gregory and Anderson 1997) and attributed this to decreased foraging efficiency of predators along 
edges (Hovel and Lipcius 2001). Other studies reported an increase in access to prey by predators along edge boundaries (Irlandi 1994), and a subsequent increase in predator density (Holmes and Laundré 2006) or preferential use of the edge area by predators (Carfagno et al. 2006, Heithaus et al. 2006, Papastamatiou et al. 2009).

In the rocky bank patches of this study, there was no difference in the density or biomass of the assemblage between the edge and interior zones of shallow rocky bank patches. However, there was an increase in both density and biomass at the edge in deep rocky bank patches. The increase in density and biomass of fishes at the edge could be due to direct selection of the edge zones by fishes or an indirect correlation of density with the edge zone, as explained by Wiens (1976). Regardless of whether the presence of fishes of the nearshore fish assemblage in close proximity to the rocky bank patch boundary is due to direct or indirect factors, these results indicate that edge effects do occur in deeper waters of the ocean than had previously been studied. Additionally, these results further document edge effects related to fish assemblage structure in temperate non-vegetative habitats.

Patterns with respect to the distance from a rocky patch boundary are not static, but rather may be influenced or driven by fine-scale movement patterns of individual fish. Lowe and Bray (2006) and Freiwald (2010) both synthesized current literature on movement patterns of fishes, concluding that the timing of movements and activity patterns vary among fish species and individuals within a species. Multiple biological (e.g., competition, prey or predator presence) and environmental (e.g., habitat quality, lunar phase, water temperature) variables have been correlated with movement patterns 
of fish. Whereas we are gaining an increased understanding of the size of home ranges, the total area used over time; unfortunately, little work to date has focused on the finescale daily movement patterns of fish. It is at this scale, of hourly or daily movements, in which the patterns with respect to the distance to rocky bank patch boundaries would be observed. Therefore, future work should focus on investigating fine-scale movement patterns with respect to landscape-scale habitat characteristics.

The lack of edge effects related to density or biomass in shallow patches suggests that different processes may affect the assemblage structure in shallow rocky bank patches as compared to seagrass meadows or terrestrial habitats. Positive edge effects related to eelgrass assemblage density have been attributed to increases in foraging opportunities (Irlandi et al. 1999, Hovel and Lipcius 2001). Patterns of increased density at the edge also have been linked with the increase in food availability at the seagrass edge as the blades dampen the currents (Bologna and Heck 2002). In this study of shallow rocky bank patches, the distribution of dwarf rockfishes, the prey species for larger fishes in the nearshore assemblage, was higher in the interior. Several reasons could explain the increase in prey items in the interior of rocky bank patches. First, prey species may seek refuge from predators in the interior of patches. Irlandi et al. (1999) reported that predation rates decreased with increasing distance from the edge zone. Second, if food is not a limiting resource for prey species because it is advected across all portions of the rocky bank patch, rather than only available at the edge zone, then there may be more food items for the prey species within the interior of the patch. Third, further research is needed to determine if predatory species have greater foraging success 
at the edges and thus the density of prey species is reduced at the edges of rocky bank patches.

The increase in the density of predatory species, such as large rockfishes, at the edge may be due to the presence of prey species in the adjacent habitats. For other species there was no difference in the density of individuals between the edge and interior as would be expected from previous research. For example, Jorgensen et al. (2006) observed Blue Rockfish most often 10-20 m from the kelp forest edge. In this study there was no edge effect related to Blue Rockfish, possibly because they occurred more often in the buffer ( $12-36 \mathrm{~m}$ from the rocky bank patch boundary).

Similar to terrestrial studies (Yahner 1988), there was a positive edge effect related to diversity of the nearshore fish assemblage throughout the depth range. The increase in diversity could be indicative of species overlap between rocky habitat fishes and soft bottom fishes occurring at the edge of rocky bank patches in the mid-depth rocky habitat, as seen in other systems (Ward et al. 1999, Baker et al. 2002). Indeed, species that associate with soft sediment, e.g., flat fishes, only were observed in the edge zones of rocky bank patches. In addition to these overlapping species, there also were species that occurred only in the edge or interior zones of the rocky bank patch (Appendix H). For instance, Big Skate (Raja binoculata, Girard 1855), Spotted Scorpionfish (Scorpaena guttata, Bloch 1789), and Yelloweye Rockfish ${ }^{4}$ were present only in the edge zones near Point Lobos. Whereas, Bank (S. rufus, Eigenmann and Eigenmann 1890), Rosethorn ( $S$.

\footnotetext{
${ }^{4}$ It is important to note that the sample size for Yelloweye Rockfish in the edge zone was very small. Many of the Yelloweye Rockfish were observed in the buffer $(12-36 \mathrm{~m}$ from the rocky bank patch boundary).
} 
helvomaculatus, Ayres 1859), and Shortbelly (S. jordani, Gilbert 1896) Rockfish were observed only in the interior zones. Furthermore, there were fewer dominant species in the edge zone in both shallow and deep rocky bank patches than in the interior zone. The increase in species evenness further suggests that there is an overlap of species from both rocky and soft bottom habitats. An increase in the diversity of the assemblage at the edge of a rocky bank patch results from both an increase in the number of species and a decrease in the dominance by individual species within the assemblage.

In terrestrial studies, researchers have observed an increase in the size of individuals along the edges due to a higher proportion of large predators (Woodroffe and Ginsberg 1998) or avoidance by smaller organisms of the edge zones (Foster and Gaines 1991). The higher density of a large predatory species group (large rockfishes) suggests that there are a higher proportion of large predators in the assemblage at the edge.

The similarity in density between edge and interior zones in shallow rocky bank patches indicates that different processes could be driving the increase in large fishes at the edge in different depths of rocky bank patches than those observed in shallow seagrass meadows. There could be increased competition from other large fishes along the edges, which potentially explains the lack of a pattern observed in shallow patches. The positive edge effect in deep patches could indicate that large predatory fish may travel farther to forage off of the rocky bank patch. For example, studies of tropical predatory fishes have observed off-reef foraging patterns of fishes that seek refuge in the reef (Frazer and Lindberg 1994, Posey and Ambrose 1994). Therefore, the observed positive edge effect could be due to their feeding habits off of the rocky habitat, not due 
to the food availablity at the edge of the rocky bank patch. Conversely, the increase in large predatory species at the edge could be because aggregations of prey items, such as zooplankton, micronekton, and small fish, often occur near abrupt topographic changes, like a rocky bank patch edge (see review by Genin 2004). Additionally, many rocky habitats in the central California coast have ledges around the edges of the habitat. These features could indicate more efficient shelter opportunities at the edges of rocky bank patches for larger fishes.

The density, diversity, and length results this study observed generally support previous landscape-scale studies in both terrestrial and marine systems. However, it seems that the ecological processes that are driving the edge effects differ across ecosystems. Similar to what Fagan et al. (1999) suggested, this study demonstrates a need for further work to focus on quantifying the key processes, e.g., food availability or refuge, which shape the nearshore fish assemblage across a landscape.

These results also have important implications for how scientists survey the nearshore fish assemblage. To increase the accuracy of our assemblage characterization it is important to conduct surveys of the fish assemblage throughout both the edge and interior zones of the rocky bank patches. If surveys only occur in the interior or at the edge of the rocky bank patch then those surveys would produce biased estimates of the fish assemblage. Starr et al. (1996) highlighted a potential bias of using a submersible when quantifying the nearshore fish assemblage. They reported greater abundances of fishes, especially semi-pelagic and pelagic fishes, more than $2 \mathrm{~m}$ off seafloor, outside the scope of the submersible surveys. These results indicate that the observed differences 
between the edge and interior zones of rocky bank patches within this study may be stronger for other portions of the nearshore fish assemblage than we are able to survey using a submersible.

Does the abundance, diversity, or length frequency of fishes increase with respect to the shape of a rocky bank patch?

The presence of edge effects related to the fish assemblage structure in sub-tidal rocky habitats indicates that the shape of the rocky bank patch should also affect the distribution and abundance of fishes. As the rocky bank patch boundary gets more complex, the proportion of the rocky bank patch that is within the edge zone increases. Due to the difficulty in and subjectivity of defining the edge width for a habitat patch and because it is easier to assess the shape of a rocky bank patch when developing a sampling design, it would be advantageous to use the shape of a rocky bank patch to account for the observed edge effects in future studies to assess the nearshore fish assemblage. Unfortunately, the shape of rocky bank patches did not significantly correlate with the density, diversity, or lengths of species within the fish assemblage in the rocky bank patches in this study. Therefore, patch shape is not a predictive indicator for most biological response variables.

Although the patch shape of rocky banks did explain roughly one quarter of the variability in species richness, it was not in the direction that was expected. The edge analyses revealed an increase in richness at the edge zones. Therefore, it was anticipated 
that as the shape of the rocky bank patch got more complex there also would be an increase in the number of species because there would be an increase in the amount of patch that occurred in the edge zone. However, fewer species were observed as the rocky bank patch shape increased in complexity.

The seemingly contradictory results of the rocky bank patch shape analyses may indicate that the patterns of foraging or dispersal are different on rocky banks than in terrestrial habitats. In terrestrial studies, researchers have correlated the shape of habitat patches with increased dispersal and foraging of organisms (as summarized by Forman and Godron 1986, Gutzwiller and Anderson 1992). In the ocean, currents advect food particles through the water column and thus organisms forage differently in the oceans (Cowen and Sponaugle 2009). Whereas habitat patch shape can be a predictor of the distribution of species on land, it may not be relevant in the marine environment because underlying food dispersal processes are different.

Alternatively, the range of P:A ratios within this study may not be wide enough to detect the influence of rocky bank patch shape on the biological response variables. Although the P:A ratio values of the rocky bank patches were 1.4 to 2.5 times more complex than a perfect circle of similar area, perhaps the effect of boundary complexity does not influence species distribution until it is of greater complexity. In addition, P:A ratio and area were highly correlated, and therefore rocky bank patch size might be more of a factor driving assemblage structure. Previous marine studies also did not observe significant relationships among the biological response variables and the shape of seagrass patches, but reported that biological response variables were correlated with 
seagrass patch size (Jelbart et al. 2006). This could also explain why the signal of edge effects was not observed in all biological response variables of the assemblage for the rocky bank patch shape analyses.

Rocky bank patch shape did correlate with the number of species and the proportion of large individuals observed throughout rocky bank patches. In addition, the species-specific analyses illustrated that the complexity of the rocky bank patch boundary can be a predictor of the size composition, but not other biological response variables at the species group or species level. The species-specific relationships with rocky bank patch shape did not match results from the edge analyses either. For example, even though there were higher densities of Blackeye Goby observed at the edge of rocky bank patches, there was no relationship between this species and rocky bank patch shape. This could be because the home range of Blackeye Goby is small in comparison to other species and thus it is almost always at the edge of the microhabitat it associates with.

These results have important implications for the design of surveys to assess the diversity of the nearshore fish assemblage. Because the length frequencies of fishes and the number of species change in response to the complexity of the boundary of rocky bank patches, it is necessary to stratify a sampling scheme throughout a range of rocky bank patch shapes. Surveying within multiple rocky bank patch shapes would increase the accuracy of the assemblage structure estimates for the region, thus the shape of rocky bank patches should be considered when developing the sampling design for a survey. 
Does the abundance, diversity, or length frequency of fishes increase with respect to the size a rocky bank patch?

Previous marine landscape studies determined that the size of habitat patches was a greater factor in explaining assemblage structure than the shape of the habitat patch (Eggleston et al. 1998, Bolger et al. 2000, Jelbart et al. 2006). The results from this study support these conclusions. Whereas rocky bank patch shape explained roughly a quarter of the variability in the number of species observed, the size of the rocky bank patch explained $48 \%$. Therefore, the size of a rocky bank patch was a more robust predictor of species richness in the nearshore fish assemblage than rocky bank patch shape. The number of species within the assemblage strongly correlated with area, as would be expected from species-area relationship curves. Additionally, the observed positive relationship between species richness and rocky bank patch size aligns with previous marine and terrestrial studies (Winemiller and Leslie 1992, Elliot et al. 1998, Heegaard et al. 2007).

Rocky bank patch size did not correlate with species density within the assemblage. Although there was a positive relationship between fish abundance and rocky bank patch size, there was no significant relationship between density and rocky bank patch size. These results support the relationship between abundance, density, and area as summarized by Risser (1995). If abundance increases proportionally to the increase in area of patches, there should be no change in density with increasing area, as density is standardized to area (Risser 1995). Additionally, Bender et al. (1998) 
suggested that using the total patch size rather than the area that species inhabit within the patch could result in underestimates of density. Future studies should investigate if similar underestimates of the nearshore fish assemblage occur by conducting tracking studies to quantify the proportion of the habitat used.

However, there were differences in the biomass and lengths of four of the species investigated with respect to rocky bank patch size. In fact, three rockfish species demonstrated an increase in biomass with increasing area. Therefore, individual species responded uniquely to the area of rocky bank patches. Sampling measures of the assemblage need to account for such species-specific differences when generalizing about patterns with respect to patch size across a landscape.

Similar to rocky bank patch shape, the size composition of the nearshore fish assemblage varied with area at the species group and species-specific level. Interestingly, there was a significant increase in the proportion of individuals of longer lengths with increasing rocky bank patch size, both for a species group and for individual species. The increase in lengths of fishes could be due to ontogenetic shifts to larger rocky bank patches with greater size due to an increase in home range requirements. Larger fishes often need a greater area to encounter enough prey to survive. Larger individuals of rocky habitat-specific species, such as Squarespot Rockfish, were observed in higher proportions in rocky bank patches of greater area. In addition, rocky bank patch size also varied with other biological response variables for some but not all species.

The relationship between the size of patches and the number of species has important sampling design implications. To survey accurately the nearshore fish 
assemblage across a landscape, it is necessary to include a range of rocky bank patch sizes, as the number of species does not increase linearly with an increase in area. Additionally, to quantify the biomass of the assemblage or the range of sizes of fishes throughout a landscape one would need to stratify the sampling design across rocky bank patches of various areas.

Are patterns in the nearshore fish assemblage with respect to independent habitat variables similar between regions of the central California coast?

The results from Point Lobos suggest that researchers need to account for independent habitat variables when investigating the nearshore fish assemblage. It is also important to understand if these relationships between assemblage structure and the landscape are specific to the Point Lobos area or if they can be generalized throughout central California. This study expected that the magnitude of the patterns would differ among regions due to differences in region-specific characteristics, but that the direction of the patterns would be similar. If the observed patterns occur in multiple regions, these results can be applied widely to current research projects collecting information for fisheries management.

Results for the biological response variables at the assemblage level of nearshore fishes were relatively similar between the two regions. There was no difference in the response of density between the two regions. However, the increase in the biomass of fishes in the edge zone was only observed near Point Lobos. This difference between the 
two regions could be due to differences in their topography. The topography of Point Lobos is interspersed with canyon heads, whereas Point Sur is a large shelf (Fig. 1). These differences could affect the advection and distribution of food items. For example, if stronger currents near Point Sur advect more food towards fishes, there could be less of a need for larger individuals to stay at the edge of rocky bank patches.

The assemblage responses to the shape and size of the rocky bank patch were similar between the two locations. For example, the shape of the rocky bank patch did not correlate with the density or biomass in either Point Lobos or Point Sur. The relationships between assemblage variables and rocky bank patch size were consistent between the two regions. This further suggests that the area of the rocky bank patches drives much of the variability in the nearshore fish assemblage.

These results demonstrate the importance of investigating patterns in assemblage structure in multiple places throughout the region, as well as against multiple independent habitat variables. The pattern of the relationships among the biological response variables and the independent habitat variables were in a similar direction near Point Lobos and Point Sur. This indicates that the patterns in the nearshore fish assemblage with respect to landscape-scale habitat variables are most likely similar throughout central California. 
What are the management implications of the observed patterns in nearshore fish assemblages with respect to landscape-scale habitat characteristics?

The spatial scales at which researchers collect fishery data, at which fish interact, and at which we manage our fisheries are substantially different. Most researchers investigate assemblages of nearshore fishes at a scale smaller than the functional subpopulations of species. However, we manage fisheries at scales larger than the spatial area of subpopulations. By determining how assemblages and individual species respond to independent habitat variables across a landscape, we are able to gain a better understanding of how assemblages of fishes are distributed and how species interact within the assemblage at spatial scales more similar to those of subpopulations. Results from this study therefore have important ecosystem-level implications for fisheries management.

Currently, the data collection technique used in this study is utilized in surveys that inform stock assessments of commercially harvested species (e.g., Yoklavich et al. 2007). This study demonstrated that species are contagiously distributed; higher densities of large rockfishes are disproportionately observed at the edge of rocky bank patches. To accurately estimate the current standing biomass of such species for stock assessments, it is imperative to design sampling schemes that survey the rocky bank patch edges where these species are present. Abundance estimates will be more accurate if sampling is stratified across the landscape based upon knowledge of the non-random patterns of species distribution. 
Some fisheries scientists have estimated regional population abundance for stock assessments by multiplying fish density estimates by the amount of available rocky habitat (O'Connell and Carlile 1993). This method holds promise for estimating population sizes and species composition when limited resources are available. However, results from this study demonstrate that species are not uniformly distributed throughout rocky bank patches within the rocky habitat. Depending on the initial sampling location, such techniques could result in biased estimates. For instance, if surveys of commercially important large rockfishes, e.g., Vermilion (S. miniatus, Jordan and Gilbert 1880) and Canary Rockfish (S. pinnger, Gill 1864) or Bocaccio, were only conducted within the interior of rocky bank patches, the estimates of density would be artificially low because these species are positively correlated with proximity to rocky bank patch edges. Further work investigating species-specific responses to the edge and interior portions of rocky bank patches is necessary prior to fully utilizing the abovementioned technique of extrapolating population size from habitat availability.

Additionally, these results illustrate that edge portions of rocky bank patches serve an important function in shaping the nearshore fish assemblage. Therefore, areabased management decisions that are intended to protect the community (e.g., MPAs) or the habitat necessary to support these communities (e.g., Essential Fish Habitat) should ensure that these edge zones of rocky bank patches are sufficiently protected. Further studies should attempt to quantify which ecological processes that occur along the edge of rocky bank habitats result in increased density, diversity, and size of individuals. 
Other results from these analyses have important implications for area-based management. Two dominant questions in designing effective area-based management approaches are the scale at which management decisions should be made and how to effectively monitor the effects of these management decisions. Results from this study provided information for both of these questions. The significant relationship between species richness and rocky bank patch size demonstrated that as the area of a rocky bank patch increases linearly, the number of species increases non-linearly. If the goal of areabased management is to protect the diversity of the fish assemblage, as estimated by the species richness, this indicates that protecting larger rocky bank patches may be more effective.

Knowing the species-area relationship for central Californian rocky banks leads to the question of what size of rocky bank patches should be protected. Results from this study demonstrated that rocky bank patches that are roughly $0.97 \mathrm{~km}^{2}$ would protect $90 \%$ of the total number of species within the region. Additionally, the relationship between cumulative abundance of fishes and rocky bank patch size provides information about the area necessary to protect a viable portion of the population, once minimum viable population size is known (Gaines et al. 1992). The species-area relationships could be determined for individual species, or for the assemblage, to include in viability analyses. Information from these two data sources would enable managers to define more robust criteria for the amount of area required to protect the nearshore fish assemblage or individual stocks. 
The relationship between species richness and area surveyed also provides important information for monitoring area-based management or for assessing the health of the nearshore fish assemblage. The species-accumulation relationships for area surveyed illustrate that at least $0.03 \mathrm{~km}^{2}$ of a rocky bank patch should be surveyed to observe $90 \%$ of the species within the rocky bank patch. Knowing how much of a rocky bank patch to survey would enable researchers to more efficiently allocate their sampling efforts and to increase the accuracy of their estimates of the biological response variables.

These results demonstrate that the size of rocky bank patches is a driving factor in the composition of the nearshore fish assemblage and in our understanding of it. Areabased management is grounded in the importance of the spatial configuration of habitats and species distributions. Research on fish-habitat relationships at the fine scale has, to date, been the primary consideration when protecting the nearshore fish assemblage. However, the results of this study demonstrate that it is imperative to consider landscapescale habitat characteristics across a landscape, especially habitat patch size. This information will improve our ability to manage fisheries in smaller areas of the coastline.

\section{Conclusions}

Landscape-scale research in the marine environment is an emerging field, and additional studies enhance our ability to determine if it is possible to transfer terrestrial models of management to the oceans. The results of this study highlight the similarities and differences among sub-tidal rocky habitat, other marine ecosystems, and terrestrial 
environments. It is important to consider these differences when attempting to apply ecological patterns across ecosystems. Additionally, having an increased understanding of the response of nearshore fish assemblages to landscape-scale habitat characteristics will enable managers to design more effective area-based management approaches (e.g., MPAs) in terms of their size, shape, and location. Therefore, understanding patterns in fish assemblages across a landscape will improve fisheries management locally as well as regionally.

This study documented that predictable landscape-scale patterns do exist in the distribution of nearshore fish assemblages. For example, there was an increase in the assemblage biomass, richness, and mean length of fishes in the edge zones of sub-tidal rocky bank habitat patches at the landscape scale. Results also indicate that there was a significant increase in the density of large rockfishes at the edge of rocky bank patches. Additionally, there was a significant increase in the species richness of fishes with increasing rocky bank patch size. In fact, rocky bank patch size explained more of the variability in the fish assemblage structure than the shape of the rocky bank patch. These results show that there are patterns in the distributions of nearshore fishes across a landscape. To appropriately survey fishes across a landscape it is imperative to design sampling protocol with an understanding of these patterns.

However, this study also demonstrated that terrestrial paradigms are not directly applicable to the nearshore fish assemblage in temperate sub-tidal marine habitats. The complexity of the rocky bank patch shape was not a good predictive indicator for the nearshore fish assemblage. There were no significant relationships among patch shape 
and the density or diversity of the nearshore fish assemblage, however the range of patch shapes used in this study may have been too restrictive to observe significant relationships. Although there was a significant relationship between patch shape and species richness, it was a negative relationship rather than the positive relationship repeatedly observed in terrestrial systems. In addition, there was no significant relationship between species density and the proximity to the patch edge for the nearshore fish assemblage. These results highlight that terrestrial paradigms should not be directly applied to the marine environment. Instead, further research should quantify the patterns of nearshore fish assemblage with respect to landscape-scale habitat characteristics. 


\section{References}

Allen LG, Pondella II DJ, Horn MH (2006) The ecology of marine fishes: California and adjacent waters. University of California Press, Berkeley

Anderson RO, Gutreuter SJ (1983) Length, weight, and associated structural indices. pp 283-300. In: Nielsen LA, Johnson DL (eds) Fisheries techniques. American Fisheries Society, Bethesda

Anderson TJ, Simon JE, Gordon DC, Hurley PC (2005a) Linking fisheries to benthic habitats at multiple scales: Eastern Scotian shelf haddock. Am Fish Soc Symp $41: 251-264$

Anderson TJ, Yoklavich MM, Eittreim SL (2005b) Linking fine-scale groundfish distribution with large-scale seafloor maps: issues and challenges of combining biological and geological data. Am Fish Soc Symp 41:667-678

Anderson TJ, Yoklavich MM (2007) Multiscale habitat selections of deepwater demersal fishes off central California. Fish Bull 105:168-179

Attrill MJ, Strong JA, Rowden AA (2000) Are macroinvertebrate assemblages influenced by seagrass structural complexity? Ecography 23:114-121

Ault TR, Johnson CR (1998) Spatially and temporally predictable fish assemblages on coral reefs. Ecol Monograph 68:25-50

Baker J, French K, Whelan RJ (2002) The edge effect and ecotonal species: bird assemblages across a natural edge in southeastern Australia. Ecol 83:3048-3059

Baltz DM, Rakocinski C, Fleeger JW (1993) Microhabitat use by marsh-edge fishes in a Louisiana estuary. Envi Biol Fish 36:109-126

Bell SS, Hall MO, Robbins BD (1995) Toward a landscape approach in seagrass beds: using macroalgal accumulation to address questions of scale. Oecol 104:163-168

Bender DJ, Contreras TA, Fahrig L (1998) Habitat loss and population decline: a metaanalysis of the patch size effect. Ecol 79:517-533

Bernstein BB, Jung N (1979) Selective pressures and coevolution in a kelp canopy assemblage in southern California. Ecol Monograph 49:335-355

Bizzarro JJ, Robinson HJ, Rinewalt CS, Ebert DA (2007) Comparative feeding ecology of four sympatric skate species off central California, USA. Environ Biol Fish 80:197-220 
Blake Jr. MC, Jones DL (1981) The Franciscan Assemblage and related rocks in northern California: a reinterpretation. In: Ernst WG (ed) The Geotectonic Development of California. Prentice-Hall, Englewood Cliffs

Bolger DT, Suarez AV, Crooks KR, Morrison SA, Case TJ (2000) Arthropods in urban habitat fragments in southern California: area, age, and edge effects. Ecol Appl 10:1230-1248

Bologna PAX, Heck KL (1999) Differential predation and growth rates of bay scallops within a seagrass habitat. J Exp Mar Biol Ecol 239:299-314

Bologna PAX, Heck KL (2002) Impact of habitat edges on density and secondary production of seagrass-associated fauna. Estuaries 25:1033-1044

Bowden DA, Rowden AA, Attrill MJ (2001) Effect of patch size and in-patch location on the infaunal macroinvertebrate assemblages of Zostera marina seagrass beds. J Exp Mar Biol Ecol 259:133-154

Bowers MA, Matter SF (1997) Landscape ecology of mammals: relationships between density and patch size. J Mammal 78:999-1013

Bowman J, Cappuccion N, Fahrig L (2002) Patch size and population density: the effect of immigration. Cons Ecol 6:9

Brooks RA, Bell SS (2001) Mobile corridors in marine landscapes: enhancement of faunal exchange at seagrass/sand ecotones. J Exp Mar Biol 264:67-84

Cailliet GM, Barry JP (1979) Comparison of food array overlap measures useful in fish feeding habit analysis. pp 67-79. In: Lipovsky SJ, Simenstad CA (eds) Fish food habits studies proceedings of the second Pacific Northwest technical workshop. Washington Sea Grant / University of Washington, Seattle

Carfagno GLF, Heske EJ, Weatherhead PJ (2006) Does mammalians prey abundance explain forest-edge use by snakes? Eco Sci 13:293-297

Carr MH, Neigel JE, Estes JA, Andelman S, Warner RR, Largier JL (2003) Comparing marine and terrestrial ecosystems: implications for the design of coastal marine reserves. Ecol Appl 13:90-107

Chittaro PM, Kaplan IC, Keller A, Levin PS (2010) Trade-offs between species conservation and the size of marine protected areas. Cons Biol 24:197-206 
Ciannelli L, Fauchald P, Chan KS, Agostini VN, Dingsør GE (2008) Spatial fisheries ecology: recent progress and future prospects. J Mar Sci 71:223-236

Connolly RM (1994) A comparison of fish assemblages from seagrass and unvegetated areas of a southern Australian estuary. Aust J Mar Freshw Res 45:1033-1044

Cowen RK, Sponaugle S (2009) Larval dispersal and marine population connectivity. Annu Rev Mar Sci 1:443-466

Dahlgren CP, Eggleston DB (2000) Ecological processes underlying ontogenetic habitat shifts in a coral reef fish. Ecol 81:2227-2240

Davidson JP, Reed WE, Davis PM (2002) Exploring earth: an introduction to physical geology, 2nd edn. Prentice Hall, Upper Saddle River

Diamond JM (1975) The island dilemma: lessons of modern biogeographic studies for the design of nature reserves. Biol Cons 7:129-146

Donovan TM, Jones PW, Annand EM, Thompson III FR (1997) Variation in local-scale edge effects: mechanisms and landscape context. Ecol 78:2064-2075

Ebeling AW, Hixon MA (1991) Tropical and temperate reef fishes: comparison of community structures. pp 509-563. In: Sale PF (ed) The ecology of fishes on coral reefs. Academic Press, Inc., San Diego

Eggleston DB, Etherington LL, Elis WE (1998) Organism response to habitat patchiness: species and habitat-dependent recruitment of decapod crustaceans. J Exp Mar Biol Ecol 223:111-132

Eggleston DB, Elis WE, Etherington LL, Dahlgren CP, Posey MH (1999) Organism responses to habitat fragmentation and diversity: habitat colonization by estuarine macrofauna. J Exp Mar Biol Ecol 236:107-132

Elliot NC, Kieckhefer RW, Lee J-H, French BW (1998) Influence of within-field and landscape factors on aphid predator populations in wheat. Landscape Ecol 14:239252

Fagan WF, Cantrell RS, Cosner C (1999) How habitat edges change species interactions. Amer Nat 153:165-182

Fields J (2005) Small-scale analysis of fish and habitat relationship off central California. Masters Thesis, Moss Landing Marine Laboratories 
Forman RTT (1995) Land mosaics: the ecology of landscapes and regions. Cambridge University Press, Cambridge

Forman RTT, Godron M (1981) Patches and structural components for landscape ecology. BioSci 31:733-740

Forman RTT, Godron M (1986) Landscape ecology. John Wiley and Sons, New York

Foster J, Gaines MS (1991) The effects of a successional habitat mosaic on a small mammal assemblage. Ecol 72:1358-1373

Fraser S, Gotceitas V, Brown JA (1995) Interactions between age-classes of Atlantic cod and their distribution among bottom substrates. Can J Fish Aquat Sci 53:305-314

Frazer TK, Lindberg WJ (1994) Refuge spacing similarly affects reef-associated species from three phyla. Bull Mar Sci 55:388-400

Friedlander AM, Parrish JD (1998) Habitat characteristics affecting fish assemblages on a Hawaiian coral reef. J Exp Mar Biol Ecol 224:1-30

Gaines MS, Foster J, Diffendorfer JE, Sera WE, Holt RD (1992) Population processes and biological diversity. Department of Systematics and Ecology. University of Kansas, Lawrence KS

García-Charton JA, Pérez-Ruzafa Á, Sánchez-Jerez P, Bayle-Sempere JT, Renones O, Moreno D (2004) Multi-scale spatial heterogeneity, habitat structure, and the effect of marine reserves on Western Mediterranean rocky reef fish assemblage. Mar Biol $144: 161-182$

Genin A (2004) Bio-physical coupling in the formation of zooplankton and fish aggregations over abrupt topographies. J Mar Syst 50:3-20

Golden DM, Crist TO (2000) Experimental effects of habitat fragmentation on rove beetles and ants: patch area or edge? Oikos 90:525-538

Gosz JR (1993) Ecotone hierarchies. Ecol Appl 3:369-376

Gotceitas V, Brown JA (1993) Substrate selection by juvenile Atlantic cod (Gadus morhua): effects of predation risk. Oecol 93:31-37

Gotceitas V, Fraser S, Brown JA (1995) Habitat use by juvenile Atlantic cod (Gadus morhua) in the presence of an actively foraging and non-foraging predator. Mar Biol $132: 421-430$ 
Gotelli NJ (2001) A primer of ecology, 3rd edn. Sinauer Associates, Inc., Sunderland

Gratwicke B, Speight MR (2005) The relationship between fish species richness, abundance and habitat complexity in a range of shallow tropical marine habitats. $\mathrm{J}$ Fish Biol 66:650-667

Greene HG, Yoklavich MM, Starr RM, O'Connell VM, Wakefield WW, Sullivan DE, McRea Jr. JE, Cailliet GM (1999) A classification scheme for deep seafloor habitats. Oceanol Acta 22:663-378

Gregory RS, Anderson TJ (1997) Substrate selection and use of protective cover by juvenile Atlantic cod Gadus morhua in inshore waters of Newfoundland. Mar Ecol Prog Ser 146:9-20

Gutzwiller KJ, Anderson SH (1992) Interception of moving organisms: influences of patch shape, size, and orientation on assemblage structure. Landscape Ecol 6:293303

Hawrot RY, Niemi GJ (1996) Effects of edge type and patch shape on avian assemblages in a mixed conifer-hardwood forest. Auk 113:586-598

Heegaard E, Økland RH, Bratli H, Dramstad WE, Engan G, Pedersen O, Solstad H (2007) Regularity of species richness relationships to patch size and shape. Ecography 30:589-597

Heggens J, Saltveit SJ (2007) Summer stream habitat partitioning by sympatric Artic charr, Atlantic salmon and brown trout in tow sub-arctic rivers. J Fish Biol 71:10691081

Heithaus MR, Hamilton IM, Wirsins AJ, Dill LM (2006) Validation of a randomization procedure to assess animal habitat preferences: microhabitat use of tiger sharks in a seagrass ecosystem. J Anim Ecol 75:666-676

Hixon MA, Beets JP (1989) Shelter characteristics and Caribbean fish assemblages: experiments with artificial reefs. Bull Mar Sci 44:666-680

Holmes BR, Laundré JW (2006) Use of open, edge, and forest areas by pumas Puma concolor in winter: are pumas foraging optimally? Wildlife Biol 12:201-209

Hovel KA, Fonseca MS, Myer DL, Kenworthy WJ, Whitfield PE (2002) Effects of seagrass landscape structure, structural complexity and hydrodynamic regime on macro-faunal densities in North Carolina seagrass beds. Mar Ecol Prog Ser 243:1124 
Hovel KA, Lipcius RN (2001) Habitat fragmentation in a seagrass landscape: patch size and complexity control blue crab survival. Ecol 82:1814-1829

Hynes, HBN (1970) The ecology of running waters. University of Toronto Press, Toronto

Irlandi EA (1994) Large- and small-scale effects of habitat structure on rates of predation: how percent coverage of seagrass affects rates of predation and siphon nipping on an infaunal bivalve. Oecol 98:176-183

Irlandi EA (1997) Seagrass patch size and survivorship of an infaunal bivalve. Oikos 78:511-518

Irlandi EA, Ambrose Jr. WG, Orlando BA (1995) Landscape ecology and the marine environment: how spatial configuration of seagrass habitat influences growth and survival of the bay scallop. Oikos 72:307-313

Irlandi EA, Orlando BA, Ambrose WG (1999) Influence of seagrass habitat patch size on growth and survival of juvenile bay scallops Argopecten irradians concentricus (Say). J Exp Mar Biol Ecol 235:21-43

Jelbart JE, Ross PM, Connolly RM (2006) Edge effects and patch size in seagrass landscapes: an experimental test using fish. Mar Ecol Prog Ser 319:93-102

Johnson TD, Barnett AM, DeMartini EE, Craft LL, Ambrose RF, Purcell LJ (1994) Fish production and habitat utlization on a southern California artificial reef. Bull Mar Sci 55:709-723

Jorgensen SJ, Kaplan DM, Klimley AP, Morgan SG, O'Farrell MR, Botsford LW (2006) Limited movement in Blue Rockfish Sebastes mystinus: internal structure of home range. Mar Ecol Prog Ser 327:157-170

Kareiva P (1990) Population dynamics in spatially complex environments: theory and data. Phil Trans R Soc B 330:175-190

Kotliar NB, Wiens JA (1990) Multiple scales of patchiness and patch structure: a hierarchical framework for the study of heterogeneity. Oikos 59:253-260

Kramer DL, Chapman MR (1999) Implications of fish home range size and relocation for marine reserve function. Envi Biol Fish 55:65-79

Krebs CJ (1999) Ecological methodology, 2nd edn. Addison Welsley Longman, Inc., Menlo Park 
Kritzer JP, Sale PF (2006) Marine Metapopulations. Elsevier Academic Press, Burlington

Kunin WE (1998) Biodiversity at the edge: a test of the importance of spatial "mass effects" in the Rothamsted Park Grass experiments. Proc Natl Acad Sci U S A 95:207-212

Lidicker Jr. WZ (1995) The landscape concept: something old, something new. In: Lidicker Jr. WZ (ed) Landscape approaches in mammalian ecology and conservation. University of Minnesota Press, Minneapolis, pp 3-19

Lidicker Jr. WZ (1999) Responses of mammals to habitat edges: an overview. Landscape Ecol 14:333-343

Lindsay MJ, Patterson HM, Swearer SE (2008) Habitat as a surrogate measure of reef fish diversity in the zoning of the Lord Howe Island Marine Park, Australia. Mar Ecol Prog Ser 353:265-273

Love MS, Yoklavich MM (2006) Deep rock habitats. In: Allen LG, Pondella DJ, Horn HM (eds) The ecology of marine fishes: California and adjacent waters. University of California Press, Berkeley

Love MS, Yoklavich MM, Thorsteinson L (2002) The rockfishes of the Northeast Pacific. University of California Press, Berkeley

Luckhurst BE, Luckhurst K (1978) Analysis of the influence of substrate variables on coral reef fish assemblages. Mar Biol 49:317-323

MacArthur R, Levins R (1964) Competition, habitat selection, and character displacement in a patchy environment. Proc Natl Acad Sci U S A 51:1207-1210

MacArthur RH, Wilson EO (1967) Theory of island biogeography. Princeton University Press, Princeton

Manel S, Schwartz MK, Luikart G, Taberlet P (2003) Landscape genetics: combining landscape ecology and population genetics. Trends Ecol Evolut 18:189-197

Miller DJ, Lea RN (1976) Guide to the coastal marine fishes of California: California Fish Bulletin Number 157, publ 4065. Cooperative Extension University of California

NOAA Technical Memorandum (2004). Conservation of North Pacific Rockfishes: Ecological Genetics and Stock Structure. Proceedings of the Workshop March 2-3, 2004 Seattle, Washington NMFS-NWFSC-80 
Norris R, Webb R (1990) Geology of California, 2nd ed, Webb, John Wiley and Sons, Inc., New York

O’Connell VM, Carlile DW (1993) Habitat-specific density of adult yelloweye rockfish Sebastes ruberrimus in the eastern Gulf of Alaska. Fish Bull 91:304-309

O'Farrell MR, Yoklavich MM, Love MS (2009) Assessment of habitat and predator effects on dwarf rockfishes (Sebastes spp.) using multi model inference. Envi Biol Fish 85:239-250

Odum EP (1958) Fundamentals of ecology, 2nd edn. Saunders, Philadelphia

Oksanen T, Oksanen L, Gyllenberg M (1992) Exploitation ecosystems in heterogeneous habitat complexes II: impact of small-scale heterogeneity on predator-prey dynamics. Evol Ecol 6:383-398

Osman RW (1977) The establishment and development of a marine epifaunal assemblage. Ecol Monograph 47:37-63

Pacific Fishery Management Council (2009) Pacific coast groundfish fishery management plan: for California, Oregon, and Washington groundfish fishery as amended through Amendment 19. Portland,

Papastamatiou YP, Lowe CG, Caelle JE, Friednlander AM (2009) Scale-dependent effects of habitat on movements and path structure of reef sharks at a predatordominated atoll. Ecol 90:996-1008

Pearcy WG, Stein DL, Hixon MA, Pikitch EK, Barss WH, Starr RM (1989) Submersible observations of deep-reef fishes of Heceta Bank, Oregon. Fish Bull 87:955-965

Peterson GW, Turner RE (1994) The value of salt marsh edge vs. interior as a habitat for fish and decapod crustaceans in a Louisiana tidal marsh. Estuaries 17:235-262

Posey MH, Ambrose WG (1994) Effects of proximity to an offshore hard-bottom reef on infaunal abundances. Mar Biol 118:745-753

Quinn GP, Keough MJ (2002) Experimental design and data analysis for biologists. Cambridge University Press, Cambridge

Ralston S, Gooding RM, Ludwig GM (1986) An ecological survey and comparison of bottom fish resource assessments (submersible versus handline fishing) at Johnston Atoll. Fish Bull 84:141-155 
Richards LJ (1986) Depth and habitat distributions of three species of rockfish (Sebastes) in British Columbia: observations from the submersible PISCES IV. Envi Biol Fish $17: 13-21$

Risser PG (1995) The status of the science of examining ecotones. BioSci 45:318-325

Saunders DA, Hobbs RJ, Margules CR (1991) Biological consequences of ecosystem fragmentation: a review. Cons Biol 5:18-32

Selgrath JC, Hovel KA, Whale RA (2007) Effects of habitat edges on American lobster abundance and survival. J Exp Mar Biol Ecol 353:253-264

Starr RM, Fox DS, Hixon MA, Tissot BN, Johnson GE, Brass WH (1996) Comparison of submersible-survey and hydroacoustic-survey estimates of fish density on a rocky bank. Fish Bull 94:113-123

Starr RM, Yoklavich MM (2008) Monitoring MPAs in Deep Water Off Central California:2007 IMPACT Submersible Baseline Survey. California Sea Grant College Program publ T-067

Stein DL, Tissot BN, Hixon MA, Brass W (1992) Fish-habitat associations on a deep reef at the edge of the Oregon continental shelf. Fish Bull 90:540-551

Tanner JE (2003) Patch shape and orientation influences on seagrass epifauna are mediated by dispersal abilities. Oikos 100:517-524

Tanner JE (2005) Edge effects on fauna in fragmented seagrass meadows. Austral Ecol $30: 210-218$

Temple SA, Cary JR (1988) Modeling dynamics of habitat-interior bird populations in fragmented landscapes. Cons Biol 2:340-347

Tissot BN (2008) Video analysis, experimental design, and database management of submersible-based habitat studies. In: Marine Habitat Mapping Technology for Alaska. Reynolds JR, Greene HG (eds) Alaska Sea Grant College Program, University of Alaska Fairbanks

Turner MG (2005) Landscape ecology: what is the state of the science? Annu Rev Ecol Evolut Syst 36:319-344

Turner MG, Gardner RH, O'Neill RV (2001) Landscape ecology in theory and practice: pattern and process. Springer-Verlag, New York 
van Dorp A, Opdam PFM (1987) Effects of patch size, isolation and regional abundance on forest bird assemblages. Landscape Ecol 1:59-73

Vannote RL, Minshall GW (1982) Fluvial processes and local lithology controlling abundance, structure, and composition of mussel beds. Proc Natl Acad Sci U S A 79:4103-4107

Wang L, Lyons J, Rasmussen P, Seelbach P, Simon T, Wiley M, Kanehl P, Baker E, Niemela S, Stewart PM (2003) Watershed, reach, and riparian influences on stream fish assemblages in the Northern Lakes and Forest Ecoregion, U.S.A. Can J Fish Aquat Sci 60:491-505

Ward JV, Tockner K, Schiemer F (1999) Biodiversity of floodplain river ecosystems: ecotones and connectivity. Regul Rivers:Res Mgmt 15:125-139

Wiens JA (1976) Population responses to patchy environments. Annu Rev Ecol Syst $7: 81-120$

Wiens JA (1989) Spatial scaling in ecology. Funct Ecol 3:385-397

Wiens JA, Stenseth NC, Van Horne B, Ims RA (1993) Ecological mechanisms and landscape ecology. Oikos 66:369-380

Wilson EO, Willis EO (1975) Applied biogeography. In: Cody ML, Diamond JM (eds) Ecology and evolution of assemblages. Belknap Press, Cambridge

Wilson SK, Burgess SC, Cheal AJ, Emslie M, Fisher R, Miller E, Polunin NVC, Sweatman HPA (2008) Habitat utilization by coral reef fish: implications for specialists vs. generalists in a changing environment. J Anim Ecol 77:220-228

Winemiller KO, Leslie MA (1992) Fish assemblages across a complex, tropical freshwater/marine ecotone. Envi Biol Fish 34:29-50

With KA, Crist TO (1995) Critical thresholds in species' response to landscape structure. Ecol 76:2446-2459

Woodroffe R, Ginsberg JR (1998) Edge effects and the extinction of populations inside protected areas. Science 280:2126-2128

Yahner RH (1988) Changes in wildlife near edges. Cons Biol 2:333-339

Yoklavich MM, Cailliet GM, Lea RN, Greene HG, Starr RM, De Marignac J, Field J (2002) Deepwater habitat and fish resources associated with the Big Creek Marine Ecological Reserve. CalCOFI Rep 43:120-140 
Yoklavich MM, Greene HG, Cailliet GM, Sullican DE, Lea RN, Love MS (2000) Habitat associations of deep-water rockfishes in a submarine canyon: an example of a natural refuge. Fish Bull 98:625-641

Yoklavich MM, Love MS, Forney KA (2007) A fishery-independent assessment of an overfished rockfish stock, cowcod (Sebastes levis), using direct observations from an occupied submersible. Can J Fish Aquat Sci 64:1795-1804

Yoklavich MM, O’Connell V (2008) Twenty years of research on demersal assemblages using the Delta submersible in the Northeast Pacific. In: Marine Habitat Mapping Technology for Alaska. Reynolds JR, Greene HG (eds) Alaska Sea Grant College Program, University of Alaska Fairbanks 


\section{Appendices}

Appendix A Species observed near Point Lobos and Point Sur, by abundance and percentage abundance. Species in bold, individually make up more than $1 \%$ of the total abundance

\begin{tabular}{|c|c|c|c|c|c|}
\hline & & \multicolumn{2}{|c|}{ Lobos } & \multicolumn{2}{|c|}{ Sur } \\
\hline Scientific Name & Common Name & Abundance & Percentage & Abundance & Percentage \\
\hline Agonidae & Poacher & 1 & $0.00 \%$ & 1 & $0.01 \%$ \\
\hline Anarrhichthys ocellatus & Wolf Eel & 0 & $0.00 \%$ & 1 & $0.01 \%$ \\
\hline Bathymasteridae & Ronquil & 17 & $0.08 \%$ & 15 & $0.22 \%$ \\
\hline Citharichthys sordidus & Sanddab & 5 & $0.02 \%$ & 1 & $0.01 \%$ \\
\hline Cottidae & Sculpin & 12 & $0.05 \%$ & 1 & $0.01 \%$ \\
\hline Damalichthys vacca & Pile Surfperch & 25 & $0.11 \%$ & 12 & $0.18 \%$ \\
\hline Embiotoca jacksoni & Black Surfperch & 9 & $0.04 \%$ & 2 & $0.03 \%$ \\
\hline Embiotoca lateralis & Striped Surfperch & 11 & $0.05 \%$ & 1 & $0.01 \%$ \\
\hline Hexagrammos decagrammus & Kelp Greenling & 34 & $0.15 \%$ & 15 & $0.22 \%$ \\
\hline Hydrolagus colliei & Ratfish & 7 & $0.03 \%$ & 1 & $0.01 \%$ \\
\hline Pleuronectiformes & Flatfishes & 4 & $0.02 \%$ & 1 & $0.01 \%$ \\
\hline NA & Unidentified & 78 & $0.35 \%$ & 22 & $0.32 \%$ \\
\hline Odontopyxis trispinosa & Pygmy Poacher & 1 & $0.00 \%$ & 0 & $0.00 \%$ \\
\hline Ophiodon elongatus & Lingcod & 27 & $0.12 \%$ & 27 & $0.40 \%$ \\
\hline Oxyjulis californica & Senorita & 9 & $0.04 \%$ & 0 & $0.00 \%$ \\
\hline Oxylebius pictus & Painted Greenling & 321 & $1.45 \%$ & 284 & $4.16 \%$ \\
\hline Phanerodon spp. & Surfperch & 46 & $0.21 \%$ & 6 & $0.09 \%$ \\
\hline Phanerodon atripes & Sharpnose Seaperch & 5 & $0.02 \%$ & 1 & $0.01 \%$ \\
\hline Phanerodon furcatus & White Seaperch & 36 & $0.16 \%$ & 0 & $0.00 \%$ \\
\hline Pholidae & Gunnel & 6 & $0.03 \%$ & 4 & $0.06 \%$ \\
\hline Raja binoculata & Big Skate & 1 & $0.00 \%$ & 0 & $0.00 \%$ \\
\hline Rathbunella hypoplecta & Stripedfin Ronquil & 7 & $0.03 \%$ & 9 & $0.13 \%$ \\
\hline Rhacochilus toxotes & Rubberlip Surfperch & 7 & $0.03 \%$ & 2 & $0.03 \%$ \\
\hline Rhinogobiops nicholsii & Blackeye Goby & 3698 & $16.65 \%$ & 1179 & $17.26 \%$ \\
\hline Scorpaena guttata & Striped Scorpionfish & 1 & $0.00 \%$ & 0 & $0.00 \%$ \\
\hline Scorpaenichthys marmoratus & Cabezon & 0 & $0.00 \%$ & 1 & $0.01 \%$ \\
\hline Sebastes atrovirens & Kelp Rockfish & 2 & $0.01 \%$ & 0 & $0.00 \%$ \\
\hline Sebastes carnatus & Gopher Rockfish & 139 & $0.63 \%$ & 144 & $2.11 \%$ \\
\hline Sebastes caurinus & Copper Rockfish & 21 & $0.09 \%$ & 21 & $0.31 \%$ \\
\hline Sebastes chlorostictus & Greenspot Rockfish & 27 & $0.12 \%$ & 8 & $0.12 \%$ \\
\hline Sebastes constellatus & Starry Rockfish & 256 & $1.15 \%$ & 51 & $0.75 \%$ \\
\hline Sebastes emphaeus & Puget Rockfish & 9 & $0.04 \%$ & 2 & $0.03 \%$ \\
\hline Sebastes ensifer & Swordspine Rockfish & 7 & $0.03 \%$ & 1 & $0.01 \%$ \\
\hline Sebastes entomelas & Widow Rockfish & 362 & $1.63 \%$ & 385 & $5.64 \%$ \\
\hline Sebastes flavidus & Yellowtail Rockfish & 91 & $0.41 \%$ & 129 & $1.89 \%$ \\
\hline Sebastes helvomaculatus & Rosethorn Rockfish & 1 & $0.00 \%$ & 0 & $0.00 \%$ \\
\hline Sebastes hopkinsi & Squarespot Rockfish & 1749 & $7.87 \%$ & 1559 & $22.82 \%$ \\
\hline Sebastes jordani & Shortbelly Rockfish & 1 & $0.00 \%$ & 0 & $0.00 \%$ \\
\hline Sebastes maliger & Quillback Rockfish & 7 & $0.03 \%$ & 0 & $0.00 \%$ \\
\hline Sebastes melanops & Black Rockfish & 0 & $0.00 \%$ & 1 & $0.01 \%$ \\
\hline Sebastes miniatus & Vermilion Rockfish & 53 & $0.24 \%$ & 83 & $1.22 \%$ \\
\hline Sebastes moseri & Whitespeckeled Rockfish & 0 & $0.00 \%$ & 1 & $0.01 \%$ \\
\hline
\end{tabular}




\begin{tabular}{llcccc} 
Sebastes mystinus & Blue Rockfish & $\mathbf{5 0 1}$ & $\mathbf{2 . 2 6 \%}$ & $\mathbf{1 4 9}$ & $\mathbf{2 . 1 8 \%}$ \\
Sebastes nebulosus & China Rockfish & 31 & $0.14 \%$ & 8 & $0.12 \%$ \\
Sebastes ovalis & Speckled Rockfish & 9 & $0.04 \%$ & 4 & $0.06 \%$ \\
Sebastes paucispinis & Bocaccio & 21 & $0.09 \%$ & 4 & $0.06 \%$ \\
Sebastes pinniger & Canary Rockfish & 41 & $0.18 \%$ & 11 & $0.16 \%$ \\
Sebastes rosaceus & Rosy Rockfish & $\mathbf{1 4 8 3}$ & $\mathbf{6 . 6 8 \%}$ & $\mathbf{7 2 6}$ & $\mathbf{1 0 . 6 3 \%}$ \\
Sebastes ruberrimus & Yelloweye Rockfish & 3 & $0.01 \%$ & 5 & $0.07 \%$ \\
Sebastes rufus & Bank Rockfish & 10 & $0.05 \%$ & 0 & $0.00 \%$ \\
Sebastes semicinctus & Halfbanded Rockfish & 161 & $0.72 \%$ & 7 & $0.10 \%$ \\
Sebastes serranoides & Olive Rockfish & $\mathbf{2 5 3}$ & $\mathbf{1 . 1 4 \%}$ & $\mathbf{1 6 8}$ & $\mathbf{2 . 4 6 \%}$ \\
Sebastes serriceps & Treefish & 1 & $0.00 \%$ & 1 & $0.01 \%$ \\
Sebastes spp & Rockfish & $\mathbf{6 1 3 4}$ & $\mathbf{2 7 . 6 2 \%}$ & $\mathbf{1 4 6 5}$ & $\mathbf{2 1 . 4 5 \%}$ \\
Sebastes wilsoni & Pygmy Rockfish & $\mathbf{6 2 2 5}$ & $\mathbf{2 8 . 0 3 \%}$ & $\mathbf{7 6}$ & $\mathbf{1 . 1 1 \%}$ \\
Sebastes zacentrus & Sharpchin Rockfish & 1 & $0.00 \%$ & 0 & $0.00 \%$ \\
Sebastomus spp & Sebastomus & $\mathbf{2 2 1}$ & $\mathbf{1 . 0 0 \%}$ & $\mathbf{2 3 6}$ & $\mathbf{3 . 4 5 \%}$ \\
Stichaeidae & Prickleback & 6 & $0.03 \%$ & 0 & $0.00 \%$ \\
Torpedo Californica & Pacific Electric Ray & 1 & $0.00 \%$ & 0 & $0.00 \%$ \\
Zalembius rosaceus & Pink Surfperch & 9 & $0.04 \%$ & 0 & $0.00 \%$ \\
Zaniolepis frenata & Shortspine Combfish & 6 & $0.03 \%$ & 0 & $0.00 \%$ \\
\hline
\end{tabular}


Appendix B Length-weight parameters obtained from published, peer-reviewed literature that were used during this study. The listed units are from the original publication. Sources of each parameter, or the proxy species used, are listed

\begin{tabular}{|c|c|c|c|c|c|}
\hline Scientific Names & Common Names & $\mathbf{a}$ & $\overline{\mathbf{b}}$ & units & Sources \\
\hline Agonidae & Poacher & 0.003 & 3.206 & $\mathrm{~g} / \mathrm{cm}$ & Glubokov \& Orlov 2007 (Percis japonica , Sarritor frenatus ) \\
\hline Anarrhichthys ocellatus & Wolf Eel & 0.050 & 3.091 & $\mathrm{~kg} / \mathrm{mm}$ & Karpov 1986 \\
\hline Citharichthys sordidus & Sanddab & 0.000 & 3.260 & $\mathrm{~g} / \mathrm{mm}$ & Rackowski\& Pikitch 1989 \\
\hline Cottidae & Sculpin & 0.055 & 3.160 & $\mathrm{~g} / \mathrm{mm}$ & Stokley 1952 \\
\hline Damalichthys vacca & Pile Surfperch & 0.000 & 3.135 & $\mathrm{~g} / \mathrm{mm}$ & DeMartini et al. 1994 \\
\hline Embiotoca jacksoni & Black Surfperch & 0.001 & 2.864 & $\mathrm{~g} / \mathrm{mm}$ & Froeschke et al 2007 \\
\hline Embiotoca lateralis & Striped Surfperch & 0.154 & 3.010 & $\mathrm{~kg} / \mathrm{mm}$ & Karpov 1986 \\
\hline Hexagrammos decagrammus & Kelp Greenling & 0.016 & 3.000 & $\mathrm{~g} / \mathrm{cm}$ & Fishbase \\
\hline Hydrolagus colliei & Ratfish & 0.002 & 2.755 & $\mathrm{~kg} / \mathrm{mm}$ & Barnet 2008 \\
\hline Icelinus tenuis & Spotfin Sculpin & 0.179 & 2.896 & $\mathrm{~kg} / \mathrm{mm}$ & Karpov 1986 \\
\hline Microstomus pacificus & Dover Sole & 0.002 & 3.436 & $\mathrm{~g} / \mathrm{cm}$ & NOAA-TM-AFSC-89 \\
\hline Pleuronectiformes & Flatfishes & 0.004 & 3.223 & $\mathrm{~g} / \mathrm{cm}$ & NOAA-TM-AFSC-89 \\
\hline Odontopyxis trispinosa & Pygmy Poacher & 0.003 & 3.206 & $\mathrm{~g} / \mathrm{cm}$ & Glubokov \& Orlov 2007 \\
\hline Ophiodon elongatus & Lingcod & 0.002 & 3.390 & $\mathrm{~g} / \mathrm{cm}$ & Pikitch \& Rogers 1989 \\
\hline Oxyjulis californica & Senorita & 0.000 & 3.500 & $\mathrm{~g} / \mathrm{mm}(\mathrm{SL})$ & Eschmeyer 1998 \\
\hline Oxylebius pictus & Painted Greenling & 0.032 & 3.384 & $\mathrm{~g} / \mathrm{mm}$ & deMartini \& Anderson \\
\hline Phanerodon spp. & Surfperch & 0.100 & 3.192 & $\mathrm{~kg} / \mathrm{mm}$ & Karpov 1986 \\
\hline Phanerodon atripes & Sharpnose Seaperch & 0.100 & 3.192 & $\mathrm{~kg} / \mathrm{mm}$ & Karpov 1986 \\
\hline Phanerodon furcatus & White Seaperch & 0.001 & 2.996 & $\mathrm{~g} / \mathrm{mm}$ & Quast 1968b; Antrim 1981 \\
\hline Pholidae & Gunnel & 0.007 & 3.249 & $\mathrm{~g} / \mathrm{cm}$ & Fishbase \\
\hline Raja binoculata & Big Skate & 0.050 & 3.106 & $\mathrm{~kg} / \mathrm{mm}$ & Ebert et al. 2008 \\
\hline Raja rhina & Longnose Skate & 0.060 & 3.091 & $\mathrm{~kg} / \mathrm{mm}$ & Ebert et al. 2008 \\
\hline Raja spp. & Skates & 0.004 & 3.181 & $\mathrm{~g} / \mathrm{cm}$ & Moutopoulos \& Stergiou 2002 (Raja miraletus , Raja radula ) \\
\hline Rathbunella hypoplecta & Stripedfin Ronquil & NA & NA & NA & $\mathrm{NA}$ \\
\hline Rhacochilus toxotes & Rubberlip Surfperch & 0.000 & 3.360 & $\mathrm{~g} / \mathrm{mm}(\mathrm{SL})$ & Quast 1968b \\
\hline Rhamphocottus richardsonii & Grunt Sculpin & 0.179 & 2.896 & $\mathrm{~kg} / \mathrm{mm}$ & Karpov 1986 \\
\hline Rhinogobiops nicholsii & Blackeye Goby & 0.000 & 3.470 & $\mathrm{mg} / \mathrm{mm}$ & Mesa 1999 (Aphia minuta , Crystallogobius linearis ) \\
\hline Scorpaena guttata & Striped Scorpionfish & 0.020 & 3.007 & $\mathrm{~g} / \mathrm{cm}$ & Love et al 1987 \\
\hline Scorpaenichthys marmoratus & Cabezon & 0.029 & 3.000 & $\mathrm{~g} / \mathrm{cm}$ & Fishbase \\
\hline Sebastes atrovirens & Kelp Rockfish & 0.000 & 3.172 & $\mathrm{~g} / \mathrm{mm}$ & Lea et al. 1999 \\
\hline Sebastes carnatus & Gopher Rockfish & 0.027 & 3.000 & $\mathrm{~g} / \mathrm{cm}$ & Fishbase \\
\hline Sebastes caurinus & Copper Rockfish & 0.018 & 3.040 & $\mathrm{~g} / \mathrm{cm}$ & Fishbase; Haldstorm \& Love 1991 \\
\hline Sebastes chlorostictus & Greenspot Rockfish & 0.000 & 3.001 & $\mathrm{~g} / \mathrm{mm}$ & Love 1987 \\
\hline Sebastes constellatus & Starry Rockfish & 0.016 & 3.160 & $\mathrm{~g} / \mathrm{cm}$ & Fishbase; Haldstorm \& Love 1991 \\
\hline Sebastes elongatus & Greenstripe Rockfish & 0.008 & 3.144 & $\mathrm{~g} / \mathrm{cm}$ & NOAA-TM-AFSC-89 \\
\hline Sebastes emphaeus & Puget Rockfish & 0.059 & 2.687 & $\mathrm{~g} / \mathrm{cm}$ & Fishbase \\
\hline Sebastes ensifer & Swordspine Rockfish & 0.013 & 2.970 & $\mathrm{~g} / \mathrm{cm}$ & Love 1987 \\
\hline Sebastes entomelas & Widow Rockfish & 0.005 & 3.341 & $\mathrm{~g} / \mathrm{cm}$ & Pikitch \& Rogers 1989 \\
\hline Sebastes flavidus & Yellowtail Rockfish & 0.013 & 3.055 & $\mathrm{~g} / \mathrm{cm}$ & Pikitch \& Rogers 1989 \\
\hline Sebastes helvomaculatus & Rosethorn Rockfish & 0.010 & 3.119 & $\mathrm{~g} / \mathrm{cm}$ & NOAA-TM-AFSC-89 \\
\hline Sebastes hopkinsi & Squarespot Rockfish & 0.015 & 2.964 & $\mathrm{~g} / \mathrm{cm}$ & Love 1987 \\
\hline Sebastes jordani & Shortbelly Rockfish & 0.014 & 3.152 & NA & NA \\
\hline Sebastes levis & Cowcod & 0.014 & 3.093 & $\mathrm{~g} / \mathrm{cm}$ & Fishbase; Haldstorm \& Love 1991 \\
\hline Sebastes maliger & Quillback Rockfish & 0.030 & 3.000 & $\mathrm{~g} / \mathrm{cm}$ & Fishbase \\
\hline Sebastes melanops & Black Rockfish & 0.021 & 3.286 & $\mathrm{~g} / \mathrm{cm}$ & Fishbase; Haldstorm \& Love 1991 \\
\hline Sebastes miniatus & Vermilion Rockfish & 0.033 & 2.923 & $\mathrm{~g} / \mathrm{cm}$ & Fishbase; Haldstorm \& Love 1991 \\
\hline Sebastes moseri & Whitespeckeled Rockfis & 0.014 & 3.152 & NA & NA \\
\hline Sebastes mystinus & Blue Rockfish & 0.017 & 2.808 & $\mathrm{~g} / \mathrm{cm}$ & Fishbase; Haldstorm \& Love 1991 \\
\hline Sebastes nebulosus & China Rockfish & 0.023 & 3.000 & $\mathrm{~g} / \mathrm{cm}$ & Fishbase \\
\hline Sebastes ovalis & Speckled Rockfish & 0.006 & 3.177 & $\mathrm{~g} / \mathrm{cm}$ & Love 1987 \\
\hline Sebastes paucispinis & Bocaccio & 0.008 & 3.199 & $\mathrm{~g} / \mathrm{cm}$ & Pikitch \& Rogers 1989 \\
\hline Sebastes pinniger & Canary Rockfish & 0.012 & 3.107 & $\mathrm{~g} / \mathrm{cm}$ & Pikitch \& Rogers 1989 \\
\hline Sebastes rosaceus & Rosy Rockfish & 0.005 & 3.386 & $\mathrm{~g} / \mathrm{cm}$ & Love 1987 \\
\hline Sebastes ruberrimus & Yelloweye Rockfish & 0.014 & 3.000 & $\mathrm{~g} / \mathrm{cm}$ & Fishbase \\
\hline Sebastes rubrivinctus & Flag Rockfish & 0.015 & 3.000 & $\mathrm{~g} / \mathrm{cm}$ & Fishbase \\
\hline Sebastes rufus & Bank Rockfish & 0.015 & 3.147 & $\mathrm{~g} / \mathrm{cm}$ & Fishbase; Haldstorm \& Love 1991 \\
\hline Sebastes semicinctus & Halfbanded Rockfish & 0.014 & 2.977 & $\mathrm{~g} / \mathrm{cm}$ & Haldstorm \& Love 1991 \\
\hline Sebastes serranoides & Olive Rockfish & 0.011 & 2.968 & $\mathrm{~g} / \mathrm{cm}$ & Fishbase \\
\hline Sebastes serriceps & Treefish & 0.005 & 3.341 & $\mathrm{~g} / \mathrm{cm}$ & Pikitch \& Rogers 1989 \\
\hline Sebastes spp. & Rockfish & 0.014 & 3.154 & NA & NA \\
\hline Sebastes wilsoni & Pygmy Rockfish & 0.014 & 3.154 & NA & NA \\
\hline Sebastes zacentrus & Sharpchin Rockfish & 0.006 & 3.282 & $\mathrm{~g} / \mathrm{cm}$ & NOAA-TM-AFSC-89 \\
\hline Sebastomus spp. & Sebastomus & 0.000 & 3.293 & $\mathrm{~g} / \mathrm{mm}$ & Rogers at al 1998, Ianelli et al. 1994, Miller 1985 \\
\hline Stichaeidae & Prickleback & 0.024 & 3.303 & $\mathrm{~g} / \mathrm{cm}$ & LeDrew \& Green 1975 \\
\hline Torpedo Californica & Pacific Electric Ray & 0.030 & 2.948 & $\mathrm{~g} / \mathrm{mm}$ & Neer \& Cailliet 2001 \\
\hline Zalembius rosaceus & Pink Surfperch & 0.100 & 3.192 & $\mathrm{~kg} / \mathrm{mm}$ & Karpov 1986 \\
\hline Zaniolepis frenata & Shortspine Combfish & 0.003 & 3.323 & $\mathrm{~g} / \mathrm{cm}$ & Rodriguez-Romero et al 2009 (Zaniolepis latipinnis ) \\
\hline Zaniolepis spp. & Combfish & 0.003 & 3.323 & $\mathrm{~g} / \mathrm{cm}$ & Rodriguez-Romero et al 2009 (Zaniolepis latipinnis ) \\
\hline
\end{tabular}


Appendix C Equations and definitions of the diversity variables used in species composition calculations

Bray-Curtis Index of Similarity
\[ B C_{i j}=\frac{S_{i}+S_{j}-2 C_{i j}}{S_{i}+S_{j}} \quad \begin{array}{l}C_{i j} \text { - sum of minimum abundance of the various species } \\ S_{j} \text { - total number of individuals in sample i }\end{array} \]

Heterogeneity (Shannon-Weiner) $\quad S \quad n_{i}$-number of individuals in species i

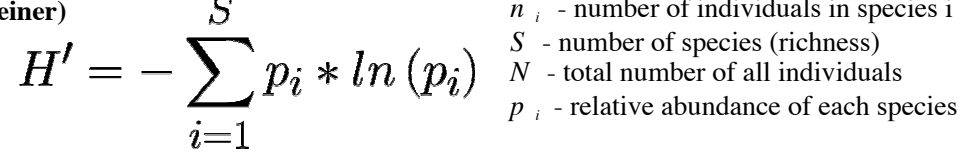

Evenness (Pielou)

$$
E=\frac{H^{\prime}}{H_{\max }}
$$

$\mathrm{H}^{\prime}$ - species heterogeneity

$\mathrm{H}$ max - maximum value of $\mathrm{H}^{\prime}$ :

$$
H_{\text {max }}=-\sum_{i=1}^{S} \frac{1}{S} * \ln \left(\frac{1}{S}\right)=\ln (S)
$$


Appendix D Frequency histograms of the independent habitat variables per rocky bank patch near Point Lobos and Point Sur. The mean depth (a), rugosity (b), P:A ratio (c), and area $(d)$ per patch near Point Lobos $(n=24)$ and near Point Sur $(n=13)$
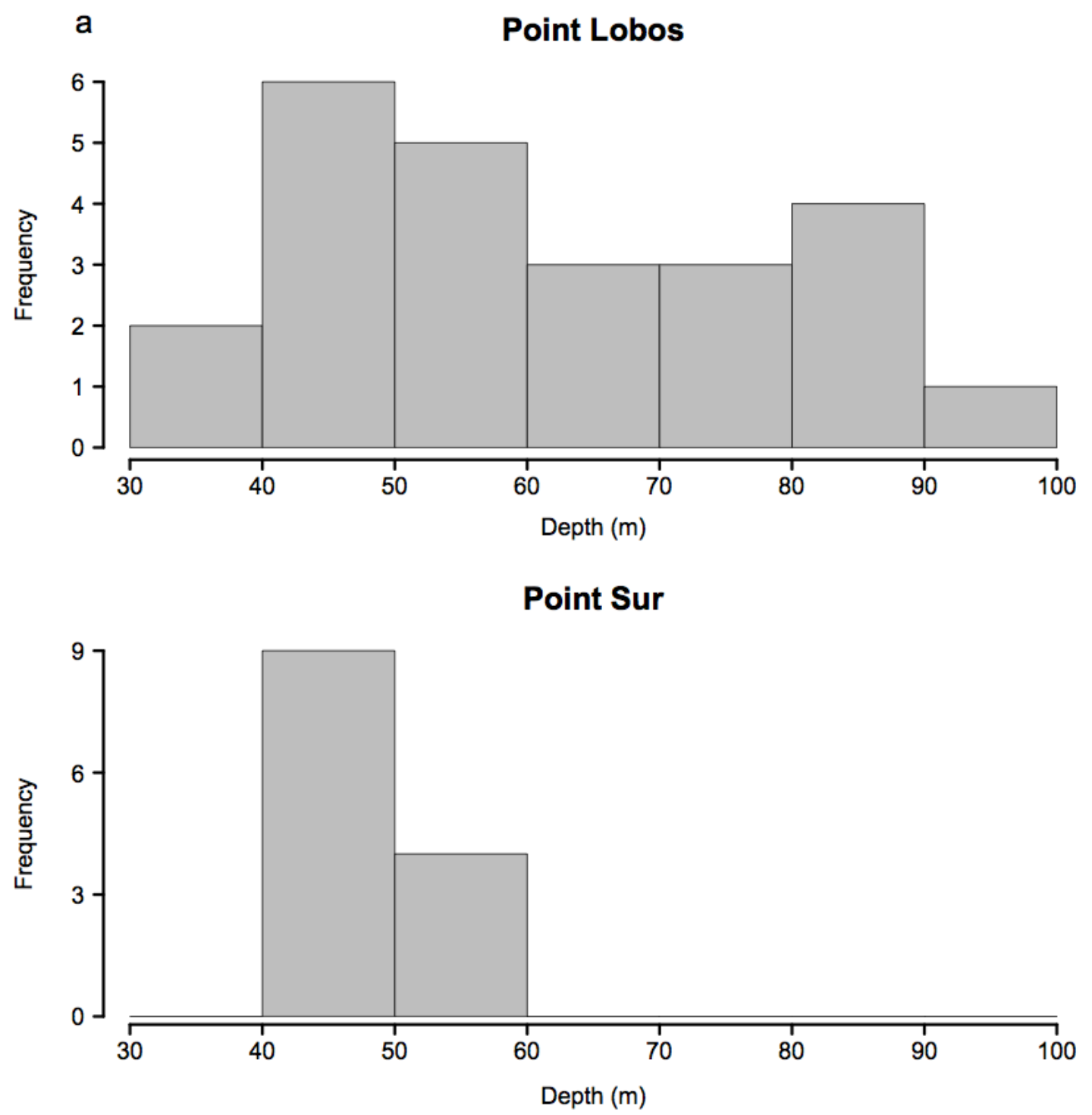


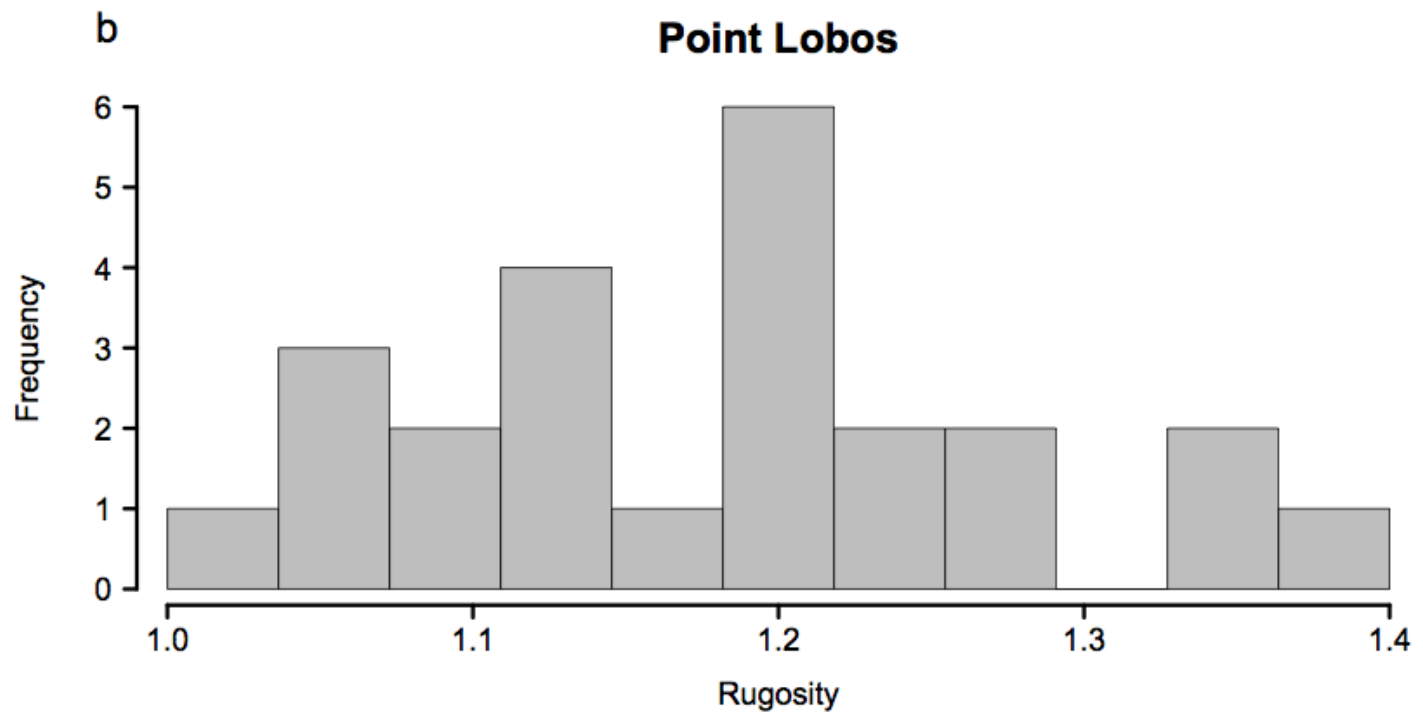

Point Sur

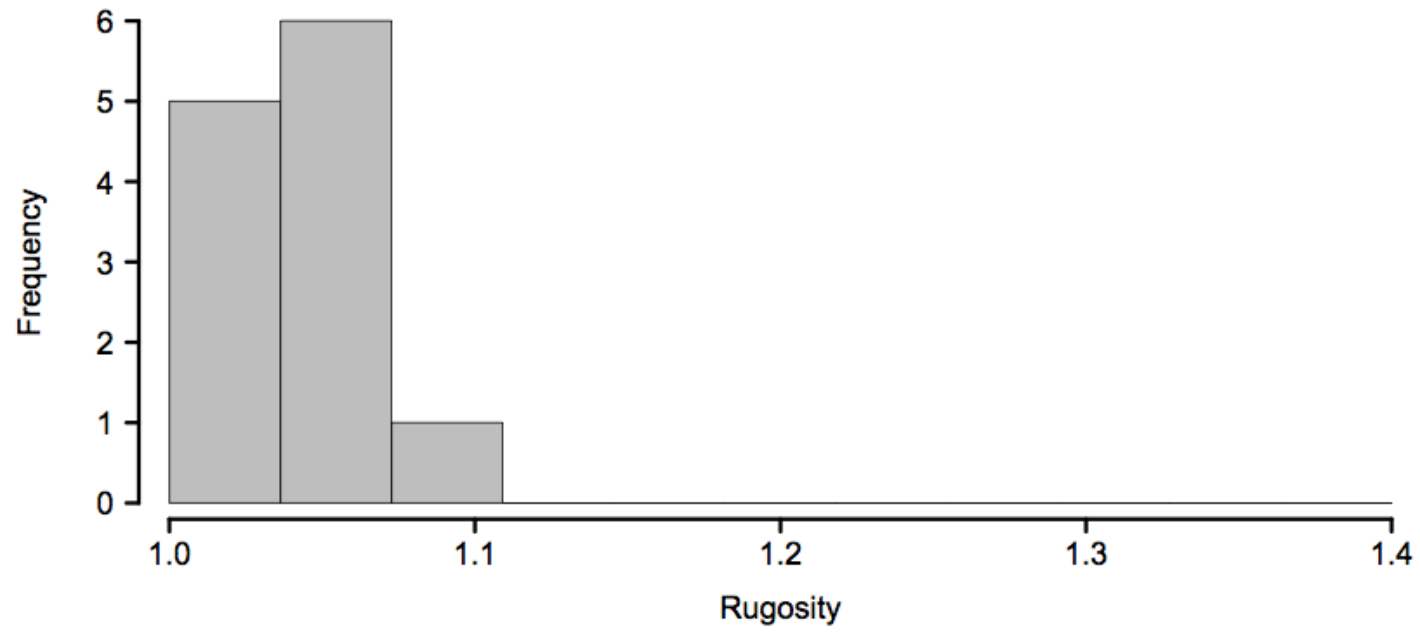




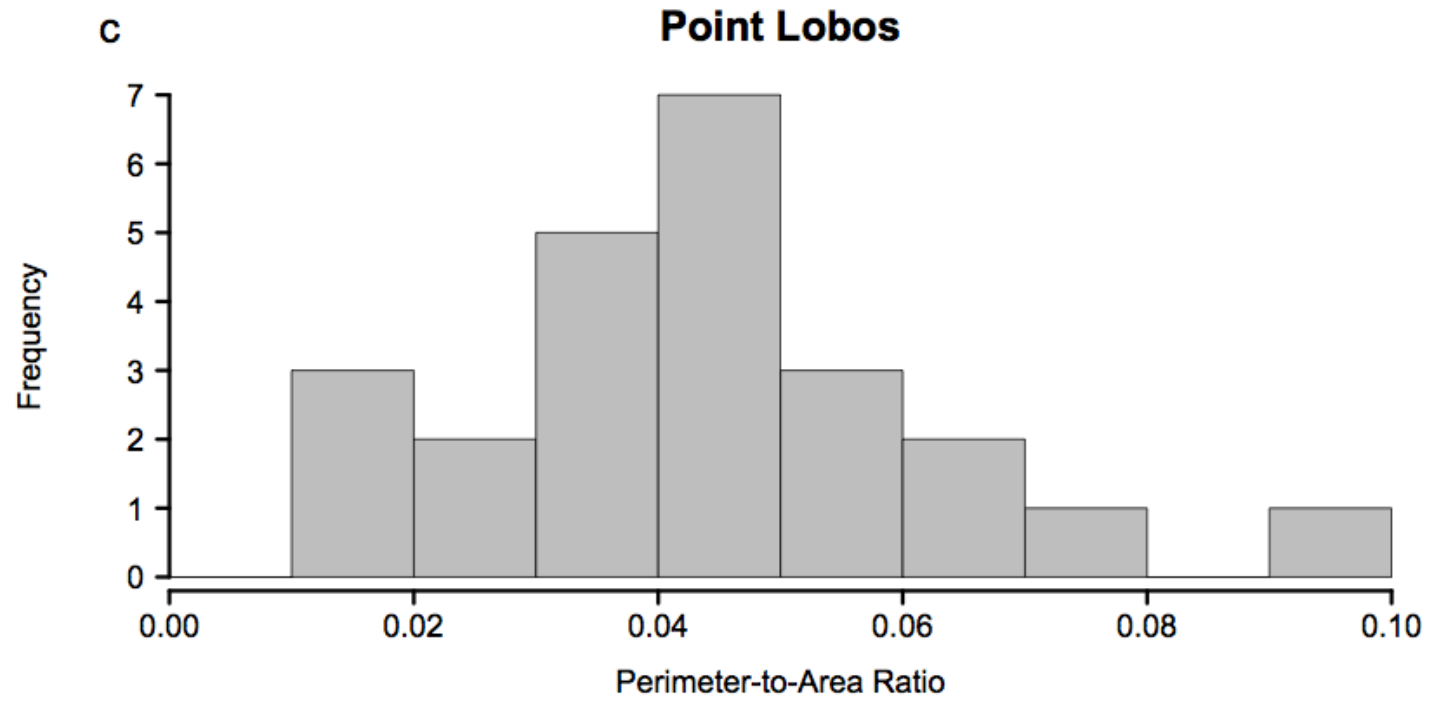

Point Sur

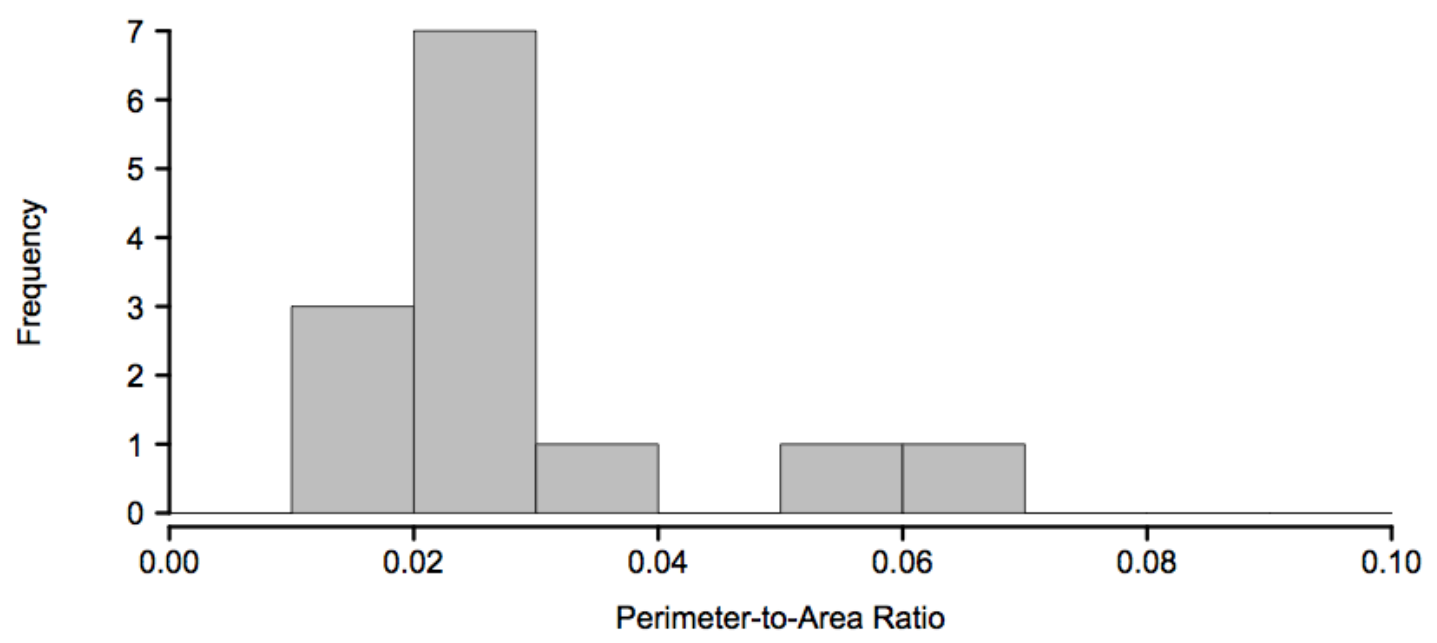



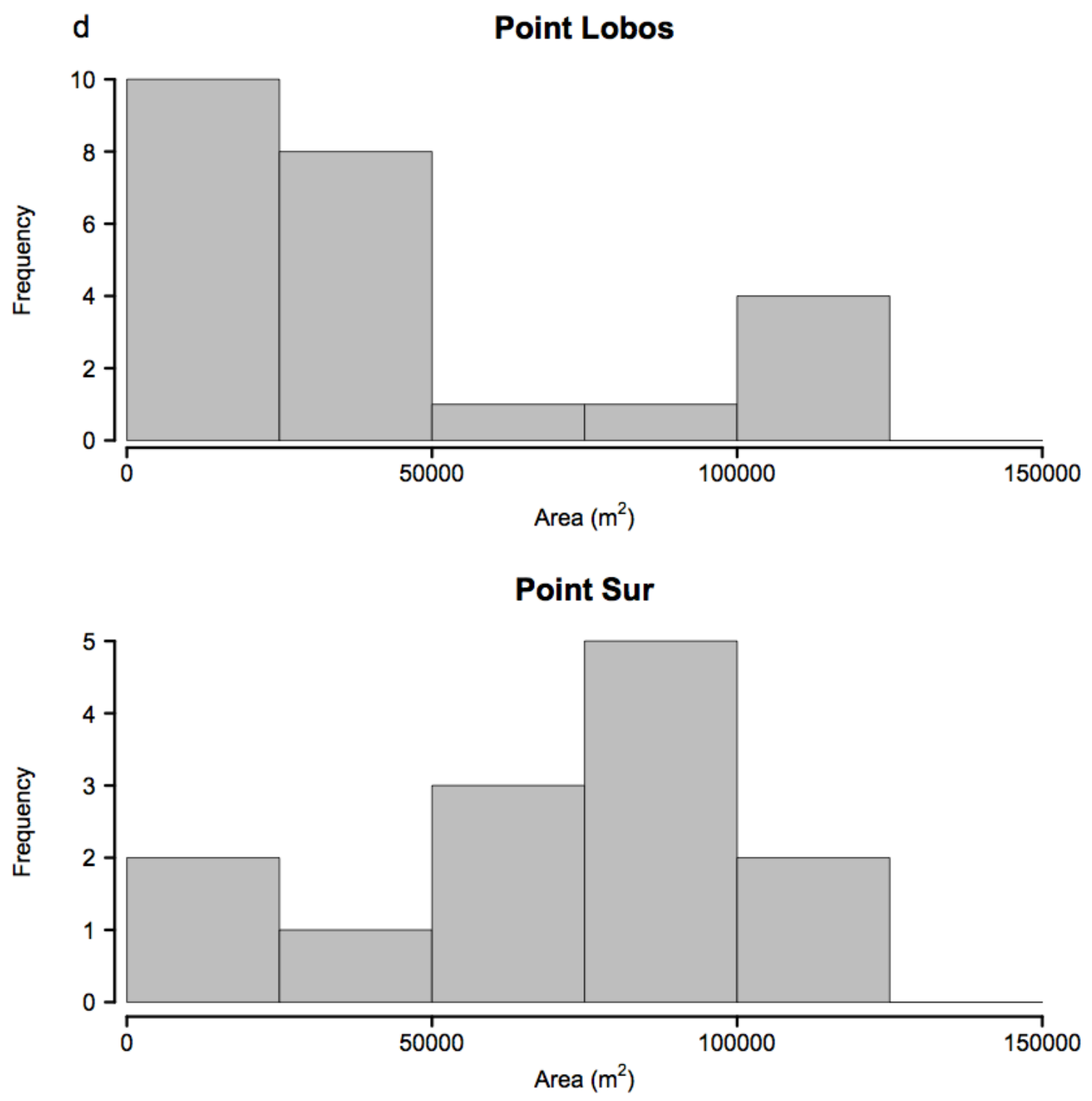
Appendix E Species-accumulation curves and comparisons of standard error and coefficient of variation of density. The results are reported for species richness with depth (a) and comparisons of standard error and coefficient of variation of density for shallow and deep rocky bank patches (b-c) near Point Lobos (1) and shallow depths near Point Lobos and Point Sur (2 e-g). The slope through the final four points, to determine if an asymptote was reached, are included in the tables for near Point Lobos (1 d) and near Point Sur $(2 \mathrm{~h})$. Open circles denote $75 \%$ of the total number of species observed and filled circles denote $90 \%$ of the total number of species observed

1) Point Lobos shallow and deep
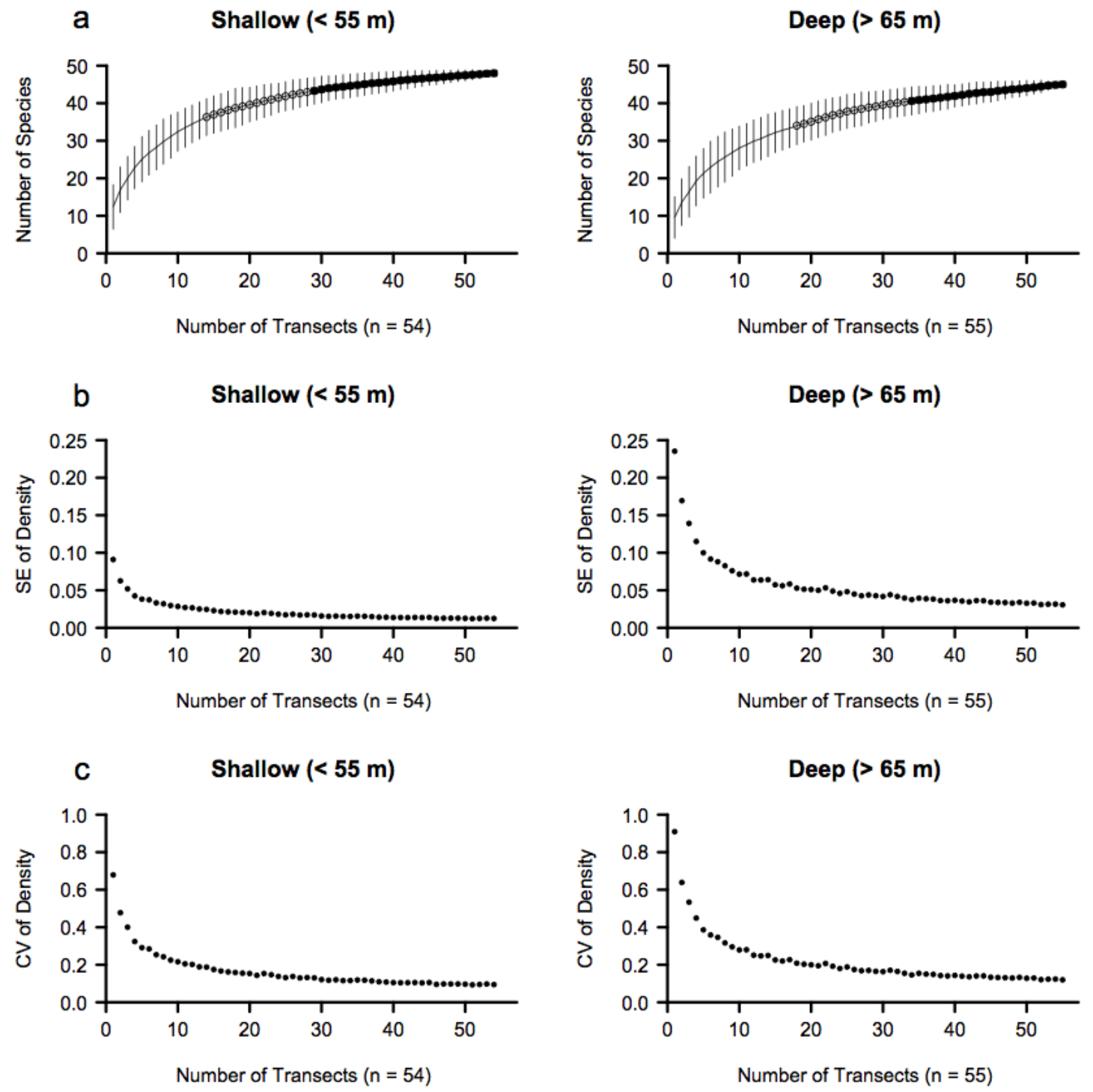


\begin{tabular}{lcccc}
\hline \multicolumn{1}{c}{ Index } & \multicolumn{2}{c}{ Shallow } & \multicolumn{2}{c}{ Deep } \\
\hline Richness & Slope & Asymptote? & Slope & Asymptote? \\
Standard Error (Density) & 0.173 & No & 0.140 & No \\
Coefficient of Variation (Density) & $<-0.001$ & Yes & $<-0.001$ & Yes \\
\hline
\end{tabular}

2) Point Lobos and Point Sur (shallow)
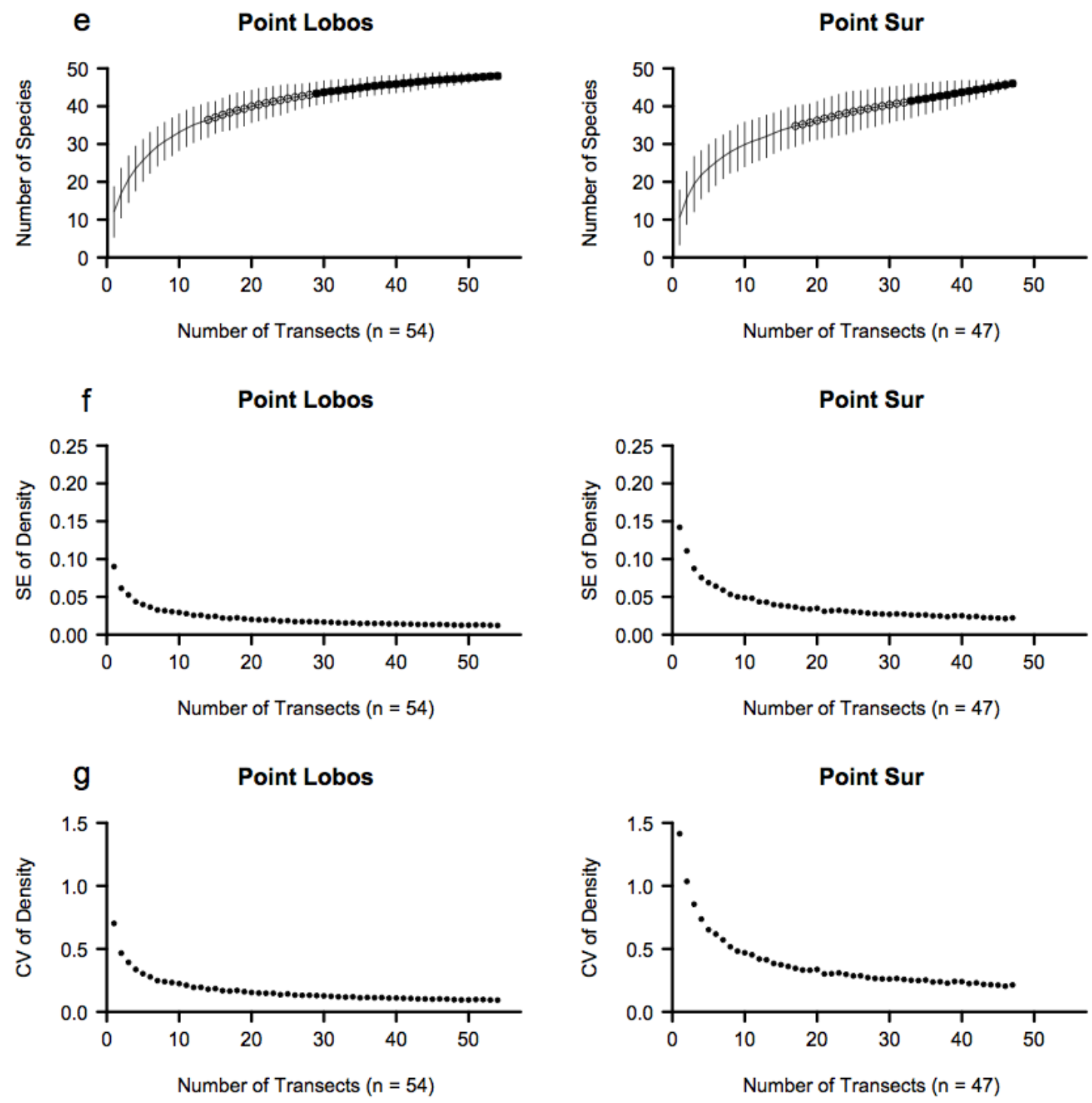


\begin{tabular}{lcccc}
\hline $\mathrm{h}$ & \multicolumn{2}{c}{ Point Lobos } & \multicolumn{2}{c}{ Point Sur } \\
\hline \multicolumn{1}{c}{ Index } & Slope & Asymptote? & Slope & Asymptote? \\
\hline Richness & 0.130 & No & 0.240 & No \\
Standard Error (Density) & $<0.001$ & Yes & $<-0.001$ & Yes \\
Coefficient of Variation (Density) & $<0.001$ & Yes & -0.002 & Yes \\
\hline
\end{tabular}


Appendix F Biological response variables of nearshore fish assemblage with respect to depth and rugosity near Point Lobos. These results are grouped by the (1) assemblage, (2) species groups, and (3) the species-specific analyses. Assemblage relationships of density (a), biomass (b), richness (c), evenness (d), and heterogeneity (e) with respect to depth are reported. In addition, the relationships among rugosity with the assemblage density (f), biomass (g), richness (h), evenness (i), and heterogeneity (j) are reported. Species-group relationships for the density ( $\mathrm{k}$ ) and length distributions (l) with respect to depth and rugosity (respectively, $\mathrm{m}-\mathrm{n}$ ) are reported. Species-specific relationships of density (o), biomass (p), mean length (q), and length distributions (r) with respect to depth are reported. Species-specific relationships among rugosity with respect to density $(\mathrm{s})$, biomass $(\mathrm{t})$, mean length $(\mathrm{u})$, and length distributions (v) are reported. Gray denotes the shallow depth category and black denotes the deep depth category. Asterisks indicate size classes in which fish were observed in abundances too small to be observed on the relative frequency histograms. Standard error is plotted as vertical bars. Significant linear relationships are denoted with dashed regression lines. P-values, and when applicable, $r^{2}$ values are included in the legends

\section{Assemblage}
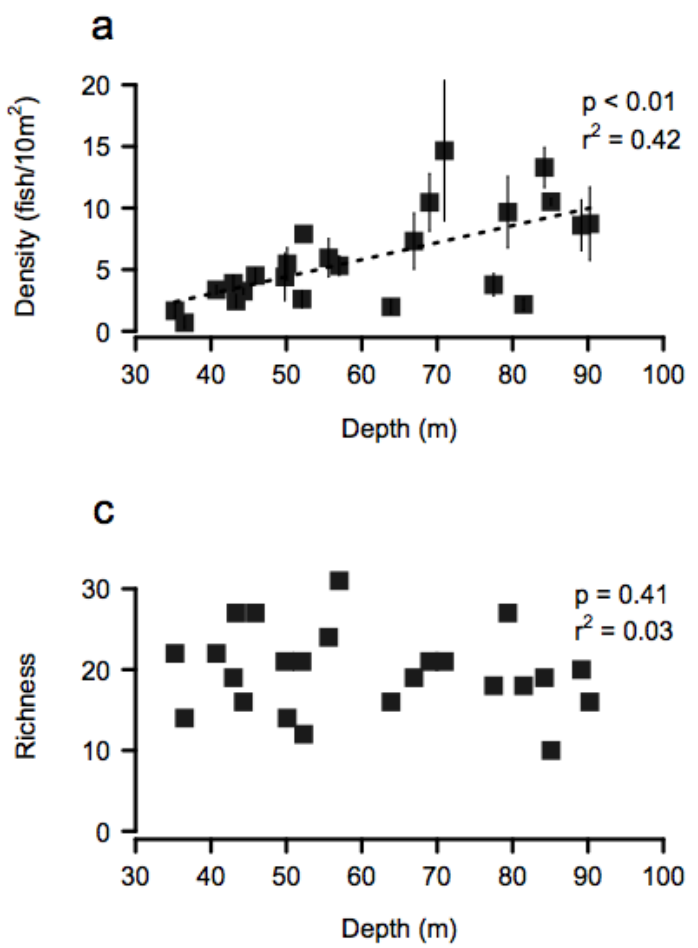
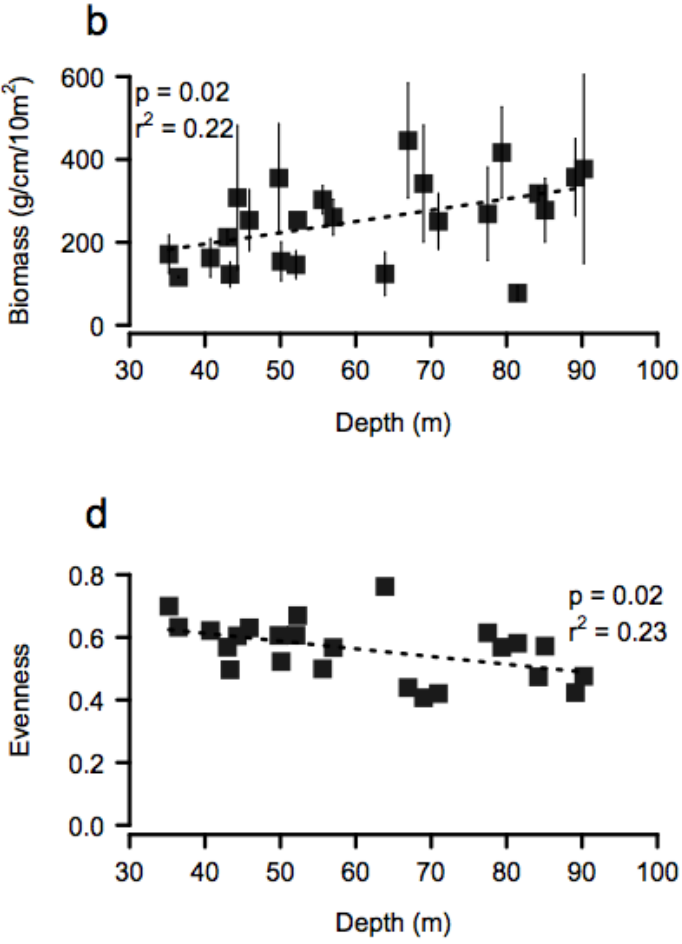

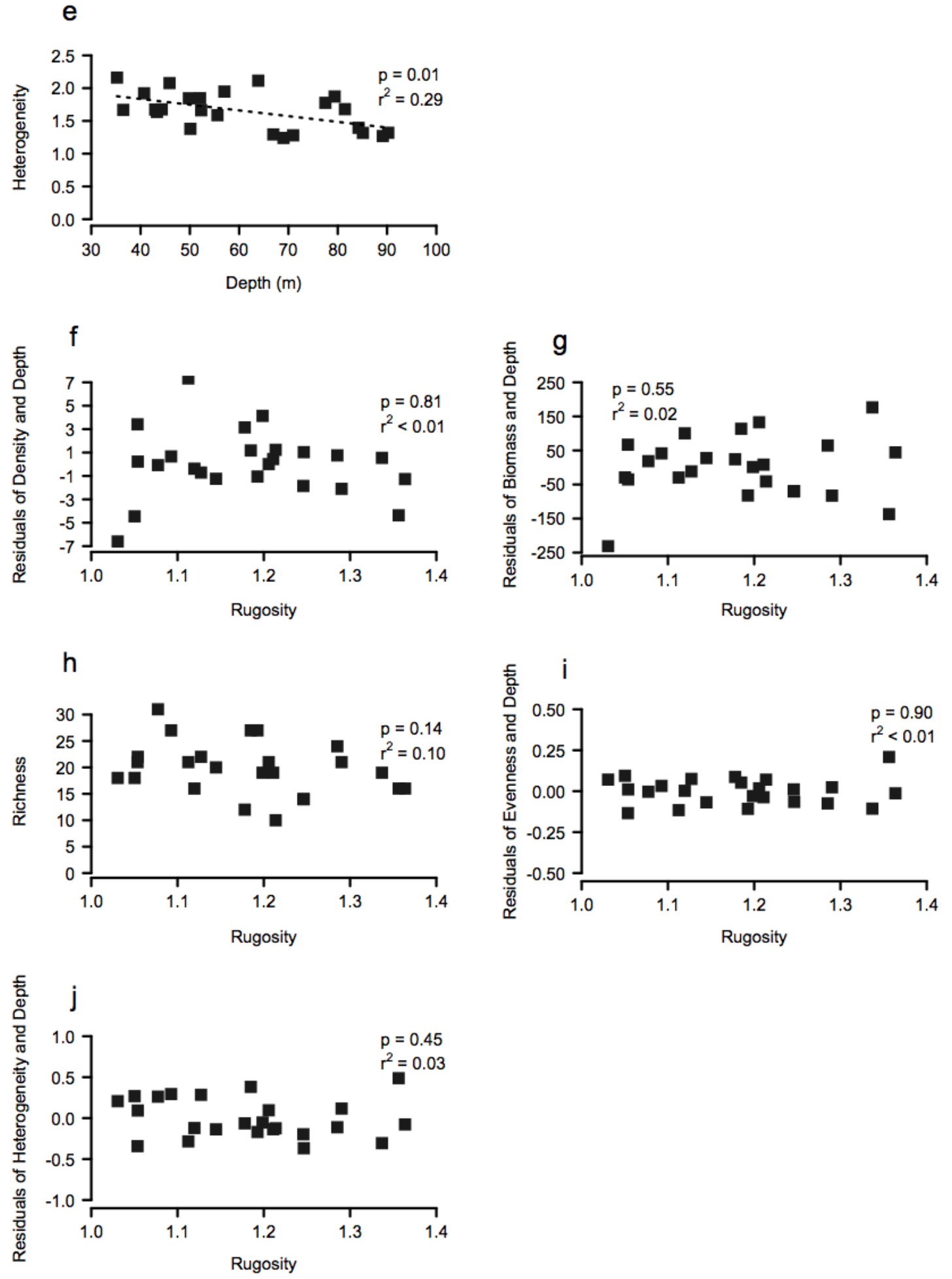

2. Species groups 


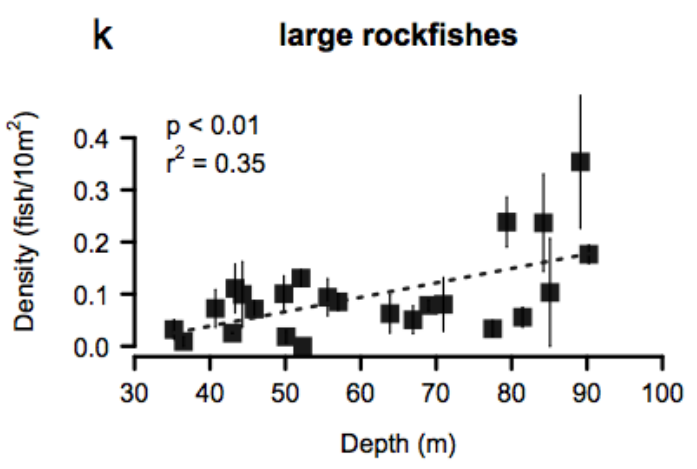

large non-rockfishes

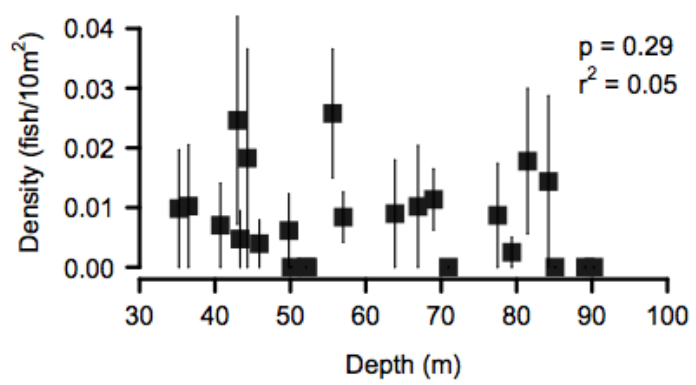

I large rockfishes

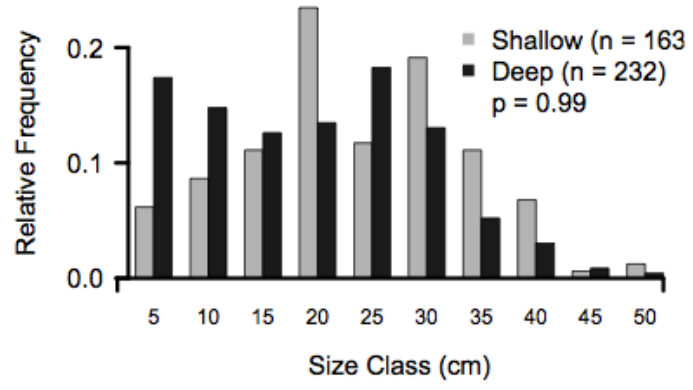

large non-rockfishes

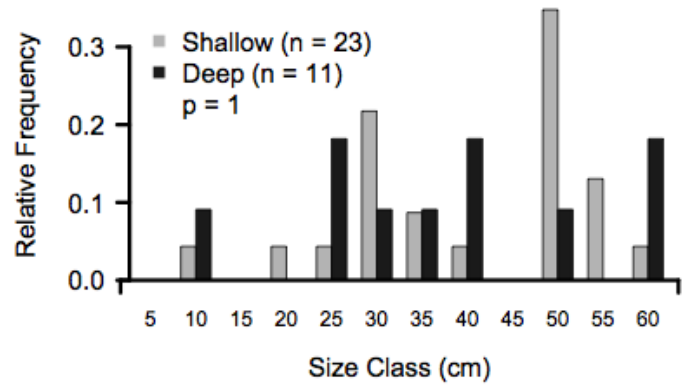

dwarf rockfishes

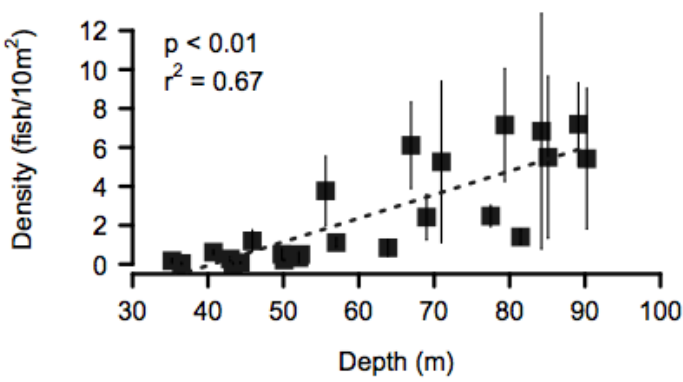

other benthic fishes

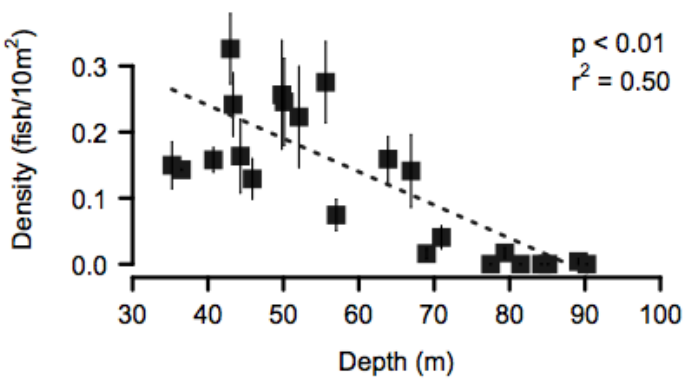

dwarf rockfishes

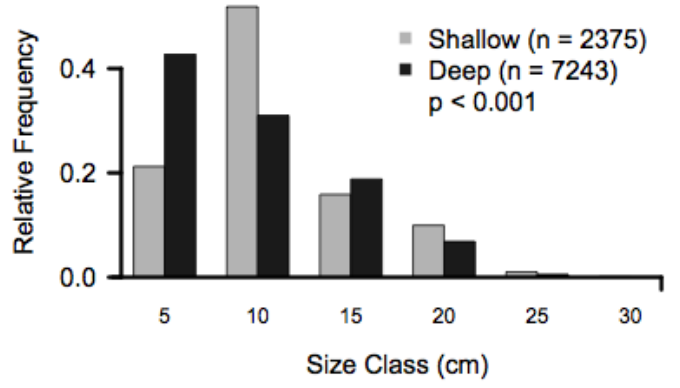

other benthic fishes

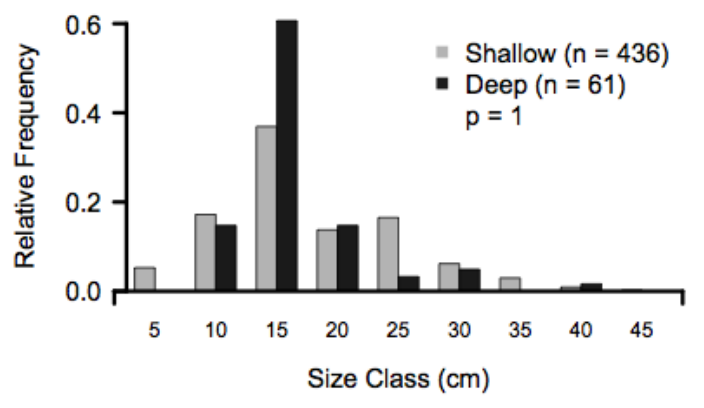



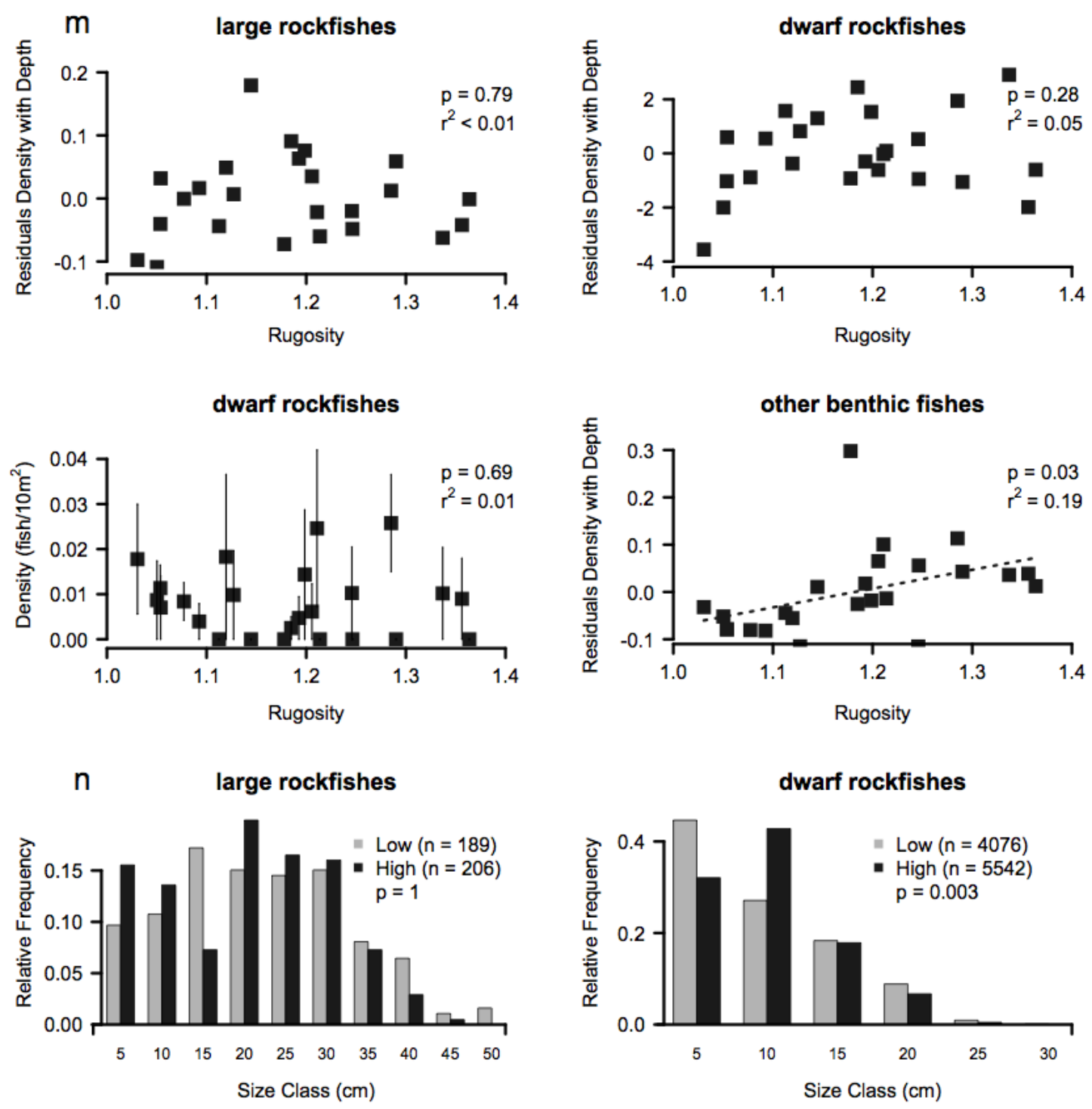

large non-rockfishes
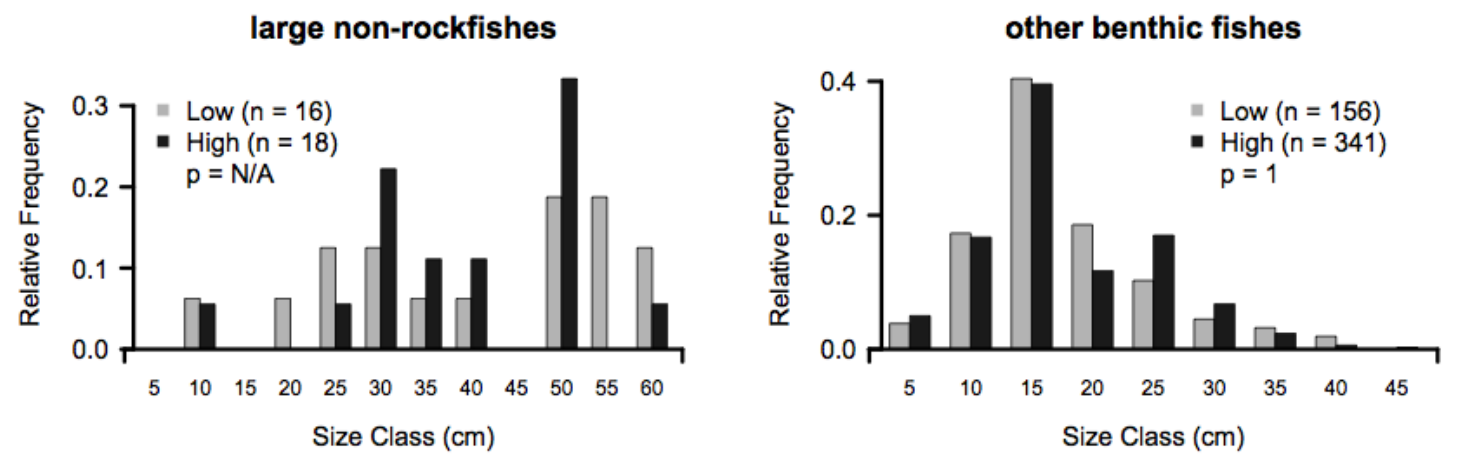

3. Specific species 


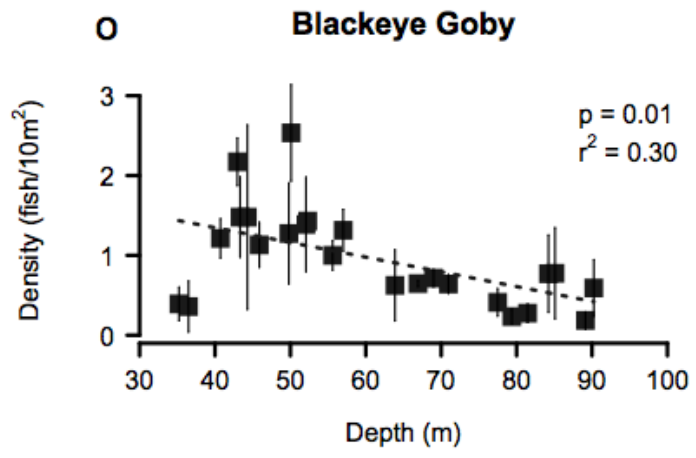

Painted Greenling

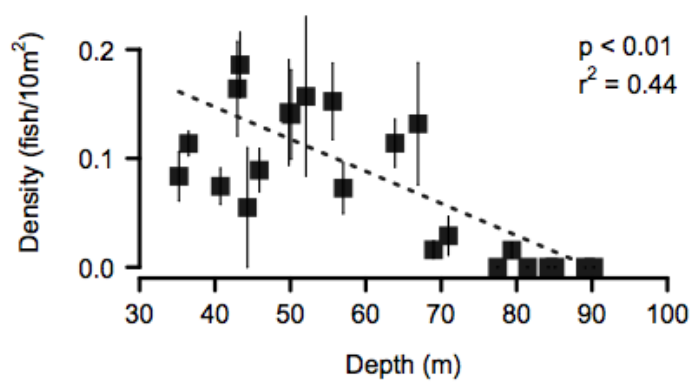

Rosy Rockfish

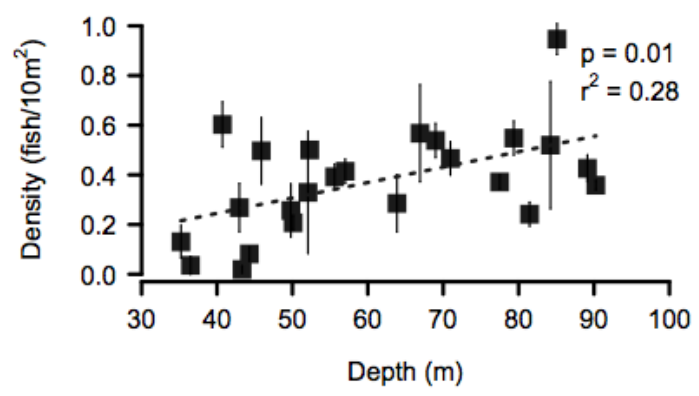

Starry Rockfish

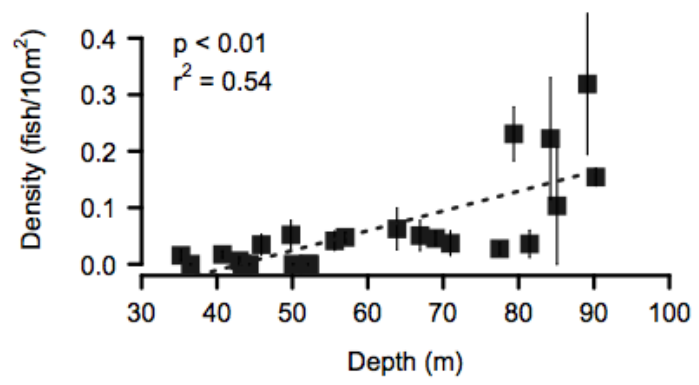

Blue Rockfish

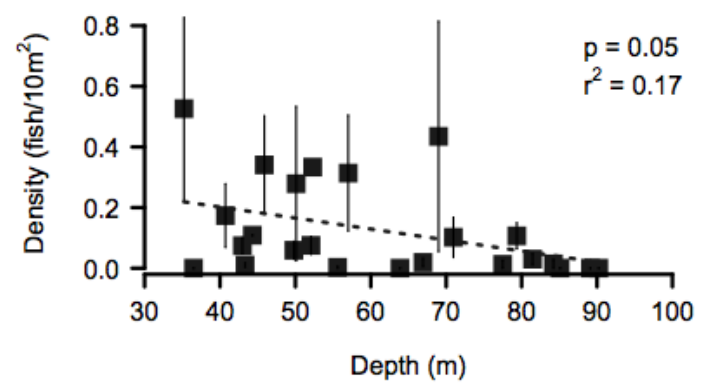

Pygmy Rockfish

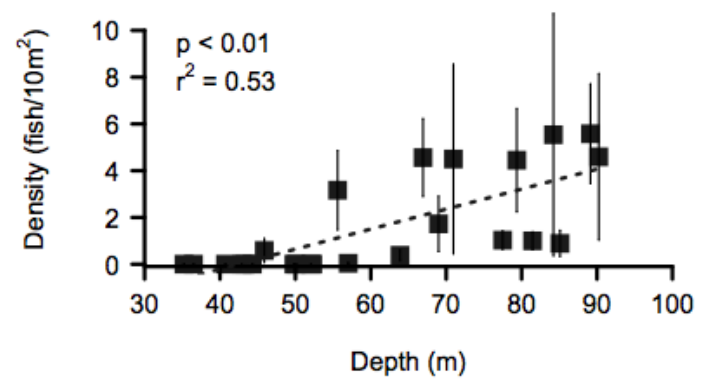

Squarespot Rockfish

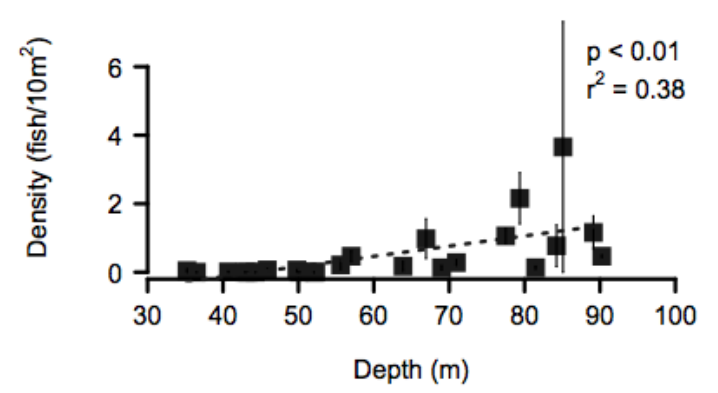




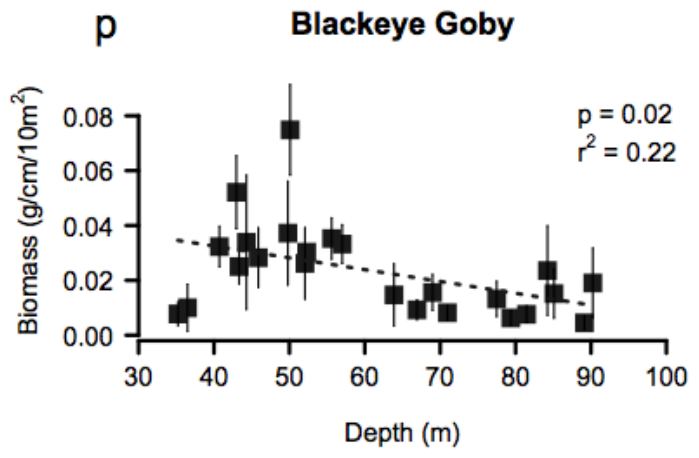

Painted Greenling

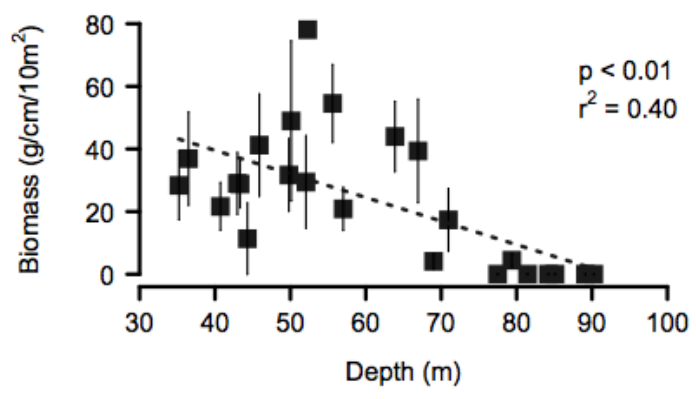

Rosy Rockfish

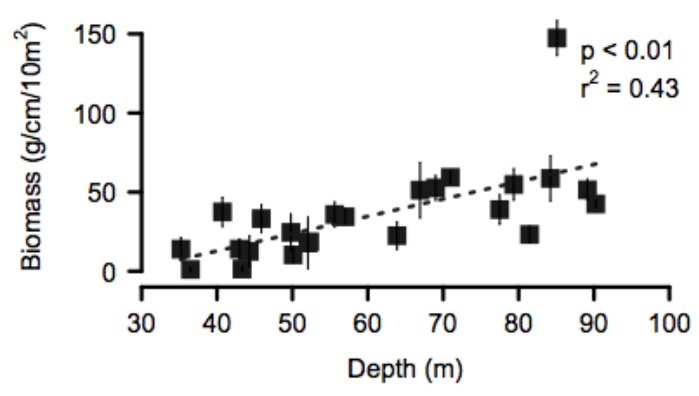

Starry Rockfish

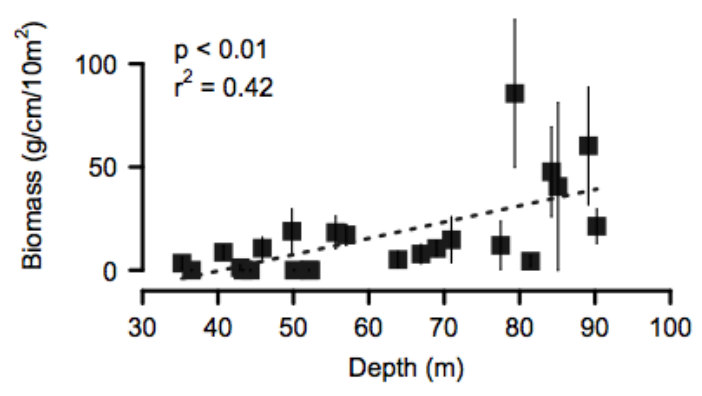

Blue Rockfish

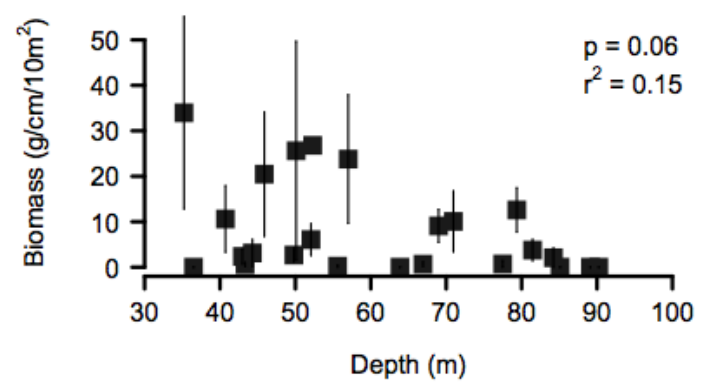

Pygmy Rockfish

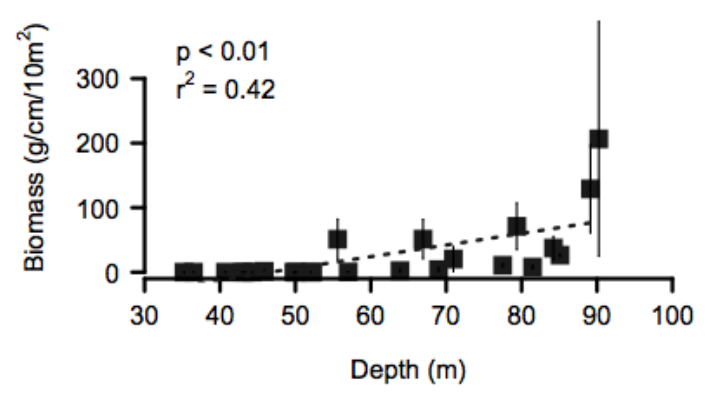

Squarespot Rockfish

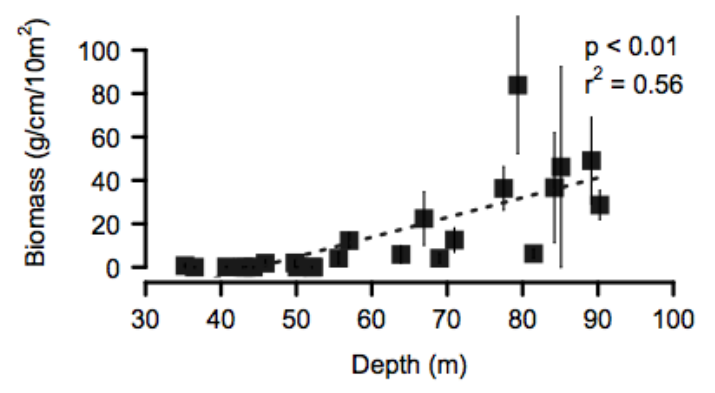




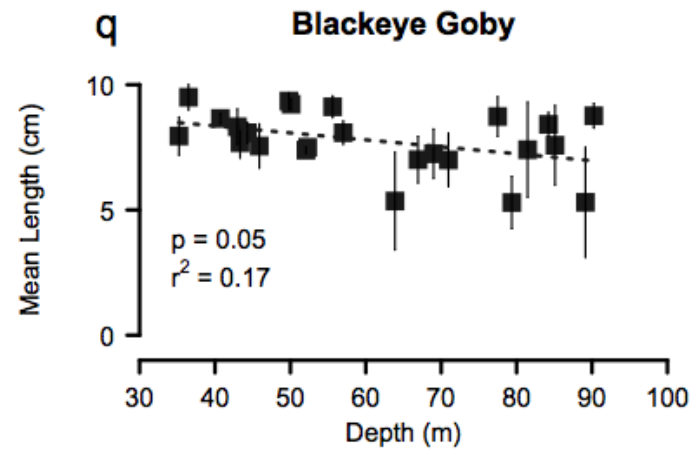

Painted Greenling

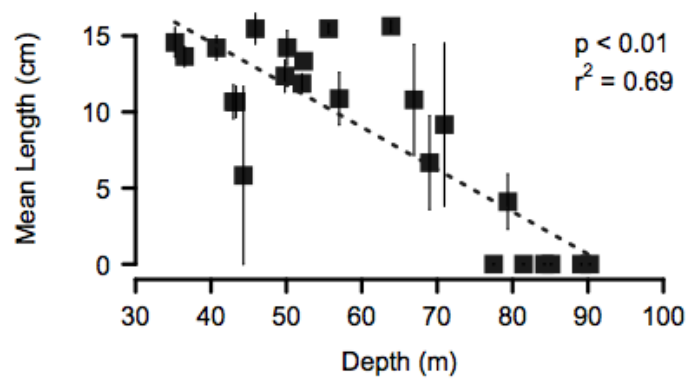

Rosy Rockfish

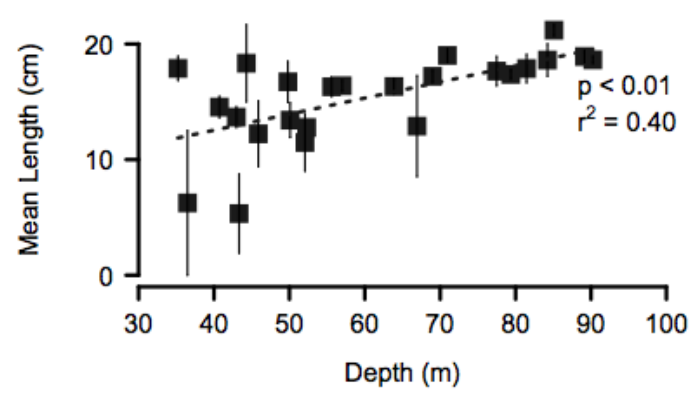

Starry Rockfish

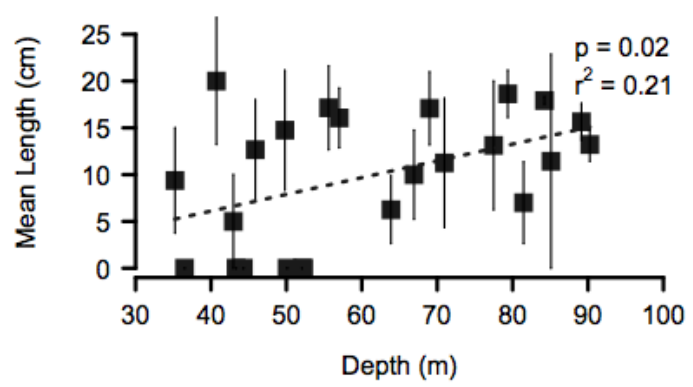

Blue Rockfish

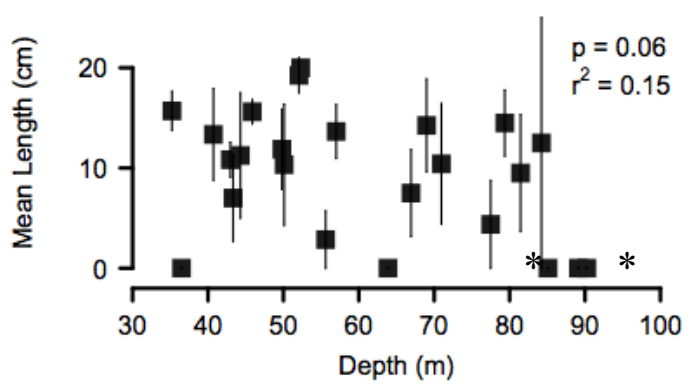

Pygmy Rockfish

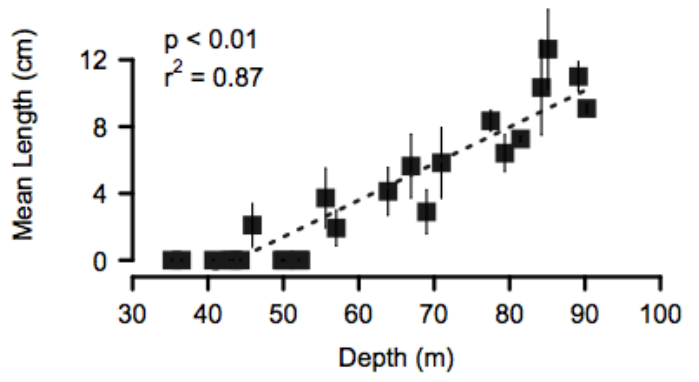

Squarespot Rockfish

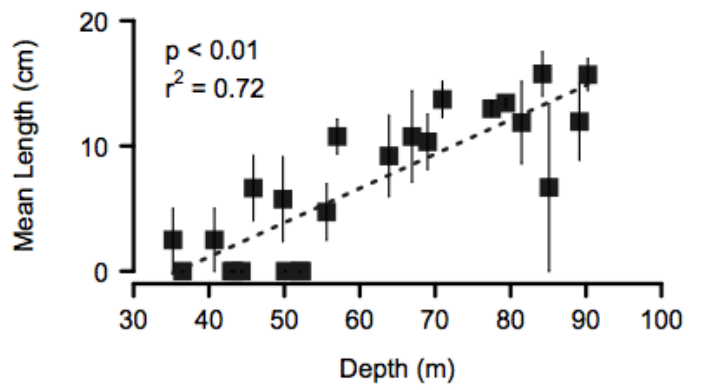




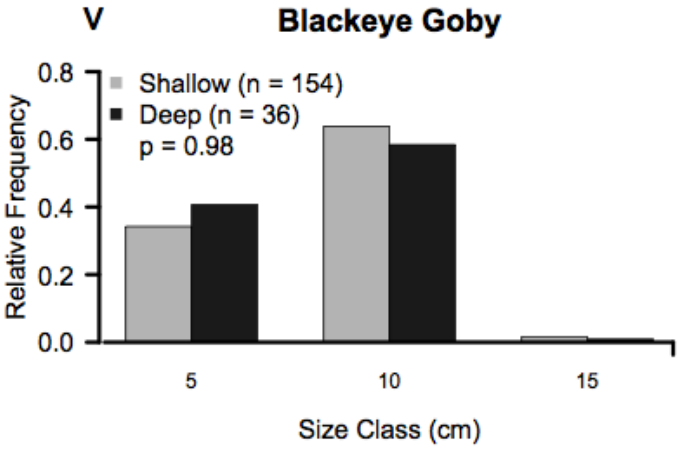

Painted Greenling

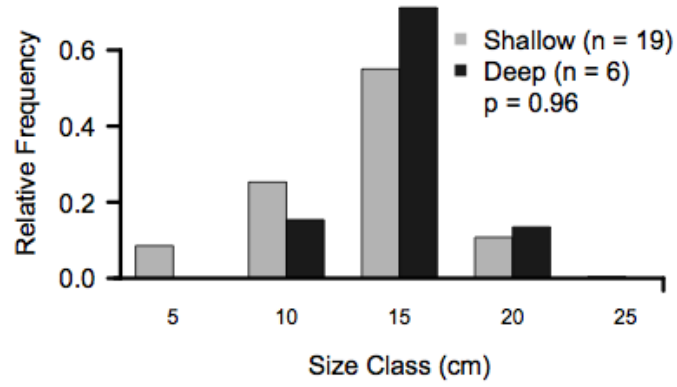

Rosy Rockfish

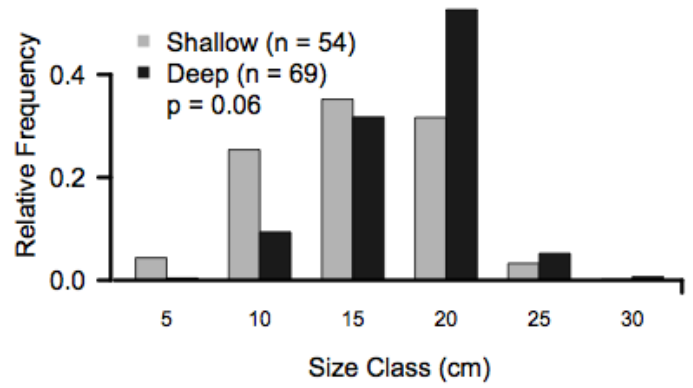

Starry Rockfish

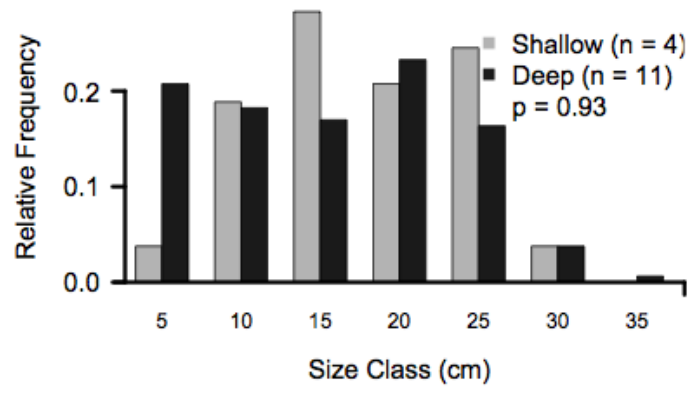

Blue Rockfish

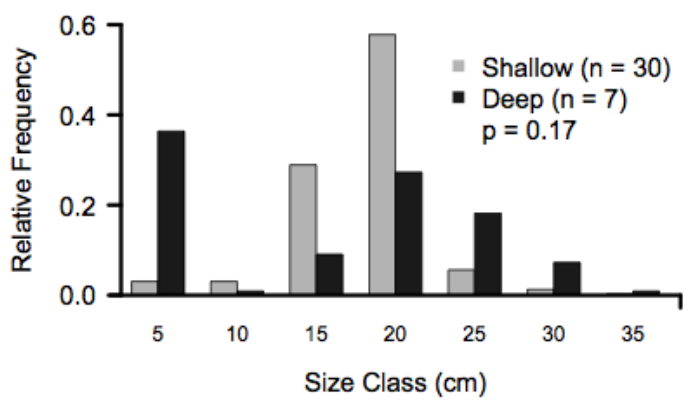

Pygmy Rockfish

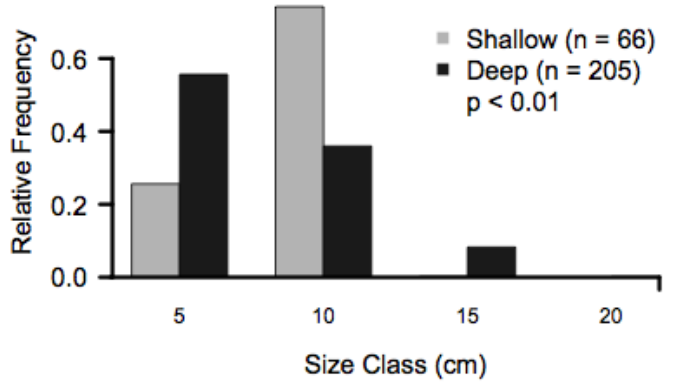

Squarespot Rockfish

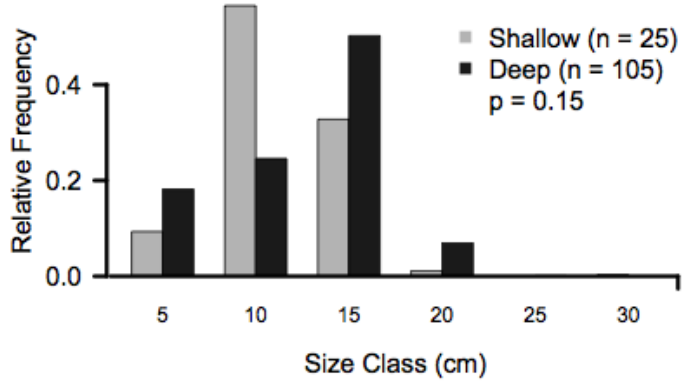



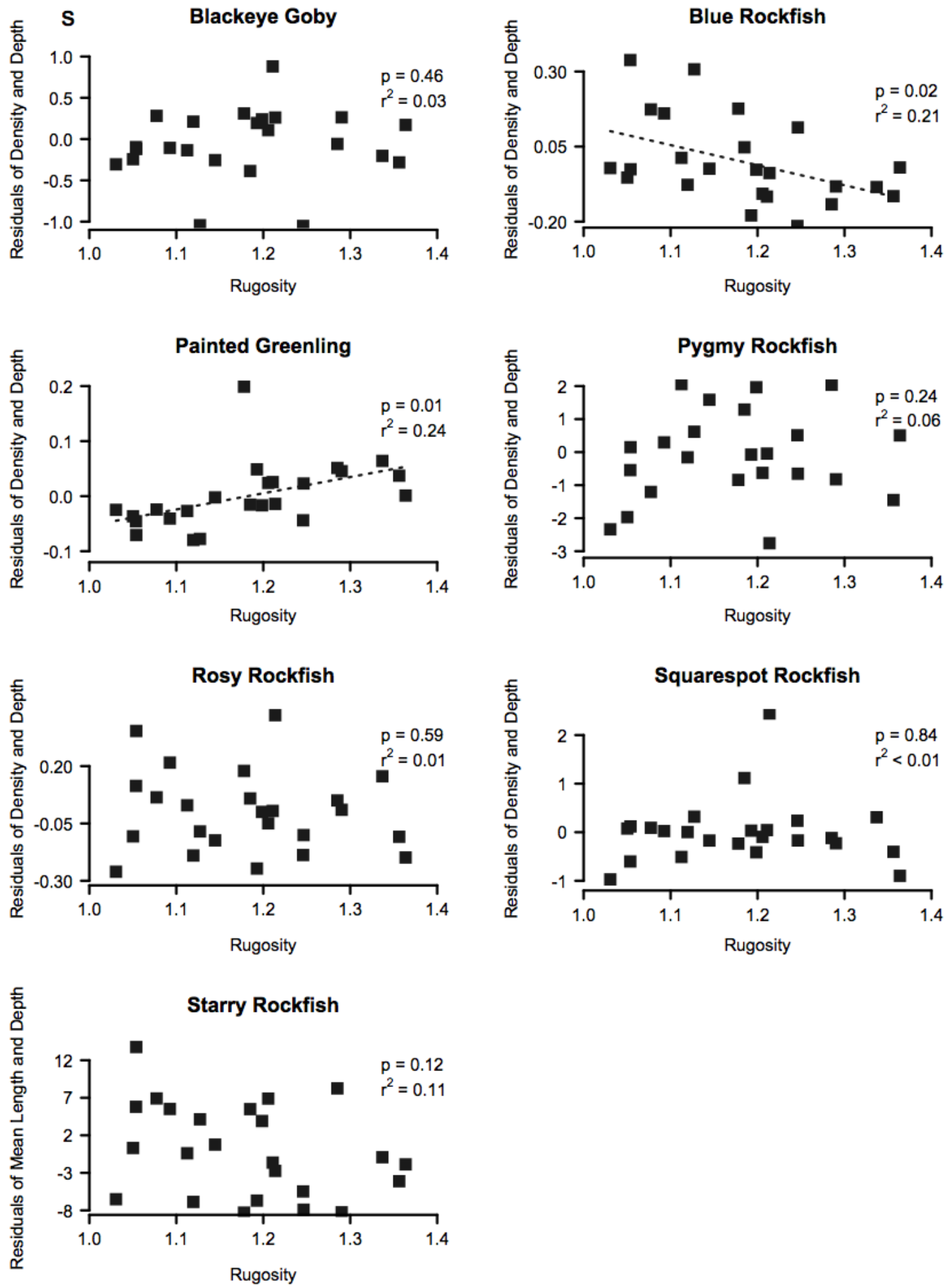

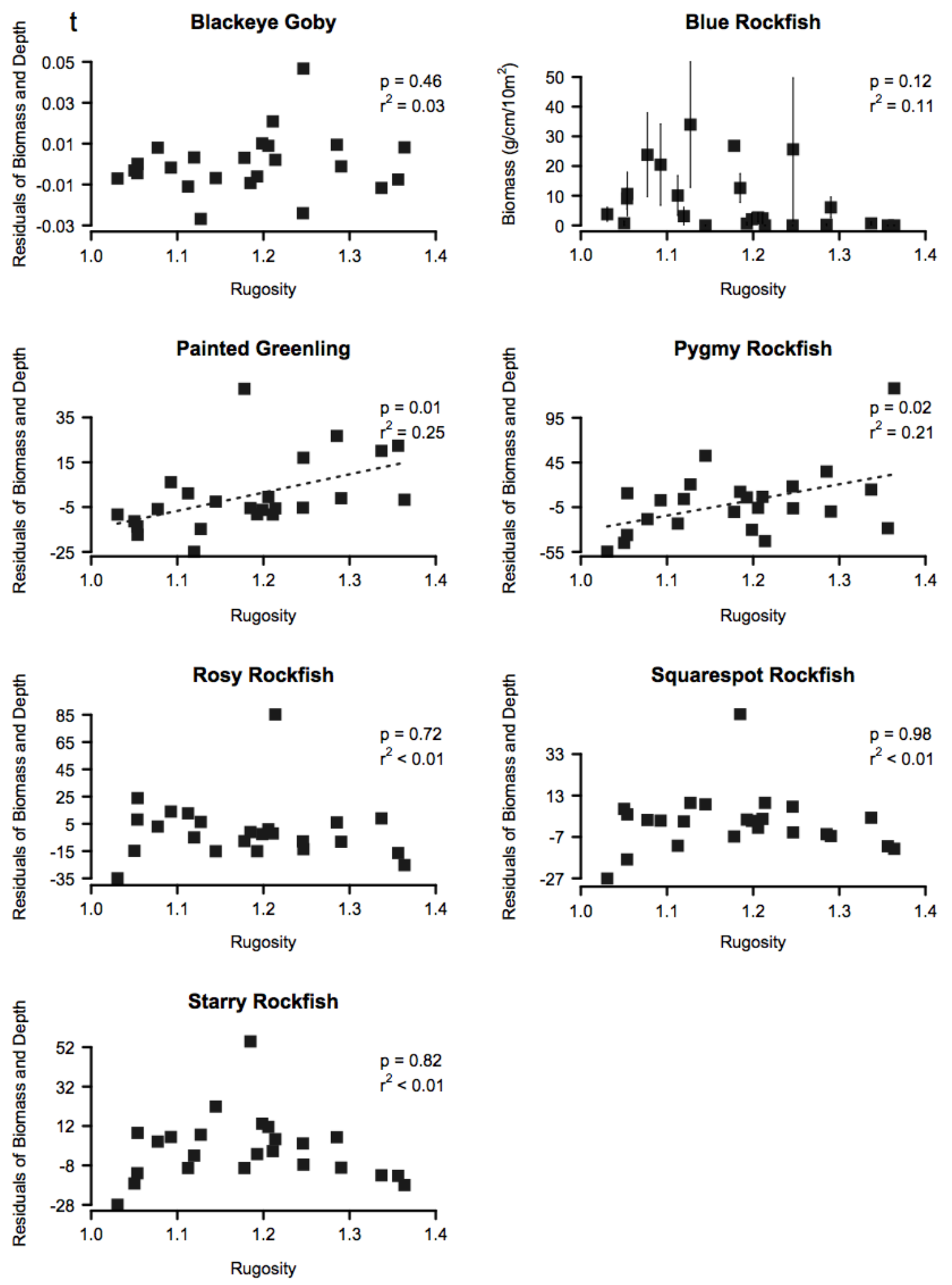

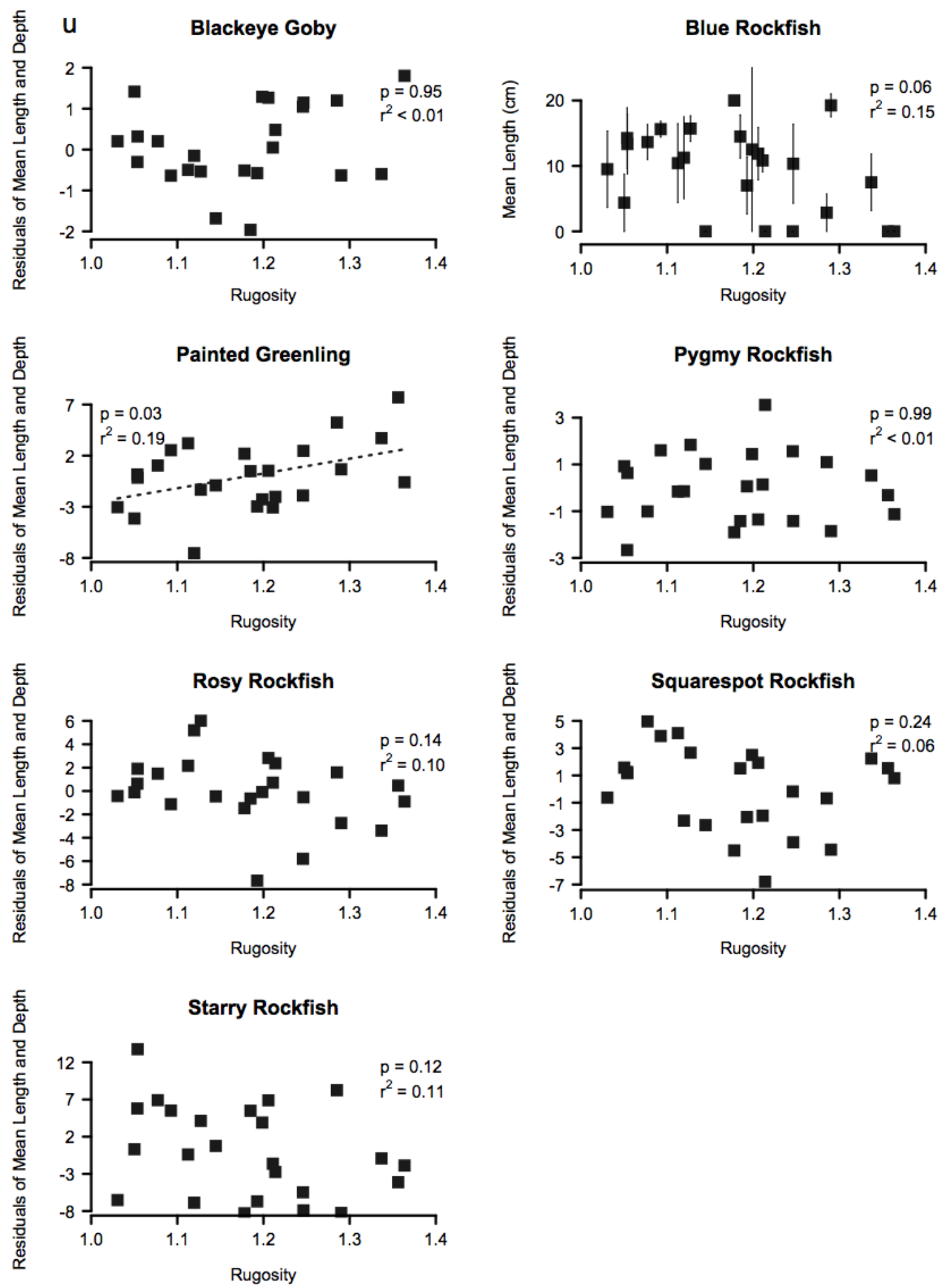


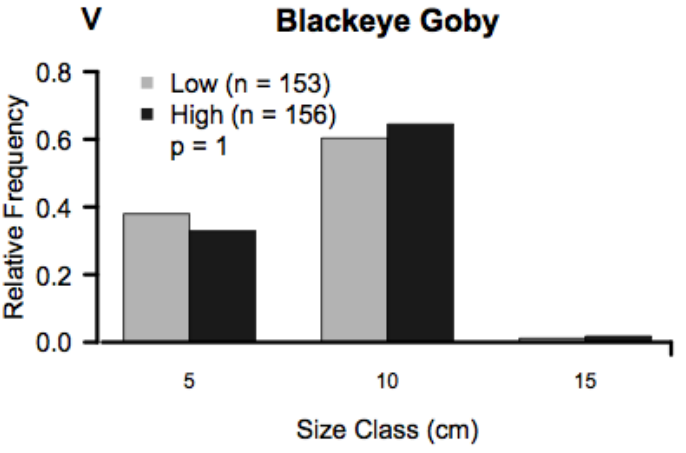

Painted Greenling

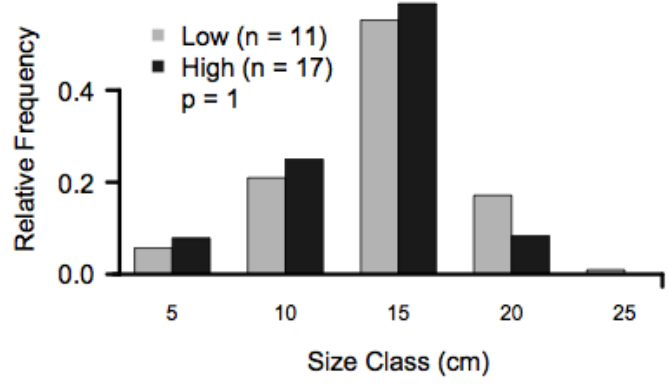

Pygmy Rockfish (Deep > 65 m)

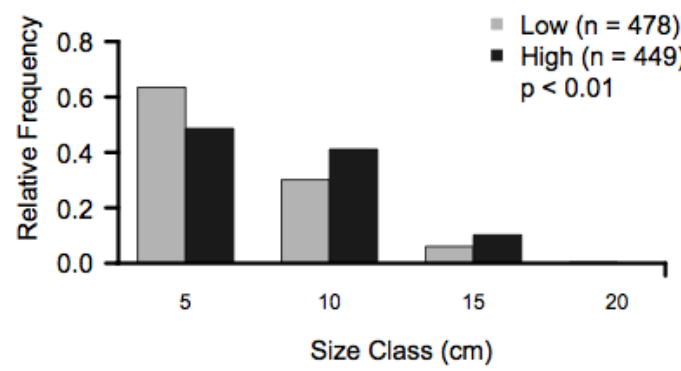

Squarespot Rockfish

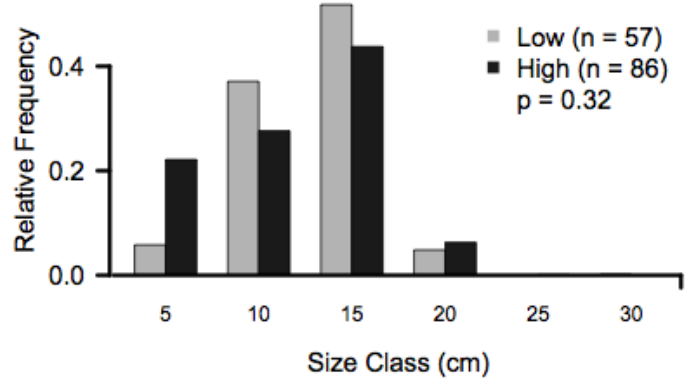

Blue Rockfish

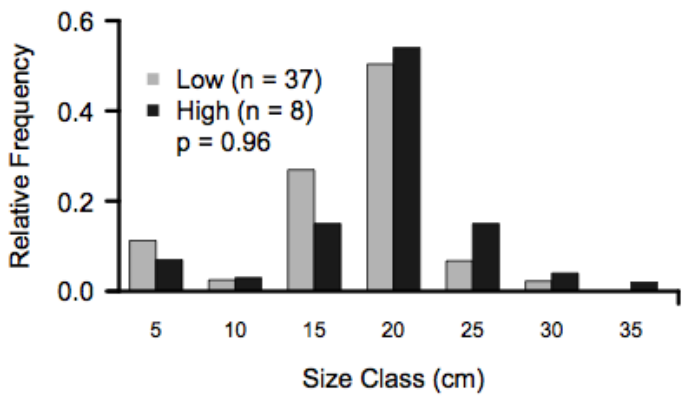

Pygmy Rockfish (Shallow $<55$ m)

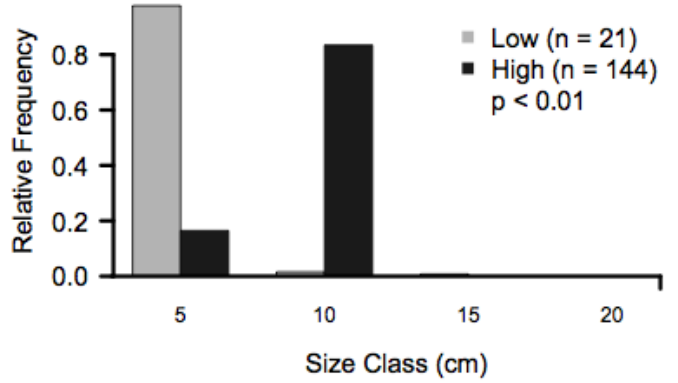

Rosy Rockfish

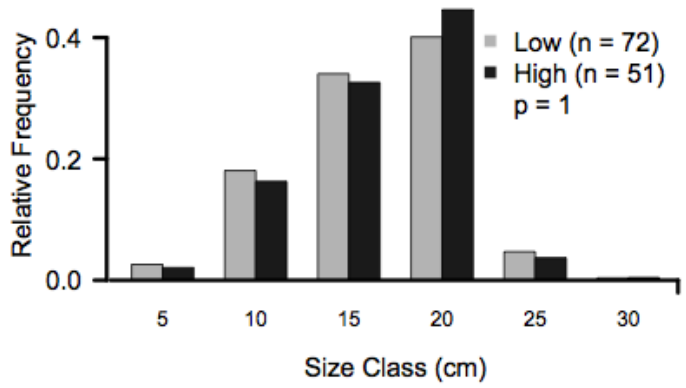

Starry Rockfish

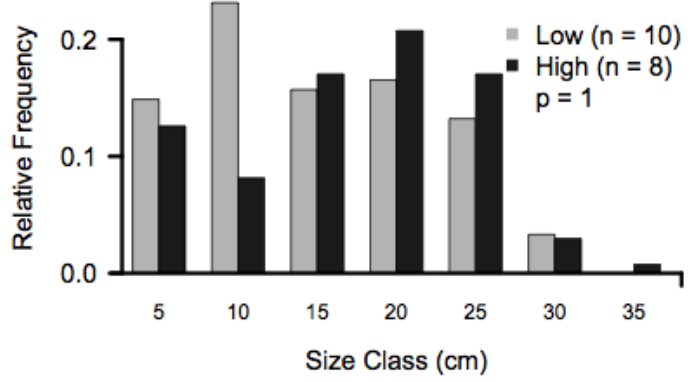


Appendix G Species group goodness-of-fit analyses with respect to three landscapescale independent habitat variables. Results are reported for the proximity to edge (a), $\mathrm{P}: \mathrm{A}$ ratio $(\mathrm{b})$, and area $(\mathrm{c})$

\begin{tabular}{lcrr}
\hline a & $\mathbf{p}$ & \multicolumn{1}{c}{$\mathbf{x}^{2}$} & $\mathbf{d f}$ \\
\hline large rockfishes & 0.955 & 0.003 & 1 \\
dwarf rockfishes & 0.671 & 0.181 & 1 \\
large non-rockfishes & 0.566 & 0.33 & 1 \\
other benthic fishes & 0.999 & 0 & 1 \\
\hline
\end{tabular}

$\mathrm{b}$

\begin{tabular}{lccr}
\hline & $\mathbf{p}$ & $\mathbf{x}^{2}$ & $\mathbf{d f}$ \\
\hline large rockfishes & 0.710 & 0.139 & 1 \\
dwarf rockfishes & $\mathbf{0 . 0 1 2}$ & 6.247 & 1 \\
large non-rockfishes & 0.592 & 0.396 & 1 \\
other benthic fishes & 0.626 & 0.237 & 1 \\
\hline
\end{tabular}

\begin{tabular}{lrrr}
\hline $\mathbf{c}$ & \multicolumn{1}{c}{$\mathbf{p}$} & \multicolumn{1}{c}{$\mathbf{x}^{2}$} & $\mathbf{d f}$ \\
\hline large rockfishes & 0.062 & 3.481 & 1 \\
dwarf rockfishes & $<\mathbf{0 . 0 0 1}$ & 12.914 & 1 \\
large non-rockfishes & 0.841 & 0.04 & 1 \\
other benthic fishes & $\mathbf{0 . 0 1 1}$ & 6.465 & 1 \\
\hline
\end{tabular}


Appendix H Species observed in the edge zone, interior zone, or neither zone

\begin{tabular}{|c|c|c|c|c|}
\hline Scientific Name & Common Name & Edge & Interior & Neither \\
\hline Agonidae & Poacher & $\mathrm{X}$ & & \\
\hline Anarrhichthys ocellatus & Wolf Eel & & & $\mathrm{X}$ \\
\hline Bathymasteridae & Ronquil & $\mathrm{x}$ & $\mathrm{x}$ & \\
\hline Citharichthys sordidus & Sanddab & $\mathrm{x}$ & & \\
\hline Cottidae & Sculpin & $\mathrm{x}$ & $X$ & \\
\hline Damalichthys vacca & Pile Surfperch & $\mathrm{x}$ & $\mathrm{x}$ & \\
\hline Embiotoca jacksoni & Black Surfperch & $\mathrm{x}$ & $\mathrm{x}$ & \\
\hline Embiotoca lateralis & Striped Surfperch & $\mathrm{x}$ & $\mathrm{x}$ & \\
\hline Hexagrammos decagrammus & Kelp Greenling & $\mathrm{x}$ & $\mathrm{x}$ & \\
\hline Hydrolagus colliei & Ratfish & $\mathrm{x}$ & $\mathrm{x}$ & \\
\hline Pleuronectiformes & Flatfishes & $\mathrm{x}$ & & \\
\hline NA & Unidentified & $\mathrm{x}$ & $\mathrm{x}$ & \\
\hline Odontopyxis trispinosa & Pygmy Poacher & $\mathrm{x}$ & & \\
\hline Ophiodon elongatus & Lingcod & $\mathrm{x}$ & $\mathrm{x}$ & \\
\hline Oxyjulis californica & Senorita & & & $\mathrm{x}$ \\
\hline Oxylebius pictus & Painted Greenling & $\mathrm{X}$ & $X$ & \\
\hline Phanerodon spp. & Surfperch & $\mathrm{x}$ & $\mathrm{x}$ & \\
\hline Phanerodon atripes & Sharpnose Seaperch & $\mathrm{x}$ & $\mathrm{x}$ & \\
\hline Phanerodon furcatus & White Seaperch & $\mathrm{x}$ & $\mathrm{x}$ & \\
\hline Pholidae & Gunnel & $\mathrm{x}$ & $\mathrm{x}$ & \\
\hline Raja binoculata & Big Skate & $\mathrm{x}$ & & \\
\hline Rathbunella hypoplecta & Stripedfin Ronquil & $\mathrm{x}$ & $X$ & \\
\hline Rhacochilus toxotes & Rubberlip Surfperch & $\mathrm{x}$ & $\mathrm{x}$ & \\
\hline Rhinogobiops nicholsii & Blackeye Goby & $\mathrm{x}$ & $\mathrm{x}$ & \\
\hline Scorpaena guttata & Striped Scorpionfish & $\mathrm{x}$ & & \\
\hline Scorpaenichthys marmoratus & Cabezon & & & $\mathrm{x}$ \\
\hline Sebastes atrovirens & Kelp Rockfish & & $\mathrm{x}$ & \\
\hline Sebastes carnatus & Gopher Rockfish & $\mathrm{x}$ & $\mathrm{x}$ & \\
\hline Sebastes caurinus & Copper Rockfish & $\mathrm{x}$ & $\mathrm{x}$ & \\
\hline Sebastes chlorostictus & Greenspot Rockfish & $\mathrm{x}$ & $\mathrm{x}$ & \\
\hline Sebastes constellatus & Starry Rockfish & $\mathrm{x}$ & $\mathrm{x}$ & \\
\hline Sebastes emphaeus & Puget Rockfish & $\mathrm{x}$ & $\mathrm{x}$ & \\
\hline Sebastes ensifer & Swordspine Rockfish & $\mathrm{x}$ & $\mathrm{x}$ & \\
\hline Sebastes entomelas & Widow Rockfish & $\mathrm{x}$ & $\mathrm{x}$ & \\
\hline Sebastes flavidus & Yellowtail Rockfish & $\mathrm{x}$ & $\mathrm{x}$ & \\
\hline Sebastes helvomaculatus & Rosethorn Rockfish & $\mathrm{x}$ & $\mathrm{x}$ & \\
\hline Sebastes hopkinsi & Squarespot Rockfish & $\mathrm{x}$ & $\mathrm{x}$ & \\
\hline Sebastes jordani & Shortbelly Rockfish & & $\mathrm{x}$ & \\
\hline Sebastes maliger & Quillback Rockfish & $\mathrm{X}$ & $\mathrm{x}$ & \\
\hline
\end{tabular}




\begin{tabular}{|c|c|c|c|c|}
\hline Sebastes melanops & Black Rockfish & $\mathrm{x}$ & & \\
\hline Sebastes miniatus & Vermilion Rockfish & $\mathrm{x}$ & $\mathrm{x}$ & \\
\hline Sebastes moseri & Whitespeckeled Rockfish & & & $\mathrm{X}$ \\
\hline Sebastes mystinus & Blue Rockfish & $\mathrm{x}$ & $\mathrm{x}$ & \\
\hline Sebastes nebulosus & China Rockfish & $\mathrm{x}$ & $\mathrm{x}$ & \\
\hline Sebastes ovalis & Speckled Rockfish & $\mathrm{x}$ & $\mathrm{x}$ & \\
\hline Sebastes paucispinis & Bocaccio & $\mathrm{x}$ & $\mathrm{x}$ & \\
\hline Sebastes pinniger & Canary Rockfish & $\mathrm{x}$ & $\mathrm{x}$ & \\
\hline Sebastes rosaceus & Rosy Rockfish & $\mathrm{x}$ & $\mathrm{x}$ & \\
\hline Sebastes ruberrimus & Yelloweye Rockfish & $\mathrm{x}$ & $\mathrm{x}$ & \\
\hline Sebastes rufus & Bank Rockfish & $\mathrm{x}$ & $\mathrm{x}$ & \\
\hline Sebastes semicinctus & Halfbanded Rockfish & $\mathrm{x}$ & $\mathrm{x}$ & \\
\hline Sebastes serranoides & Olive Rockfish & $\mathrm{x}$ & $\mathrm{x}$ & \\
\hline Sebastes serriceps & Treefish & $\mathrm{x}$ & $\mathrm{x}$ & \\
\hline Sebastes spp & Rockfish & $\mathrm{x}$ & $\mathrm{x}$ & \\
\hline Sebastes wilsoni & Pygmy Rockfish & $\mathrm{x}$ & $\mathrm{x}$ & \\
\hline Sebastes zacentrus & Sharpchin Rockfish & $\mathrm{x}$ & $\mathrm{x}$ & \\
\hline Sebastolubus spp & Sebastomus & $\mathrm{x}$ & $\mathrm{x}$ & \\
\hline Stichaeidae & Prickleback & $\mathrm{x}$ & $\mathrm{x}$ & \\
\hline Torpedo Californica & Pacific Electric Ray & & $\mathrm{x}$ & \\
\hline Zalembius rosaceus & Pink Surfperch & $\mathrm{x}$ & $\mathrm{x}$ & \\
\hline Zaniolepis frenata & Shortspine Combfish & $\mathrm{x}$ & $\mathrm{x}$ & \\
\hline
\end{tabular}

